\author{
Universidade de São Paulo \\ Faculdade de Medicina de Ribeirão Preto \\ Departamento de Medicina Social
}

SARAH TARCÍSIA REBELO FERREIRA DE CARVALHO

CONHECIMENTOS E PERCEPÇÕES DOS USUÁRIOS DA ESTRATÉGIA SAÚDE DA FAMÍLIA SOBRE A FISIOTERAPIA

Ribeirão Preto 


\section{CONHECIMENTOS E PERCEPÇÕES DOS USUÁRIOS DA ESTRATÉGIA SAÚDE DA FAMÍLIA SOBRE A FISIOTERAPIA}

Dissertação apresentada ao Departamento de Medicina Social da Faculdade de Medicina de Ribeirão Preto - FMRP - USP para obtenção do título de Mestre.

Área de Concentração: Saúde na Comunidade

Orientadora: Prof ${ }^{\mathrm{a}}$. Dr ${ }^{\mathrm{a}}$ Dra. Maria do Carmo G. G. Caccia-Bava

Ribeirão Preto 
Autorizo a reprodução e divulgação total ou parcial deste trabalho, por qualquer meio convencional ou eletrônico, para fins de estudo e pesquisa, desde que citada a fonte.

\section{FICHA CATALOGRÁFICA}

Carvalho, Sarah Tarcisia Rebelo Ferreira de

Conhecimentos e percepções dos usuários da Estratégia Saúde da Família sobre a fisioterapia

106p. : il. ; $30 \mathrm{~cm}$

Dissertação (Mestrado) apresentada à Faculdade de Medicina de Ribeirão Preto/USP - Área de concentração: Saúde na Comunidade.

Orientadora: Caccia-Bava, Maria do Carmo G. G.

1. Estratégia de Saúde da Família. 2. Conhecimentos sobre Fisioterapia. 3. Percepção. 4. População. 
FOLHA DE APROVAÇÃO

SARAH TARCISIA REBELO FERREIRA DE CARVALHO

CONHECIMENTOS E PERCEPÇÕES DOS USUÁRIOS DA ESTRATÉGIA SAÚDE DA FAMÍLIA SOBRE A FISIOTERAPIA

Dissertação apresentada à Faculdade de Medicina de Ribeirão Preto da Universidade de São Paulo para obtenção do Título de Mestre.

Área de Concentração: Saúde da Comunidade.

Aprovado em: 1

Banca Examinadora

Prof. Dr.

Instituição: Assinatura:

Prof. Dr.

Instituição: Assinatura:

Prof. Dr.

Instituição: Assinatura: 


\section{EDICATÓRIA}

Aos meus pais, Joaquim e Gislene, Obrigada por vocês terem me ensinado que os conhecimentos só adquirem sentido quando fundamentado em valores éticos e humanos. 


\section{A gradecimentos}

"Cada pessoa que passa em nossa vida, passa sozinha. É porque cada pessoa é única e nenhuma substitui a outra. Cada pessoa que passa em nossa vida, passa sozinha, e não nos deixa só, porque deixa um pouco de si e leva um pouquinho de nós. Essa é a prova de que as pessoas não se encontram por acaso." (Charles Chaplin)

Assim, agradeço a todas as pessoas que passaram em minha vida, que, de alguma forma, contribuíram para a construção de quem sou hoje. E em especial:

A Deus, por iluminar o meu caminho.

Aos meus pais, pela constante presença em minha vida, por guiarem meus passos e oportunizarem ensinamentos que levarei para sempre.

Aos meus saudosos avós Abimael, Tarcisia e Oswaldo, e a minha querida Vovó Sarah, exemplos de vida, amor e respeito, valores essenciais que sempre tiveram presentes na nossa sólida e unida família.

Aos meus irmãos, Ana Rosa, Levy, Marquinhos e Keline, pelo carinho, amizade e apoio incondicional que a distância não consegue interromper. Pessoas que admiro e amo cada vez mais.

Ao meu afilhado e sobrinho Marcos Vinicius, cujo simples sorriso traz mais cor e brilho à minha vida.

Ao Carlos, pelo carinho, compreensão e apoio.

As minhas eternas amigas, Kat, Rha, Laine, Mila e Carolsinha, que compartilham comigo todas as minhas alegrias e tristezas. 
As minhas amigas, Maíra, Suleimy, Jennifer, Ailcy, Luciana, Lígia e Fernanda, Cristiane Sonscino e Rosana que me acompanharam e me apoiaram nesta jornada, e a quem desejo muito sucesso.

A Prof ${ }^{a}$. Dr ${ }^{a}$ Soninha Bueno, minha amiga, e mãe de coração, meu eterno agradecimento pelo grande apoio e incentivo profissional e por me ajudar a crescer enquanto ser humano.

A minha orientadora, Prof ${ }^{a}$. Dr ${ }^{a}$. Maria do Carmo Caccia-Bava, pela extrema dedicação, carinho, responsabilidade e paciência com que contribuiu para a realização desse trabalho e amadurecimento profissional e pessoal.

Aos professores Altacílio Aparecido Nunes e Vera Maria Rocha, pela prontidão em aceitar participar da defesa da minha tese e pela dedicação, atenção e sugestões importantes para essa pesquisa.

A Prof ${ }^{a}$. Dr ${ }^{a}$. Maria José Bistafa Pereira, pelo carinho, apoio, e sugestões valiosas na construção desta pesquisa.

Ao prof. Dr. Juan Stuardo Yazlle Rocha e à FAEPA, pela atenção e apoio financeiro sem o qual esta pesquisa não poderia ser realizada.

A todos que fazem parte da equipe do CEMEQ, em especial ao Professor Dr. Edson Zangiacomi Martinez, Suleimy Mazin e Mayara Piani, pela dedicação, atenção e paciência dispensadas nas orientações de estatísticas deste trabalho.

A todos que trabalham no Núcleo IV do Sumarezinho de Ribeirão Preto-SP, em especial aos agentes comunitários de saúde, pela atenção e dedicação com que realizaram as entrevistas desse trabalho, e os usuários que participaram da pesquisa.

A Dona Ilda, que eu conheci há tão pouco tempo, mas que merece toda a minha admiração. Agradeço o carinho e a gentil colaboração na correção desse estudo. 
A Solange Pedersoli pela atenção, disponibilidade, carinho e paciência, como também pela revisão das normas bibliográficas dessa dissertação.

A Tânea, Carolina Cecília Bruno Batista, Mônica Elisabete Knack, Regina Helena Greggi de Alcantra, pela atenção e compreensão durante o curso.

A todos os meus professores e mestres, desde a escola ao mestrado, que, de diferentes formas, inspiraram a minha trajetória e o meu anseio pelo magistério. 
Alguns hamens vêem as caisas cama sãa, e dizem 'Par quê?'

Eu sanha cam as caisas que nunca faram e diga 'Par que nãa?'

(Gearge Bernard Shaue) 


\section{RESUMO}

CARVALHO, S. T. R. F. “Conhecimentos e percepções dos usuários da Estratégia Saúde da Família sobre a Fisioterapia”. 2008. 207f. Dissertação (Mestrado em Saúde na Comunidade). Faculdade de Medicina de Ribeirão Preto-USP.

O Ministério da Saúde criou em 1994 o Programa Saúde da Família (PSF) visando à reorientação do modelo assistencial do Brasil e a valorização da atenção básica. A partir da Portaria 648/06, passa a ser denominado de Estratégia Saúde da Família (EsSF) sinalizando para sua concepção mais ampla, voltada para as especificidades loco-regionais, para o trabalho intersetorial e para a valorização dos saberes e práticas interdisciplinares. Nesse contexto, várias experiências exitosas foram registradas de incorporação do fisioterapeuta na Atenção Básica, permitindo a ampliação de seu campo de atuação, historicamente vinculado à reabilitação, para atuar também na promoção da saúde e prevenção de agravos. No entanto, o número insuficiente de profissionais na rede assistencial, as dificuldades estruturais e materiais, e o desconhecimento da população sobre a atuação do fisioterapeuta ainda limitam a sua atividade na atenção básica. Essa pesquisa objetivou investigar o conhecimento dos usuários de uma Unidade Saúde da Família (USF) sobre a Fisioterapia, e sua percepção quanto às suas necessidades em relação à atuação do fisioterapeuta. Trata-se de um estudo transversal e descritivo, de abordagem quantitativa. Valeu-se da aplicação de um questionário elaborado pela autora a 275 usuários de uma USF em Ribeirão Preto/SP. Os entrevistados tinham como características predominantes a média de idade de 43 anos, ser do sexo feminino, morar com seus companheiros e residir na área adstrita à Unidade por cerca de 6 a 10 anos, trabalhar no próprio lar, apresentar baixa escolaridade, pertencer às classes econômicas C e D. Em relação à presença de familiares portadores de deficiência física ou doenças graves, tinham índice igual ou superior ao estimado pela OMS. Quanto aos aspectos mais específicos da Fisioterapia, embora a maioria já tivesse ouvido falar sobre a profissão e a considerasse muito importante, gostaria de saber mais sobre ela. Entretanto, o conhecimento dos entrevistados se mostrou voltado aos aspectos de reabilitação e/ou tratamento, indicaram que as pessoas que mais precisam de Fisioterapia são os deficientes físicos, portadores de lesão e/ou algias músculo-esquelético; que o fisioterapeuta trabalha principalmente no hospital; que não realiza ações educativas e que há dificuldade de acesso ao fisioterapeuta. Assim, 98\% destes consideraram necessária a inclusão do fisioterapeuta na equipe da USF. Poucos entrevistados já foram, ou tiveram familiares, atendidos por fisioterapeuta, e $29 \%$ afirmaram precisar atualmente destes serviços. Considerando-se o reduzido número de fisioterapeutas na Rede Municipal de Saúde e os benefícios que as pessoas poderiam auferir a partir de uma concepção menos restrita da profissão, propõe-se, dentro da lógica de valorização da participação popular na Atenção Básica, uma maior divulgação do campo potencial de atuação da Fisioterapia na Atenção Primária junto a esse segmento, atuando por meio de ações articuladas com as equipes de forma a qualificar cada vez mais a assistência no SUS.

Palavras-chaves: Estratégia de Saúde da Família, Conhecimentos sobre Fisioterapia, Percepção, População. 


\begin{abstract}
CARVALHO, S.. T. .R, F. "Knowledge and perceptions about Physiotherapy of users of the Family Health Strategy". 2008. 207f. Dissertation (Masters in Community Health). Faculty of Medicine, Ribeirão Preto-USP.
\end{abstract}

In 1994, the Ministry of Health created the Family Health Program (PSF) with the aim of reorienting the model of care in Brazil and placing a higher value on primary care. Order 648/06, which is now called the Family Health Strategy (EsSF), signals a broader conception, focused on local-regional specificities, for inter-sector work and for the enhancement of knowledge and interdisciplinary practice. In this context, several successful experiences have been registered for the incorporation of the physiotherapist in Primary Care. This enables an expansion of the remit of physiotherapy, which has historically been linked to rehabilitation, so that is can also be used for health promotion and disease prevention. However, the insufficient number of professionals in the care network, the structural and material difficulties, and lack of knowledge by the population on the role of a physiotherapist still limit their role in primary care. The aim of this survey was to investigate the knowledge of users of a Family Health Unit (USF) about physiotherapy, and their perception about their needs in relation to the role of a physiotherapist. It is a cross-sectional and descriptive quantitative study. A questionnaire prepared by the author was given to 275 users of a USF in Ribeirao Preto/SP. The predominant characteristics of the interviewees were: mean age of 43 years, female, live with their partners in the unit's catchment area for about 6 to 10 years, work in their own home, have a low level of education, and belong to economic classes $\mathrm{C}$ and $\mathrm{D}$. Regarding the presence of family members with physical disabilities or serious illness, there was a rate equal or higher than that estimated by the WHO. As for more specific aspects of Physiotherapy, although most have already heard about the profession and consider it very important, they would like to know more about it. However, the knowledge of the interviewees revolves around aspects of rehabilitation and/or treatment. They thought that people who most need Physiotherapy are the disabled, people with injuries and/or musculoskeletal pain; that physiotherapists mainly work in hospitals; that they do not perform educational services and that it is difficult to gain access to a physiotherapist. Thus, 98\% considered it necessary to include a physiotherapist in a USF team. Hardly any of those interviewed, or their relatives, had received physiotherapy, and 29\% reported a current need for these services. Considering the small number of physiotherapists in the Municipal Health Network and the benefits that people could derive from a less narrow conception of the profession, it is proposed, within the logic of valuing people's participation in Primary Care, that there is a greater disclosure of Physiotherapy's potential areas of responsibility in Primary Care, which could take place by a co-ordination of teams in order to lend ever more assistance to the SUS.

Key words: Family Health Strategy, Knowledge about Physiotherapy, Perception, Population, 


\section{LISTA DE TABELAS}

Tabela 1 - População cadastrada em cada microárea e amostra estratificada proporcional da população cadastrada em cada área, Sumarezinho, Ribeirão Preto (SP), 2008.

Tabela 2 - Distribuição dos usuários das cinco microáreas de uma Unidade de Saúde da Família por faixa etária, Sumarezinho, Ribeirão Preto (SP), 2008

Tabela 3 - Distribuição dos usuários das cinco microáreas de uma Unidade de Saúde da Família por cor/raça, Sumarezinho, Ribeirão Preto (SP), 2008.

Tabela 4 - Distribuição dos usuários das cinco microáreas de uma Unidade de Saúde da Família por religião, Sumarezinho, Ribeirão Preto (SP), 2008

Tabela 5 - Distribuição dos usuários das cinco microáreas de uma Unidade de Saúde da Família por situação conjugal, Sumarezinho, Ribeirão Preto (SP), 2008

Tabela 6 - Distribuição dos usuários das cinco microáreas de uma Unidade de Saúde da Família por ocupação, Sumarezinho, Ribeirão Preto (SP), 2008.

Tabela 7 - Distribuição dos usuários das cinco microáreas de uma Unidade de Saúde da Família por grau de escolaridade, Sumarezinho, Ribeirão Preto (SP), 2008

Tabela 8 - Distribuição dos usuários das cinco microáreas de uma Unidade de Saúde da Família por Critério de Classificação Econômica Brasil (CCEB), Sumarezinho, Ribeirão Preto (SP), 2008.

Tabela 9 - Distribuição dos usuários das cinco microáreas de uma Unidade de Saúde da Família (USF) por tempo em que moram na área adstrita a esta USF, Sumarezinho, Ribeirão Preto (SP), 2008.

Tabela 10 - Distribuição dos usuários das cinco microáreas de uma Unidade de Saúde da Família por presença, na família, de pessoa portadora de deficiência física ou doença grave, Sumarezinho, Ribeirão Preto (SP), 2008.

Tabela 11 - Distribuição dos usuários das cinco microáreas de uma Unidade de Saúde da Família por já ter ouvido falar em Fisioterapia, Sumarezinho, Ribeirão Preto (SP), 2008. 
Tabela 12 - Distribuição dos usuários das cinco microáreas de uma Unidade de Saúde da Família por meios através dos quais se ouviu falar em Fisioterapia, Sumarezinho, Ribeirão Preto (SP), 2008.

Tabela 13 - Distribuição dos usuários das cinco microáreas de uma Unidade de Saúde da Família por auto-avaliação do conhecimento sobre Fisioterapia, Sumarezinho, Ribeirão Preto (SP), 2008

Tabela 14 - Distribuição dos usuários das cinco microáreas de uma Unidade de Saúde da Família por conceito de Fisioterapia, Sumarezinho, Ribeirão Preto (SP), 2008.

Tabela 15 - Distribuição dos usuários das cinco microáreas de uma Unidade de Saúde da Família por grau de importância dos serviços de Fisioterapia para a saúde da população, Sumarezinho, Ribeirão Preto (SP), 2008 ....

Tabela 16 - Distribuição dos usuários das cinco microáreas de uma Unidade de Saúde da Família por recursos que o fisioterapeuta utiliza, Sumarezinho, Ribeirão Preto (SP), 2008

Tabela 17 - Distribuição dos usuários das cinco microáreas de uma Unidade de Saúde da Família por para que serve a Fisioterapia, Sumarezinho, Ribeirão Preto (SP), 2008

Tabela 18 - Distribuição dos usuários das cinco microáreas de uma Unidade de Saúde da Família por pessoas ou situações que precisam dos serviços de Fisioterapia, Sumarezinho, Ribeirão Preto (SP), 2008

Tabela 19 - Distribuição dos usuários das cinco microáreas de uma Unidade de Saúde da Família por lugares onde fisioterapeuta trabalha, Sumarezinho, Ribeirão Preto (SP), 2008

Tabela 20 - Distribuição dos usuários das cinco microáreas de uma Unidade de Saúde da Família por tipo de atividades que o fisioterapeuta realiza, Sumarezinho, Ribeirão Preto (SP), 2008

Tabela 21 - Distribuição dos usuários das cinco microáreas de uma Unidade de Saúde da Família (USF) por necessidade de inclusão do fisioterapeuta à equipe da USF em que eles estão cadastrados, Sumarezinho, Ribeirão Preto (SP), 2008à equipe Unidade, Sumarezinho, Ribeirão Preto (SP), 2008

Tabela 22 - Distribuição dos usuários das cinco microáreas de uma Unidade de Saúde da Família (USF) por justificativas da necessidade de inclusão do fisioterapeuta à equipe da USF em que eles estão cadastrados, Sumarezinho, Ribeirão Preto (SP), 2008.

Tabela 23 - Distribuição dos usuários das cinco microáreas de uma Unidade de Saúde da Família por prévio atendimento fisioterápico prestado a eles, Sumarezinho, Ribeirão Preto (SP), 2008. 
Tabela 24 - Distribuição dos usuários das cinco microáreas de uma Unidade de Saúde da Família por natureza dos atendimentos fisioterápicos prestados a eles, Sumarezinho, Ribeirão Preto (SP), 2008

Tabela 25 - Distribuição dos usuários das cinco microáreas de uma Unidade de Saúde da Família por motivos dos atendimentos fisioterápicos prestados a eles, Sumarezinho, Ribeirão Preto (SP), 2008

Tabela 26 - Distribuição dos usuários das cinco microáreas de uma Unidade de Saúde da Família por prévio atendimento fisioterápico prestado aos familiares deles, Sumarezinho, Ribeirão Preto (SP), 2008

Tabela 27 - Distribuição dos usuários das cinco microáreas de uma Unidade de Saúde da Família por motivos dos atendimentos fisioterápicos prestados aos familiares deles, Sumarezinho, Ribeirão Preto (SP), 2008

Tabela 28 - Distribuição dos usuários das cinco microáreas de uma Unidade de Saúde da Família por experiência dos mesmos e/ou familiares com a Fisioterapia, Sumarezinho, Ribeirão Preto (SP), 2008

Tabela 29 - Distribuição dos usuários das cinco microáreas de uma Unidade de Saúde da Família por, atualmente, necessitar dos serviços de Fisioterapia, Sumarezinho, Ribeirão Preto (SP), 2008

Tabela 30 - Distribuição dos usuários das cinco microáreas de uma Unidade de Saúde da Família por justificativas de que precisam, atualmente, dos serviços de Fisioterapia, Sumarezinho, Ribeirão Preto (SP), 2008.

Tabela 31 - Distribuição dos usuários das cinco microáreas de uma Unidade de Saúde da Família por justificativas de que não precisam, atualmente, dos serviços de Fisioterapia, Sumarezinho, Ribeirão Preto (SP), 2008. 


\section{LISTA DE SIGLAS}

Agentes Comunitários de Saúde

CCEB

$$
\text { Critério de Classificação Econômica Brasil }
$$

CEP

\section{Comitê de Ética em Pesquisa}

CFE

$$
\text { Conselho Federal de Educação }
$$

COFFITO Conselho Federal de Fisioterapia e Terapia Ocupacional

CREFITO Conselho Regional de Fisioterapia e Terapia Ocupacional da $3^{\circ}$ Região

CSE

\section{Centro de Saúde Escola}

ECI Estágio Comunitário Integrado

ESF $\quad$ Equipe de Saúde da Família

EsSF Estratégia Saúde da Família

FMRP Faculdade de Medicina de Ribeirão Preto

FUNDET Fundação de Educação para o Trabalho

HC Hospital das Clínicas

IBGE Instituto Brasileiro de Geografia e Estatística

INAR Instituto Nacional de Reabilitação

NADEF N N Nécleo de Atenção à Pessoa Deficiente

NAPS-1 Núcleo de Atenção Psico Social

NAPS-F Núcleo de Atenção Psico Social para Alcoolistas e Farmacodependentes

NASF Núcleos de Apoio à Saúde da Família

NGA 59 Núcleo de Gestão Assistencial

NSF Núcleo de Saúde da Família

OMS Organização Mundial de Saúde 
PAM II Ambulatório de Especialidades Pediátricas

PSF Programa Saúde da Família

SACS Serviço de Apoio ao Cidadão

SIAB Sistema de Informação da Atenção Básica

SUS Sistema Único de Saúde

UBDS Unidade Básica Distrital de Saúde

USF Unidade de Saúde da Família

USP Universidade de São Paulo

WCPT World Confederation for Physical Therapy 


\section{SUMÁRIO}

\section{APRESENTAÇÃo}

\section{INTRODUÇÃO}

2.1 Atenção Básica e o Sistema Único de Saúde

2.2 Estratégia Saúde da Família - (EsSF)

2.3 Fisioterapia

2.3.1 Gênese da Fisioterapia

2.3.2 Áreas de atuação da Fisioterapia.

2.3.3 Fisioterapia e a Estratégia Saúde da Família .

2.4 A Fisioterapia na EsSF do Município de Ribeirão Preto

\section{3}

OBJETIVOS

3.1 Objetivo geral

3.2 Objetivos específicos

\section{MATERIAL E MÉTODO}

4.1 Delineamento do Estudo

4.2 Campo de Estudo

4.3 Local de Estudo

4.4 Populações Alvo

4.5 Coletas de Dados

4.5.1 Instrumentos para a Coleta de Dados

4.5.2 Procedimento para a Coleta de Dados ..................................................................... 49

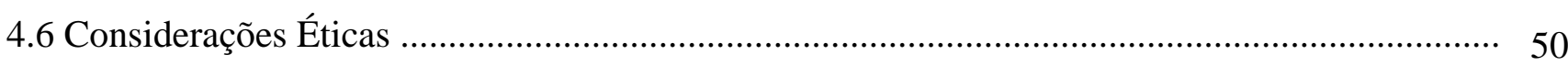

4.7 Análise de Dados 


\section{RESULTADOS}

5.1 Caracterização Sócio-Familiar e Demográfica dos Entrevistados.

5.2 Conhecimentos dos entrevistados sobre a Fisioterapia

5.3 Percepções dos entrevistados quanto às suas principais necessidades em relação à atuação do fisioterapeuta

6 DISCUSSÃO

6.1 Caracterização Sócio-Familiar e Demográfica dos Entrevistados. 76

6.2 Conhecimentos dos entrevistados sobre a Fisioterapia. 78

6.3 Percepções dos entrevistados quanto às suas principais necessidades em relação à atuação do fisioterapeuta

ANEXOS 100 


\section{APRESENTAÇÃO}

A motivação para realizar este trabalho confunde-se com minha trajetória como acadêmica de Fisioterapia, no Centro Universitário de João Pessoa - UNIPÊ, em João Pessoa PB.

Quando da prática da disciplina denominada Estágio Comunitário Integrado (ECI), tive o primeiro contato com a Estratégia Saúde da Família (EsSF), atuando nessa área, sob supervisão, em Unidade de Saúde da Família (USF). Na oportunidade, pude participar, diretamente, de uma Equipe de Saúde da Família (ESF) e vivenciar todo o seu processo de organização, planejamento e atuação.

A possibilidade de interagir em ambiente fora da clínica-escola e em uma comunidade, além de atender pacientes com suas necessidades assistenciais próprias e adentrar casas e escolas, me fez perceber a magnitude e a responsabilidade de ser um profissional de saúde.

Essa vivência me permitiu identificar grande discrepância entre a necessidade de assistência fisioterápica da população e a atuação lacunosa desse profissional na saúde coletiva. A partir de então, identifiquei-me com essa área, especificamente na atuação do fisioterapeuta na EsSF, tema que escolhi para minha monografia de conclusão do curso de graduação.

Durante a pesquisa para essa monografia, percebi que a literatura sobre a atuação fisioterápica na EsSF ainda é escassa. No entanto, em sua maioria, estudos em diferentes regiões do Brasil promovem evidências da necessidade de atuação desse profissional próximo da ESF.

Cursando, no momento, mestrado nessa área, continuo o estudo da atuação da Fisioterapia na comunidade, com a pretensão de contribuir, agora, para a construção de uma ponte entre a atuação do fisioterapeuta e o que a comunidade pensa sobre isso. 


\section{INTRODUÇÃO}

Este capítulo está organizado em três tópicos que visam contextualizar o tema proposto. O primeiro tópico aborda a Atenção Básica e o Sistema Único de Saúde (SUS), incluindo conceitos, princípios e forma de organização. O segundo tópico se refere à Estratégia Saúde da Família (EsSF), compreendendo o contexto em que essa estratégia foi implantada, os objetivos, os princípios, e a descrição do seu modo peculiar de operacionalização. O terceiro tópico aborda a Fisioterapia, sendo dividido em quatro subseções. Na primeira, Gênese da Fisioterapia, é descrito um breve histórico da sua origem, pontuada por sua legislação e enfatizando o seu constante vínculo com a reabilitação. A segunda parte aborda as áreas de atuação da Fisioterapia, seja na clínica, na educação, ou na saúde coletiva. Já a terceira, a Fisioterapia e a Estratégia de Saúde da Família, restringe-se à descrição da inserção da Fisioterapia nessa estratégia, trazendo os objetivos, a importância e as dificuldades para essa atuação, além de relatos de diversas experiências existentes no Brasil. Para situar o campo de estudo da presente pesquisa, a quarta subseção aborda, especificamente, a Fisioterapia na Estratégia Saúde da Família do Município de Ribeirão Preto-SP.

\subsection{Atenção Básica e o Sistema Único de Saúde}

A atenção básica à saúde foi definida e reconhecida internacionalmente na Declaração de Alma-Ata (capítulo VI), proveniente da Conferência de Saúde Mundial de Alma-Ata em 1978 e instituída nas políticas oficiais de saúde dos países desenvolvidos e em desenvolvimento para alcançar “saúde para todos no ano 2000” (CHAZAN, 2004). A principal estratégia para atingir essa meta seria o desenvolvimento da atenção básica à saúde, dentro de uma organização sistêmica do setor (ALEIXO, 2002).

Para cumprir os fatores acima mencionados, tornou-se necessária a edificação de um Sistema de Saúde que contemplasse a universalização da assistência em todos os seus níveis. É nesse contexto que foi implantado o Sistema Único de Saúde (SUS), regulamentado com base na Lei $\mathrm{n}^{\circ}$. 8.080 de 19 de setembro de 1990, como o conjunto de ações e serviços de saúde, prestados por órgãos e instituições públicas, federais, estaduais e municipais, da administração direta e indireta e das fundações mantidas pelo poder público, e seguindo princípios específicos (BRASIL, 1990). 
A viabilização dos princípios do SUS - integralidade, universalidade e equidade predispõe às alterações das principais características do perfil da política de atenção à saúde que vigorou no Brasil por três décadas e prevaleceu até meados dos anos 80. Dentre essas características destacavam-se: forte centralização na esfera federal de governo, fragmentação organizacional, ausência de mecanismos de controle público e social, forte concentração do atendimento nas unidades hospitalares ou no atendimento ambulatorial de nível secundário (SILVA, 2003).

Kell (2008) indica que a integralidade pode apresentar vários sentidos que refletem diversas dimensões de uma crítica radical às práticas, instituições e forma de organização do Sistema de Saúde do Brasil. Para essa autora, a integralidade relaciona-se à medicina integral, como crítica da assistência médica fragmentária e; à medicina preventiva, ao indicar a necessidade de assistir o paciente para além da atenção individual e curativa, incorporando, também, ações de promoção e prevenção. Esse princípio, ainda, vincula-se: à organização dos serviços e das práticas de saúde, opondo-se aos programas verticais; ao modo de organização do processo de trabalho em saúde, através da articulação da assistência à demanda espontânea com a oferta programada da atenção à saúde e; ao acesso da população aos diversos níveis de atenção, ou seja, às técnicas de diagnóstico e tratamento necessárias a cada caso.

A organização do SUS baseia-se em conceitos importantes que incluem: regionalização e hierarquização dos serviços de saúde, descentralização, resolutividade e participação dos cidadãos. A regionalização e hierarquização correspondem à organização dos serviços em níveis de complexidade tecnológica crescente, dispostos em área geográfica demarcada e com a definição da população a ser atendida (COSTA, 2004).

A regionalização é uma forma de organização dos Sistemas de Saúde, com base territorial e populacional, visando melhorar a distribuição de serviços que possam promover eqüidade de acesso, qualidade, otimização de recursos e racionalidade de gastos (BRASIL, 2005). Esse princípio segue a premissa de que grande parte dos municípios brasileiros não tem condições de oferecer, em seus territórios, todos os serviços necessários ao atendimento resolutivo e integral à saúde de seus cidadãos. Dessa forma, objetiva-se corrigir as desigualdades ao acesso e a fragmentação dos serviços de saúde, mediante organização funcional do sistema, com definição das responsabilidades de cada município e dos fluxos de referência.

No tocante à descentralização, Elias (1999) a considera como princípio norteador do SUS, e a define como repasse de recursos e delegação de poder para que os níveis estaduais e municipais estabeleçam a Política de Saúde adequada, de acordo com prioridades que 
satisfaçam à especificidade local e correspondam, ao mesmo tempo, às diretrizes nucleares formuladas para o âmbito nacional.

Para Rezende et al. (2008), a efetiva estruturação da capacidade de resolução da atenção básica em relação à grande parte dos problemas de saúde da população, acarreta redução do fluxo de usuários para níveis de maior densidade tecnológica, racionalização do uso da tecnologia e dos recursos terapêuticos mais dispendiosos e, por conseguinte, proporciona maior acesso da população aos serviços de saúde. Assim, a atenção básica visa oferecer, a partir do primeiro nível do cuidado, a integração dos diversos pontos de atenção à saúde, possibilitando uma assistência contínua, de qualidade, com menor custo e em lugar e tempo adequados.

Em relação à participação social, o Ministério da Saúde, em Brasil (2005) a considera como uma das maneiras de se efetivar a democracia, responsável pela inclusão de novos sujeitos sociais nos processos de gestão do SUS e de formulações e fiscalização das Políticas de Saúde Pública do país. Essa participação garante realismo, transparência, comprometimento coletivo e efetividade de resultados na gestão do SUS. Está diretamente relacionada ao grau de consciência política e de organização da própria sociedade civil. Para Marin et al. (2007), a participação popular permite que a população adquira maior consciência política e compartilhe responsabilidade e informações, buscando melhorar a sua autonomia e qualidade de vida.

Diante desses fatores, Rezende et al. (2008) afirmam que formular e implementar um Sistema de Saúde que englobe esses princípios e diretrizes implica, de forma necessária e obrigatória, em mudança brusca de concepção no que se refere à compreensão da saúde e sua dimensão. Para esses autores, a nova perspectiva demanda reflexão e diálogo, tanto na esfera interna de cada profissão, quanto no campo da saúde como um todo. Assim, é preciso que os profissionais reflitam conjuntamente sobre as finalidades de suas práticas, restaurando o sentido e o significado do seu agir, tornando-os coerentes com essa proposta, especialmente, em relação à atenção básica. Também é indispensável a ponderação, junto a gestores e organizações comprometidas com a participação social, sobre a relação entre a composição das equipes e as necessidades de saúde das comunidades.

O conceito de atenção básica ainda é objeto de discussão. Tomando como referência a Portaria $n^{\circ}$. 648/GM, de 28 de março de 2006, essa é caracterizada como um conjunto de ações que abrange a promoção e a proteção da saúde, a prevenção de agravos, o diagnóstico, o tratamento, a reabilitação e a manutenção da saúde, tanto de caráter individual quanto coletivo, considerando-a "porta de entrada” preferencial do Sistema de Saúde. Estabelece, 
ainda, a Saúde da Família como estratégia prioritária para prestação da atenção básica no país (BRASIL, 2006a).

\subsection{Estratégia Saúde da Família - (EsSF)}

O Ministério da Saúde, tendo em vista reorientar o modelo assistencial do Brasil e baseando-se na valorização da atenção básica, criou, em 1994, o Programa Saúde da Família (PSF), que reafirma e incorpora os princípios básicos do SUS (BRASIL, 1997). Esse a partir da Portaria nº. 648/06, passa a ser denominado Estratégia Saúde da Família (EsSF), visto buscar transcender à lógica do grande número de programas verticalizados (Programa de Mulher, da Criança, do Trabalhador, de Controle da Hanseníase, de Controle da Tuberculose, da AIDS, de Hipertensão, da Diabetes, etc.) (BRASIL, 2006a).

Para Souza (1999), a efetiva implantação da EsSF é uma tentativa de garantir a integralidade de assistência e a criação de vínculo de compromisso e responsabilidade compartilhados entre os serviços de saúde e a população, favorecendo a consolidação do SUS.

Segundo o Ministério da Saúde em Brasil (1997), a EsSF apresenta caráter inovador, já que constitui uma concepção diferente dos demais programas implantados, uma vez que não é intervenção vertical e paralela às atividades dos serviços de saúde, mas compreende estratégia que possibilita a integração e promove organização das atividades em território definido, visando enfrentar e resolver problemas identificados.

O mesmo autor, acima referido, acrescenta que essa estratégia é considerada modelo substitutivo da rede básica tradicional, seguindo os princípios da eqüidade e da universalidade, reconhecidos como ação que necessita de tecnologia avançada nos campos do conhecimento e do desenvolvimento de habilidades e de mudanças. Sendo, portanto, um equívoco identificá-lo como Sistema de Saúde pobre para os pobres e com utilização de baixa tecnologia. Para Campos (2003), esse nível de atenção desenvolve ações baseadas na lógica da multicausalidade, demandando domínio de conhecimentos diversificados das partes dos profissionais e, não fragmentado e especializado, como nos demais níveis.

A EsSF foi implantada para funcionar como porta de entrada para o Sistema de Saúde. Dessa forma, salienta-se o conceito de acessibilidade, que deve garantir a plena utilização do Sistema de Saúde para a população. Esse conceito, segundo Starfield (2002), engloba os seguintes aspectos: geográficos, relacionados à distância, o tempo e aos obstáculos a serem transpostos para alcançar e obter os serviços; sócio-culturais, relacionados à inserção do serviço de saúde nos hábitos e costumes da população; e os relacionados à forma de 
organização da Unidade de Saúde, que inclui o horário de funcionamento, a disponibilidade de serviços e a qualidade. Essa autora entende que a acessibilidade está relacionada à estrutura do serviço, enquanto o acesso refere-se ao modo como o usuário experimenta essa característica do serviço.

Já, em 2002, a EsSF era considerada o maior programa assistencial desenvolvido em escala em todo o Brasil (ALEIXO, 2002). Hoje, é uma realidade nacional estando presente em 5.125 municípios, atuando com 27.324 ESF, assistindo cerca de 90\% da população brasileira, conforme dados apresentados pelo Ministério da Saúde (BRASIL, 2007). Campos (2003) acrescenta que esses números estão em constante evolução, dado o ritmo de aumento do total de equipes no país.

Caccia-Bava; Mattos e Rocha (2007), enfatizam que a EsSF visa proporcionar uma atenção integral, através de ações que incluam: proteção específica a segmentos populacionais expostos a situações de risco e vulnerabilidade (idosos, trabalhadores, gestantes e mulheres, crianças, jovens, desempregados); diagnóstico e tratamento precoce de problemas já instalados (atendimentos a urgência de baixa complexidade, doenças crônicas, egressos de internações e portadores de deficiência); reabilitação; como também, ações referentes à promoção de saúde.

Souza (1999) indica que, para a realização de assistência integral, os profissionais de saúde devem apresentar um vínculo afetivo e de confiança com os usuários, gerando, portanto, um forte elo entre a população e os servidores de saúde.

Para assegurar essas finalidades, a EsSF estrutura-se através de Unidade de Saúde da Família (USF), que consiste em Unidade Pública de Saúde, com Equipe de Saúde da Família (ESF) que assume a responsabilidade por uma determinada população, onde é desenvolvida (BRASIL, 2006a).

Na EsSF, a atenção está centrada na família, entendida e percebida a partir do seu ambiente físico e social, sendo de primordial importância que a ESF conheça a realidade epidemiológica dos indivíduos, pelos quais são responsáveis, para estabelecer as características sociais, políticas, econômicas e emocionais envolvidas no processo saúde/doença, já que essas são ferramentas essenciais para as ações de saúde (FERREIRA et al., 2005).

Cada ESF responsabiliza-se pelo acompanhamento de cerca de três a quatro mil pessoas, ou de mil famílias de uma determinada área (BRASIL, 2006b). Domingues (1998) indica que essa operacionalização deve adequar-se a realidade local, desde que esteja baseada nos princípios e diretrizes fundamentais da EsSF. 
A ESF deve dispor na própria USF, ou quando necessário, no domicílio, de meios e profissionais capazes de proporcionar solução efetiva a mais de $85 \%$ dos casos de saúde da população atendida. Dessa forma, ocorre diminuição do fluxo intenso de clientes para os setores especializados. Acrescenta-se ainda, que a proporção restante dos problemas de saúde, em torno de 15\%, deve ser encaminhada pela ESF para unidades onde haja profissionais especializados e equipamentos mais sofisticados. No entanto, durante todo o tratamento especializado e mesmo após o seu término, a ESF é responsável pelos cuidados necessários para a recuperação do indivíduo (BRASIL, 2001).

Para Campos et al. (2007), a ESF é o componente primário de um Sistema de Saúde e o seu impacto na saúde dos usuários do SUS depende, essencialmente, da sua capacidade de integração com as redes de atenção à saúde: ambulatorial especializada, hospitalar secundária e terciária, rede de serviços de urgência e emergência, e rede de serviços de atenção à saúde mental.

Desse modo, a ESF é um componente fundamental para a concretização da EsSF, sendo constituída, no mínimo, por: um médico da família, um enfermeiro, um auxiliar de enfermagem e seis Agentes Comunitários de Saúde (ACS). Quando ampliada, acrescenta-se um dentista, um auxiliar de consultório dentário e um técnico em higiene dental. Outros profissionais de saúde poderão ser incorporados às equipes ou formar equipes de apoio, conforme as necessidades e possibilidades locais (BRASIL, 2006b).

As equipes de apoio constituem um modelo operacional denominado apoio matricial, e funcionam de modo que o profissional, atuando em determinado setor, ofereça apoio para outros profissionais, equipes e setores (BRASIL, 2005).

Em relação a isso, a Portaria nº. 154/GM, de 24 de janeiro de 2008, propõe a criação dos Núcleos de Apoio à Saúde da Família (NASF) para atuarem de forma integrada com as ESF e com toda a rede de serviços de saúde, através de mecanismo de referência e contrareferência, objetivando ampliar o escopo de ações da EsSF e, conseqüentemente, a sua resolutividade. Entretanto, os NASF não são considerados como porta de entrada do sistema (BRASIL, 2008).

São duas as modalidades de NASF, ambas compostas de profissionais de forma nãocoincidente: NASF 1, incluindo, no mínimo, três dos seguintes profissionais: Médico Acupunturista, Assistente Social, Professor de Educação Física, Farmacêutico, Fisioterapeuta, Fonoaudiólogo, Médico Generalista, Médico Homeopata, Nutricionista, Médico Pediatra, Psicólogo, Médico Psiquiatra e Terapeuta Ocupacional. E o NASF 2, composto por, no mínimo, cinco, dentre os seguintes profissionais: Assistente Social, Professor de Educação 
Física, Farmacêutico, Fisioterapeuta, Fonoaudiólogo, Nutricionista, Psicólogo e Terapeuta Ocupacional. Tais composições serão definidas pelo gestor municipal de acordo com as necessidades locais e disponibilidade dos profissionais. Cada NASF 1 estará vinculado a, no mínimo, oito e, no máximo, 20 ESF, exceto nos Municípios com menos de 100.000 habitantes dos Estados da Região Norte, em que essa relação será de, no mínimo, cinco e, no máximo, vinte equipes. Já o NASF 2 realizará suas atividades vinculado a, no mínimo, três ESF (BRASIL, 2008).

Diante dessa realidade, percebe-se que o advento da EsSF fez com que novas profissões ganhassem ascensão, uma vez que a complexidade da área da saúde exige ações que englobem diferentes conhecimentos, oriundos de diversas categorias da saúde. Apresentase, assim, como uma “abertura” para novos questionamentos a respeito da atuação do fisioterapeuta na atenção básica e da relação entre eles e os diversos níveis de complexidade do SUS, rompendo com o paradigma desse profissional como agente exclusivamente reabilitador (VÉRAS et al., 2004). No entanto, esse fato vincula-se à origem da Fisioterapia, objeto do capítulo seguinte.

\subsection{Fisioterapia}

\subsubsection{Gênese da Fisioterapia}

A Fisioterapia é considerada uma profissão, ou área de conhecimento, recente. Contudo, o estudo do seu objeto de trabalho é antigo e desenvolvido de maneira difusa e não exclusiva por uma categoria profissional (GALLO, 2005). Esse fato poderá ser melhor compreendido através de uma breve analise histórica e da regulamentação dessa profissão.

Para Barros (2003), a origem da Fisioterapia remonta à antiguidade, quando os recursos da natureza e o movimento humano eram utilizados para fins terapêuticos de alívio da dor e na cura de doenças. Na China, por exemplo, existem registros de obras que abordam a cura pelo movimento, desde o ano de 2.698 A.C.

A Idade Média, caracterizada por uma ordem social estabelecida no plano divino, constituiu um período de interrupção nos estudos e na atuação na área de saúde. A cultura religiosa fez com que o corpo fosse desvalorizado e considerado um mero recipiente do espírito. Nessa época, as denominadas “diferenças incômodas” deveriam ser "exorcizadas” (REBELATTO; BOTOMÉ, 1999; SANCHEZ, 1984).

Ao contrario do período anterior, o renascimento foi marcado por manifestações artísticas, políticas e por uma maior valorização do homem, da cultura física e da saúde. 
Assim, a manutenção da saúde e a beleza corporal ganharam ênfase e a atividade física deixou de ser apenas uma forma de tratamento, para tornar-se, também, uma preocupação com a manutenção das condições normais, ou seja, a saúde não se restringia à cura e à reabilitação (REBELATTO; BOTOMÉ, 1999).

No século XIX, com a Revolução Industrial, a população oprimida era submetida a exaustivas e excessivas jornadas de trabalho, além de condições alimentares e sanitárias precárias. Nesse período, volta-se ao interesse de tratar as "diferenças incomodas”, surgindo à necessidade de tratamento das doenças e seqüelas com a finalidade de aumentar a produtividade e, para esse fim, são criados diversos tipos de ginástica e exercícios (BARROS, 2003).

A partir do século XX, aconteceram vastas mudanças na área da saúde influenciadas pelo aumento da complexidade em ciência e tecnologia, como também pelo aumento no número de casos relativos às epidemias de poliomielite e às Grandes Guerras. Esses fatores fizeram com que várias profissões, inclusive a do fisioterapeuta, fossem incorporadas ao atendimento em saúde, constituindo equipes de profissionais de saúde, com obrigações e atribuições determinadas (BRAZ, 2006).

Rebelato e Botomé (1999) acrescentam que, no cenário da segunda Guerra Mundial, surgem as escolas de Cinesioterapia, com a finalidade de tratar ou reabilitar os lesados ou mutilados que necessitavam readquirir um mínimo de condições para retornar a uma atividade social integrada e produtiva. Por isso, as ações das equipes de saúde eram restritas ao atendimento do individuo doente e a reabilitação tornou-se necessidade social.

No Brasil, o curso e a profissão de fisioterapeuta surgiram da necessidade de profissionais que atuassem juntamente com seqüelados de poliomielite e expandiram com o objetivo de diminuir os altos índices de acidentes de trabalho, contribuindo para que o fisioterapeuta se fundamentasse como profissional da reabilitação (AFONSO, 1994).

Dessa forma, a prática da Fisioterapia no Brasil, iniciou-se na Santa Casa de Misericórdia de São Paulo, sendo ainda, considerada uma atividade de nível técnico. O primeiro curso para formação de fisioterapeutas teve inicio em 1951, no Serviço de Fisioterapia do Hospital das Clínicas de São Paulo com duração de um ano, permanecendo assim até 1956. No Rio de Janeiro, em 1954, foi criada a Associação Brasileira Beneficente de Reabilitação (ABBR), originando o técnico de reabilitação, mais tarde denominado fisioterapeuta. Como as demais profissões da área da saúde, a origem do fisioterapeuta como profissão reconhecida está direcionada para as atividades predominantemente curativas e reabilitadoras (LUCAS, 2005). 
Nesse contexto, a Faculdade de Medicina da Universidade de São Paulo criou o Instituto Nacional de Reabilitação (INAR), cujo curso apresentava duração de dois anos e teve a formação da primeira turma de fisioterapeutas em 1959. Também foi criada a Associação Brasileira de Fisioterapia (ABF), filiada à WCPT (World Confederation for Physical Therapy), com a finalidade de oferecer amparo técnico-científico e sócio-cultural para o desenvolvimento dessa profissão (SCHMIDT, 2002).

A definição da ocupação do fisioterapeuta, dos limites de seu trabalho e de suas atividades apresenta como um dos documentos oficiais pioneiros o Parecer $n^{\circ}$. 388/63 do Conselho Federal de Educação (CFE):

\begin{abstract}
1-[...] A referida comissão insiste na caracterização desses profissionais como auxiliares médicos que desempenham tarefas de caráter terapêutico sob a orientação e responsabilidade do médico. A este cabe dirigir, chefiar e liderar a equipe de reabilitação, dentro da qual são elementos básicos: o médico, o assistente social, o psicólogo, o fisioterapeuta e o terapeuta ocupacional.

2- [...] Não compete aos dois últimos o diagnóstico da doença ou da deficiência a ser corrigido. Cabe-lhes executar, com perfeição, aquelas técnicas, aprendizagens e exercícios recomendados pelo médico, que conduzem à cura ou à recuperação dos parcialmente inválidos para vida social. Daí haver a comissão preferido que os novos profissionais paramédicos se chamassem Técnicos em Fisioterapia e Terapia Ocupacional, para marcar-lhes bem a competência e as atribuições. O que se pretende é formar profissionais de nível superior; tal como acontece a enfermeiros, obstetrizes e nutricionistas. Diante disso, não há como evitar os nomes de Técnicos em Fisioterapia e Técnicos em Terapia Ocupacional (REBELLATO; BOTOMÉ, 1999, p. 52).
\end{abstract}

Baseando-se nos autores acima mencionados, o processo de definição da profissão do fisioterapeuta como uma profissão liberal e de nível superior iniciou-se a partir do Decreto-Lei no . 938/69, de 13 de outubro de 1969, hoje comemorado o dia do fisioterapeuta, e cujos artigos $2^{\circ}$ e $3^{\circ}$ estão retratados a seguir:

[...] Art. $2^{\circ}$ - O fisioterapeuta e o terapeuta ocupacional, diplomados por escolas e cursos reconhecidos, são profissionais de nível superior.

[...] Art. $3^{\circ}$ - É atividade privativa do fisioterapeuta executar métodos e técnicas fisioterápicas com a finalidade de restaurar, desenvolver e conservar a capacidade física do paciente (REBELLATO; BOTOMÉ, 1999, p. 53).

Salienta-se nesse decreto, o emprego do termo paciente, que segundo Schmidt (2002), sugere que o campo de atuação do fisioterapeuta ainda estava restrito ao cuidado de indivíduos já acometidos por uma patologia. 
Nesse contexto, percebe-se que a história da Fisioterapia no Brasil apresenta suas ações concentradas em dois níveis de atenção à saúde: o secundário, referente ao diagnóstico e tratamento das doenças; e o terciário, responsável pela limitação dos danos e reabilitação, conseqüente da influência do modelo biomédico ou Flexneriano de saúde. Dessa forma, a atuação da Fisioterapia no nível primário de atenção, ou seja, na promoção da saúde e prevenção de agravo, tem sua importância considerada secundária (BRAZ, 2006).

Em relação ao constante vínculo da Fisioterapia com a reabilitação, Rebellato e Botomé (1999) relatam que desde o seu surgimento, a Fisioterapia não apresenta um objeto de estudo ou de intervenção nitidamente definido. Esse problema da clareza sobre o objeto de trabalho da Fisioterapia gera absoluta atenção à doença e suas seqüelas, esgotando as possibilidades da profissão na tentativa de recuperar, reabilitar ou, ao menos, minimizar os sofrimentos.

Esse fato é evidenciado pelo próprio nome da profissão, já que o mesmo é formado pela união de dois elementos de origem grega: $p h \Omega s i s$, natureza; e therapeía, tratamento, significando, portanto, o tratamento do que é natural, próprio da natureza, especificamente, da natureza humana (NICIDA, 2004). Assim, em princípio, contendo o termo “terapia”, a Fisioterapia exclui algumas modalidades de atuação profissional, como a prevenção das doenças e a promoção da saúde. Essa tendência também é fortalecida pela pouca experiência e fraca tradição de pesquisa crítica na área de saúde e nos trabalhos das instituições de saúde (REBELLATO; BOTOMÉ, 1999).

No entanto, com a nova concepção de saúde, enquanto qualidade de vida, o âmbito da Fisioterapia desenvolveu-se, e o fisioterapeuta integrou-se nas ações de atenção básica, deixando de atuar exclusivamente na reabilitação, para atuar, também, na promoção da saúde e na prevenção de doenças (PEREIRA et al., 2004).

O primeiro documento da Fisioterapia, cujo conteúdo ultrapassa concepção de uma assistência em âmbito curativo e reabilitador é o Código de Ética Profissional de Fisioterapia e Terapia ocupacional, estabelecido pela Resolução n. ${ }^{0} 10$ do Conselho Federal de Fisioterapia e Terapia Ocupacional - COFFITO, de 3 de julho de 1978. Os principais artigos dessa resolução estão descritos a seguir: 
[...] Art. $1^{\circ}$ - O fisioterapeuta e o terapeuta ocupacional prestam assistência ao homem, participando da promoção, tratamento e recuperação de sua saúde.

[...] Art. $7^{\circ}$ - São deveres do fisioterapeuta e do terapeuta ocupacional, nas respectivas áreas de atuação: V- Utilizar todos os conhecimentos técnicos e científicos a seu alcance para prevenir ou minorar o sofrimento do ser humano e evitar seu extermínio.

[...] Art. $21^{\circ}$ - O fisioterapeuta e o terapeuta ocupacional participam de programas de assistência à comunidade, em âmbito nacional e internacional (COFFITO, 1978, p. 5265).

Além de ampliar o campo de atuação do fisioterapeuta em relação aos níveis de assistência (prevenção primária, secundária e terciária), essa resolução também expandiu o foco da atenção, passando a abranger a saúde do indivíduo como um todo e não mais apenas no que diz respeito à sua capacidade física.

No entanto, Ribeiro (2002) salienta que a formação acadêmica do fisioterapeuta também constitui entrave para romper o paradigma de reabilitador que o caracteriza e dificulta sua atuação no âmbito da atenção primária. Isso ocorre, uma vez que essa formação não prepara e nem incentiva o fisioterapeuta a atuar no primeiro nível de atenção à saúde, estando direcionada, principalmente, para o atendimento em centros de reabilitação e hospitais, num enfoque eminentemente voltado à reabilitação e com uma estrutura curricular preocupada com a abordagem de doenças que deixam seqüelas reabilitáveis.

A fim de assegurar ao fisioterapeuta uma formação acadêmica que contemple todos os níveis de atenção à saúde, de forma equilibrada, o Conselho Nacional de Educação aprovou, em 2002, as novas Diretrizes Curriculares Nacionais para os Cursos de Graduação em Fisioterapia. Essas diretrizes propõem uma formação generalista, humanística, crítica e reflexiva, que contemple o Sistema de Saúde vigente no país, o trabalho em equipe e a atenção integral à saúde (CONSELHO NACIONAL DE EDUCAÇÃO, 2002).

Atualmente, a Fisioterapia é considerada atividade de saúde, regulamentada pelo Decreto-lei $n^{\circ}$. 938/69, Lei nº . 6.316/75, Resoluções do COFFITO, Decreto nº 9.640/84 e Lei $n^{\circ}$. 8.856/94 (COFFITO, 2008). A mesma é definida como:

[...] Uma ciência da Saúde que estuda, previne e trata os distúrbios cinéticos funcionais intercorrentes em órgãos e sistemas do corpo humano, gerados por alterações genéticas, por traumas e por doenças adquiridas. Fundamenta suas ações em mecanismos terapêuticos próprios, sistematizados pelos estudos da Biologia, das ciências morfológicas, das ciências fisiológicas, das patologias, da bioquímica, da biofísica, da biomecânica, da cinesia, da sinergia funcional, e da cinesia patologia de órgãos e sistemas do corpo humano e as disciplinas comportamentais e sociais (COFFITO, 2008). 
Para Lins (2003), essa definição da Fisioterapia exclui dúvidas, antes existentes, sobre a capacidade desse profissional em ser inserido na atenção básica. Considera-se que a evolução da fisioterapia fez com que seu campo atuação se expandisse e não permanecesse preso à história e limitado à reabilitação.

Portanto, percebe-se que o fisioterapeuta atual diverge do conceito restrito à reabilitação do qual se originou e cuja evolução foi conquistada pela profissão, no campo legal e científico, através da competência e amadurecimento dessa categoria. Assim, o fisioterapeuta ampliou seu campo de atuação e deixou de ser um "profissional da reabilitação" para tornar-se um "profissional da saúde”, atuante na promoção, desenvolvimento, prevenção, tratamento e recuperação da saúde (BARROS, 2003).

Lucas (2005) destaca a existência de um conflito entre o que significa o vocábulo Fisioterapia e o que significa a atuação profissional de quem a aplica. E acrescenta a necessidade de mudar a própria denominação desse profissional, para que os clientes e os fisioterapeutas possam ter mais consciência de seu amplo campo de atuação,

O fisioterapeuta é considerado por Barros (2003) como o profissional que cuida da saúde da população, com ênfase no movimento e na função, prevenindo, tratando e recuperando disfunções e doenças, visando melhorar a qualidade de vida do indivíduo. Para Ragasson et al. (2006), a Fisioterapia apresenta missão essencial através da aplicação de meios terapêuticos físicos, na prevenção, eliminação ou melhora de estados patológicos do homem, na promoção e na educação em saúde.

No entanto, são vários os obstáculos que ainda impedem essa ampliação do campo de atuação do fisioterapeuta. Dentre eles, destaca-se a procura do serviço de Fisioterapia pela população. Robalo e Silva (2005) enfatizam que a população, devido a aspectos sócioculturais, muitas vezes, só recorre à Fisioterapia por necessidades consideradas urgentes e imediatas, tais como seqüelas de Acidente Vascular Cerebral ou dor lombar aguda. Esse fato desvaloriza o esforço e o investimento em ações de promoção da saúde, cujo resultado só é reconhecido a longo prazo.

Diante do exposto, percebe-se que a origem histórica e a forma como a Fisioterapia foi caracterizada e definida pela legislação, somadas ao modelo de atenção centrado basicamente na doença vigente no país, foram fatores decisivos para a caracterização do fisioterapeuta como profissional reabilitador. Perante esse fato, torna-se importante descrever as atuais áreas de atuação da Fisioterapia. 


\subsection{2 Áreas de atuação da Fisioterapia}

Paralelamente ao crescimento do conhecimento cientifico e do perfil profissional, ampliou-se o mercado de trabalho do fisioterapeuta. Atualmente, ele é membro do campo da saúde com concreta formação científica que desenvolve ações preventivas e de promoção da saúde, avaliações, tratamentos e reabilitações. Para tanto, o fisioterapeuta atua em hospitais, clínicas, consultórios, centros de reabilitação, empresas de home care, centros aquáticos, centros hípicos, indústrias, escolas, entidades filantrópicas, centros universitários, centros de pesquisa, empresas e laboratórios de equipamento de reabilitação (DELIBERATO, 2002).

Conforme o COFFITO (2008), a Fisioterapia apresenta as seguintes áreas de atuação: Clínica, podendo atuar em hospitais, clínicas, ambulatórios, consultórios e centros de reabilitação; Educação, incluindo a docência, extensão, pesquisa, supervisão, direção e coordenação de cursos; Saúde Coletiva, englobando programas institucionais, ações básicas de saúde, Fisioterapia do trabalho e vigilância sanitária; além de outros campos, como na indústria de equipamentos de uso fisioterápico e no esporte.

Em relação à atuação clínica, esse profissional realiza o processo fisioterápico, que abrange o diagnóstico cinesiológico-funcional, prognóstico, prescrição, indução do tratamento, reavaliação e alta do paciente/cliente. Pode atuar de forma isolada ou em equipe com outros fisioterapeutas e/ou demais profissionais de saúde. Utiliza técnicas específicas: manuais, biomecânicas e neurofisiológicas para induzir movimentos e posturas terapêuticas. E também agrega equipamentos elétricos e eletrônicos com finalidade de analgesia, eletroestimulação, cicatrização de tecidos, etc. (BARROS, 2003).

No tocante à atuação em Saúde Coletiva, a principal atribuição do fisioterapeuta é realizar atividades de educação, prevenção e assistência coletiva, na atenção primária em saúde (COFFITO, 2008). No entanto, como referido no capítulo anterior, a atuação fisioterápica nos serviços de atenção primária ainda é um processo em consolidação. Isso ocorre, uma vez que desde sua criação, essa profissão é vinculada à reabilitação, referindo-se apenas a uma pequena parte de seu objeto de trabalho. Esse conceito acarretou exclusão dos serviços de Fisioterapia da rede básica, causando uma grande dificuldade de acesso da população a esse serviço e impedindo o profissional de atuar na atenção primária (RIBEIRO, 2002).

Afonso (1994) acrescenta que a crescente ênfase da Fisioterapia na atenção básica é influenciada pelo aumento dos índices de patologias originadas da falta de cuidados primários e educativos, bem como pelo alto custo do tratamento de reabilitação para as empresas e para o Estado. 
Diante desse contexto, percebe-se a importância de descrever a atuação da Fisioterapia na atenção básica, em especial na EsSF.

\subsubsection{Fisioterapia e a Estratégia Saúde da Família}

A inserção do fisioterapeuta na atenção básica à saúde encontra-se em edificação, pretendendo tornar a Fisioterapia cada vez mais acessível e, assim, colaborar com os princípios que regem a EsSF.

A atuação fisioterápica na atenção primária já é fato concreto em alguns países da Europa, como a Espanha, cuja legislação do estatuto do profissional sanitário determina que o fisioterapeuta deva integrar a ESF. No Brasil, o fisioterapeuta está começando a atuar na EsSF em algumas regiões, contribuindo para uma ação mais sistêmica da atenção à saúde (VÉRAS et al., 2005). Dessa forma, ainda observa-se um restrito número de pesquisas em relação à atuação do fisioterapeuta nesta estratégia.

Para Rebellato e Botomé (1999), os fisioterapeutas que atuam na EsSF devem realizar um trabalho, cujo objetivo maior seja propiciar condições de saúde que permitam amplo grau de conforto e segurança à população, sendo necessárias ações de promoção e manutenção da saúde e de prevenção de doenças, além de assistência curativa e reabilitadora.

Segundo Pereira et al. (2004), os objetivos específicos da atuação fisioterápica na EsSF são: trabalhar a promoção de saúde, considerando as necessidades do território; prevenir os distúrbios cinético-funcionais em todos os ciclos da vida; tratar e reabilitar as principais alterações do movimento mais incidentes e/ou prevalentes no território e realizar atendimento domiciliar em indivíduos restritos ao leito, através de assistência fisioterápica e orientações aos familiares.

Em estudo de resultado semelhante, Ragasson et al. (2006), através de suas experiências como fisioterapeutas em residência em Saúde da Família em Cascavel-PR, definiram algumas atribuições específicas ao fisioterapeuta na ESF. Dentre estas, destacamse: realizar ações de assistência integral em todas as fases do ciclo de vida (criança, adolescente, mulher, adulto e idoso), intervindo em todos os níveis de atenção à saúde e atuar de forma integral junto às famílias, através de ações interdisciplinares e intersetoriais, visando à assistência e à inclusão social de pessoas portadoras de deficiências, incapacitadas e desassistidas.

Para tanto, as ações do fisioterapeuta na EsSF devem abranger todo o território assistido pela USF, ou seja, escolas, indústrias, associações de moradores, creches etc., de 
forma a atuar tanto individual como coletivamente. Isso indica a prática de uma abordagem familiar e não centrada no individuo. Deve-se também considerar todos os aspectos (sociais, econômicos, culturais e ambientais) que influenciam o processo saúde/doença (VÉRAS et al., 2004).

Os estudos acima referidos enfatizam a integralidade da assistência prestada pelo fisioterapeuta. Conforme Schwingel (2002), esse é o princípio do SUS que mais influencia a atuação desse profissional na atenção básica, visto sua constante associação com a atuação restrita ao tratamento e reabilitação. Portanto, esse autor indica que, para o fisioterapeuta realizar uma assistência integral, é necessário que atue na prevenção, promoção e recuperação da saúde; na pesquisa, visando gerar conhecimento; e na educação, com o intuito de informar a população.

Véras et al. (2004) destacam a dificuldade em concretizar o princípio de integralidade da atenção, justificando que os indivíduos só buscam o atendimento, em especial a Fisioterapia, tardiamente, geralmente, quando já apresentam seqüelas. Esse fato demonstra o desconhecimento, por parte da população, de meios de prevenção de doenças. Assim, torna-se necessário, informar e conscientizar a população da importância dessa atuação. Afonso (1994) também salienta a importância da Fisioterapia na atenção primária à saúde e a necessidade de conscientizar os profissionais da área de saúde e a sociedade sobre a relevância do fisioterapeuta como agente de saúde.

Além da integralidade da assistência, para Castro, Cipriano Junior e Martinho (2006), a inclusão do fisioterapeuta nas ESF pode colaborar para a concretização de outros importantes princípios da EsSF, como a multidisciplinaridade e a resolutividade. Isto ocorre, uma vez que a atuação do fisioterapeuta poderá prevenir o aumento do volume e complexidade da atenção em saúde, reduzindo os gastos públicos. Ao mesmo tempo, essa atuação colabora com a mudança do modelo assistencial, evitando o incremento das doenças e suprindo demandas reprimidas do serviço de Fisioterapia nas áreas cobertas, além de também atuar na seleção e triagem de pacientes para o sistema de referência e contra-referência. Porém, ressalta-se que essas atribuições não excluem a atuação do fisioterapeuta no tratamento e na reabilitação de diversas patologias, mas se somam a elas.

Segundo Ragasson et al. (2006), o serviço prestado pelo SUS, muitas vezes, é caracterizado como uma proposta de saúde pobre, para uma população pobre, mas a inserção do fisioterapeuta, bem como de outros profissionais da área nos programas de saúde, principalmente na EsSF, poderá contribuir para reverter esse conceito equivocado, pois 
aumentará a eficácia e a resolutividade dos problemas de saúde, através de uma equipe qualificada e apta à promover saúde .

Lins (2003) também constatou que a inserção da fisioterapeuta na EsSF poderá tornar o serviço de Fisioterapia de fácil acesso à população; realizar assistência básica ao paciente e superar os entraves de acesso, geralmente presentes nas comunidades carentes, como condições financeiras e físicas, empecilhos arquitetônicos que dificultam o deslocamento do paciente, superlotação nos centros de referência e, também, a rejeição do paciente ao tratamento.

Sobre a dificuldade de acesso e de deslocamento do paciente, Ragasson et al. (2006) enfatizam a importância do atendimento domiciliar realizado pelo fisioterapeuta que trabalha na atenção primária, para que esse profissional possa perceber a realidade do indivíduo que está sendo assistido, verificando suas atividades de vida diária e limitações e, assim, proceder aos encaminhamentos e orientações cabíveis a cada caso. O’Sullivan e Schmitz (2004) percebem o atendimento domiciliar como a oportunidade de avaliar o ambiente onde o paciente reside, cujas informações obtidas auxiliam na determinação das necessidades de intervenções terapêuticas adicionais, modificações ambientais e equipamentos.

Diante da literatura abordada, torna-se necessário destacar algumas pesquisas que relatam experiências relacionadas à atuação do fisioterapeuta ou de estudantes de Fisioterapia, na EsSF. Esses estudos são limitados às experiências isoladas em algumas regiões brasileiras, mas que, em geral, denotam resultados satisfatórios.

Cita-se o exemplo do estudo de Carvalho (2005), realizado em Cabedelo-PB com profissionais das ESF que apresentam estagiários de Fisioterapia, em que foi observado que 87,5\% dos entrevistados verificaram existência de melhorias na assistência à população após a inserção desses estagiários e 100\% detectaram necessidade de inclusão do fisioterapeuta em suas equipes.

Em estudo realizado em Sobral-CE, foi constatado que a atuação dos fisioterapeutas integrantes da EsSF local é realizada de forma integral, de forma que 67\% das atividades desempenhadas por esses profissionais estão relacionadas à promoção da saúde, prevenção de doenças ou estão sendo praticadas de maneira coletiva, e que mesmo as atividades relacionadas ao modelo individual e curativo estão sempre associadas com abordagem familiar, como também, envolvendo ações de prevenção e promoção (BRASIL et. al, 2005). Véras et al. (2005), concluíram que nesse município existe um trabalho integral junto à população, através da prevenção de seqüelas e incapacidades que acarretam melhor qualidade de vida aos indivíduos. Em relação à avaliação dos serviços de Fisioterapia de média 
complexidade ambulatorial nesse município, Pereira (2004) constatou que dentre os 42 usuários desse serviço apenas um referiu ter tido continuidade do atendimento na USF ou ter retornado à Unidade. Esse dado demonstra uma falha na estruturação de uma linha de cuidado, que garanta a integralidade do atendimento aos pacientes, importantes princípios da EsSF.

Kieling (2008), através de entrevistas com os fisioterapeutas que trabalham no Sistema Municipal de Saúde de Curitiba-PR, também verificou a existência de atividades fisioterápicas semelhantes nos distritos sanitários locais. Nesses, os fisioterapeutas atuam, prioritariamente, em atenção primária à saúde, realizando orientação e prevenção de doenças e seqüelas, com atividades de grupo e assistências individuais, além de fazerem triagem e encaminhamento para clinicas de referências, de acordo com a necessidade.

Lins (2003) refere à presença de atividades fisioterápicas dessa natureza em RecifePE, através do projeto piloto Reabilitação Baseada na Comunidade, que objetiva incluir o fisioterapeuta na EsSF desse município. Foi descrito o emprego de atividades, a exemplo de palestras e campanhas educativas, voltadas para grupos da comunidade e realizadas em diversos espaços sociais (igrejas, escolas, creches, associações e conselho de moradores, ou no próprio posto de saúde). Através dessas atividades são abordados temas de interesse geral da população, como: hipertensão, Diabetes Mellitus, gravidez, etc., com a finalidade de promover melhor qualidade de vida mediante sensibilização da comunidade, possibilitando a reintegração e ressocialização do usuário.

Em Londrina-PR, Trelha et al. (2007), em um estudo com fisioterapeutas que atuam na EsSF desse município, relataram que esses profissionais realizam ações dirigidas à: assistência, educação, prevenção de doenças e agravos e promoção da saúde da população. No entanto, verificou-se que a atuação educativa e preventiva não é remunerada e ocorre além da carga horária contratual desses profissionais. Assim, nesse município, as ações dessa natureza não são prioritárias, possivelmente, devido à grande demanda do atendimento curativo/reabilitador e ao reduzido número de fisioterapeutas atuantes na EsSF dessa localidade.

O estudo de Sampaio (2002) retratou a atuação do fisioterapeuta no Centro de Saúde São Gabriel, em Belo Horizonte-MG, diferenciando dois tipos de intervenções. A primeira refere-se à integração da Fisioterapia aos programas já desenvolvidos pela Secretaria Municipal de Saúde em toda a comunidade, a exemplo dos programas de hipertenso; de diabéticos e de crianças portadoras de asma. A segunda engloba os serviços oferecidos pela Fisioterapia, dirigidos aos indivíduos e à família. No primeiro momento, é realizado o 
acolhimento das pessoas que buscaram esse serviço. A partir disso, e considerando a necessidade de cada indivíduo, os usuários são encaminhados para médicos especialistas nas policlínicas; para atendimento na própria Unidade ou para locais de referência, caso demandem tratamento fisioterápico de maior complexidade. Através de visitas domiciliares, são realizados, também, tratamento e orientação para pacientes e seus familiares.

Em relação aos gastos com a saúde, estudo realizado em Paulínia-SP concluiu que a atuação de fisioterapeutas em atividades de grupo com pacientes das UBS que apresentavam algias crônicas na coluna, realizadas com uso de poucos e simples recursos, como colchonetes e bolinha de tênis, resultou na redução ou desaparecimento da dor em 88\% desses pacientes, diminuição de reconsultas nas UBS e redução do uso de medicamentos (CREFITO-3, 2008).

Ribeiro (2005) entrevistou estudantes de Fisioterapia que prestavam assistência às comunidades Maria de Nazaré e do Grotão, em João Pessoa-PB, e incluiu a escassez de recursos nos atendimentos de Fisioterapia como uma das principais dificuldades desse serviço. No entanto, para muitos entrevistados, essa carência foi apontada como um aprendizado que estimula a criatividade, a revalorização da cinesioterapia e a reaproximação entre paciente e terapeuta.

Um aspecto importante a ser considerado na atuação do fisioterapeuta na atenção básica é o acesso da população a esse serviço. Na Comunidade Maria de Nazaré e do Grotão, em João Pessoa-PB, evidencia-se a importância de tornar o tratamento fisioterápico acessível aos moradores de comunidades periféricas, colaborando para a manutenção e recuperação da saúde e melhoria da qualidade de vida da população (RIBEIRO, 2002).

A pesquisa de Lins (2003), realizada em Recife-PE, constatou essa deficiência ao afirmar que dentre todos os usuários com necessidade real de assistência fisioterápica na comunidade, apenas 7\% têm acesso a esses serviços. Os motivos para isso foram descritos na seguinte ordem: falta de solicitação médica e de condições financeiras e/ou físicas para o deslocamento do usuário, vagas insuficiente nos serviços referidos e interrupção do tratamento devido ao término das sessões autorizadas.

O mesmo ocorre em Sobral-CE, onde Véras et al. (2005), em um estudo com usuários dos serviços de Fisioterapia na EsSF desse município, verificaram que 47\% dos entrevistados nunca tinham sido atendidos por esse profissional antes do fisioterapeuta ser inserido nessa estratégia, o que demonstra limitação significativa no acesso a esse serviço. Número semelhante ao encontrado na pesquisa de Blascovi-Assis e Peixoto (2002), em Sorocaba e região, com pacientes submetidos a atendimento fisioterápico, em que foi 
constatado que 35,2\% dos entrevistados não sabiam o que era a Fisioterapia antes de utilizar este serviço.

Segundo Ribeiro (2002), o número de pessoas que não apresentam condições de acesso ao tratamento fisioterápico demonstra a deficiência do Sistema de Saúde em proporcionar o acesso universal, equânime e integral à saúde, que é direito de todos os cidadãos, conforme a Constituição.

Estudo desenvolvido por Brasil et al. (2005), com os fisioterapeutas integrantes da EsSF de Sobral-CE, constatou que a limitação do acesso da comunidade aos serviços de Fisioterapia tem suas causas relacionadas ao número insuficiente desse profissional, dificuldades estruturais e materiais, além do desconhecimento da população, dos demais profissionais e dos gestores, em relação a amplitude da atuação do fisioterapeuta.

Centa e Almeida (2003) estudaram a percepção da equipe multidisciplinar sobre a EsSF em Curitiba-PR, apontando os seguintes pontos negativos que interferem na completa implementação dessa estratégia: falta de recursos, excesso de funções, baixa qualificação profissional, falta de entrosamento da equipe, falta de consciência e conhecimento do programa por parte da população, insatisfação da população, riscos enfrentados, aspectos políticos e sistema de referência. Destaca-se dentre esses aspectos, os recursos humanos, que englobavam a ausência de profissionais de determinadas áreas e cujo exemplo de citação, inclui o fisioterapeuta.

Assim, percebe-se que os estudos demonstram a importância da atuação do fisioterapeuta de forma integral, em todos os níveis de atenção à saúde, e que a inserção desse profissional junto à comunidade, especificamente na EsSF, na maioria das vezes, é a única possibilidade de acesso da população a esses serviços.

A Portaria $n^{\circ}$. 154/2008, anteriormente referida, propõe a criação dos NASF, que inclui um fisioterapeuta vinculado a um número determinado de ESF. Essa portaria é, sem dúvida, um grande avanço para todos os profissionais incluídos nessa estratégia. Mas, por ser recente, não existe até o momento da construção dessa pesquisa, um estudo em relação à experiência da atuação fisioterápica no NASF.

No entanto, semelhante ao que foi proposto, a realidade atual, em muitos municípios, configura um fisioterapeuta para assistir algumas ESF, sendo esse um ponto relevante para discussão. Trelha et al. (2007), discorrem sobre essa situação em um estudo com fisioterapeutas que atuam na EsSF de Londrina-PR, no qual foi destacada a dificuldade de atuação desses profissionais, devido ao curto tempo dispensado a cada USF frente à grande demanda e pela falta de infra-estrutura adequada para a assistência fisioterápica, já que esse 
profissional não estava fixo na equipe e não possuía local próprio para atuação. Fato concernente ao descrito por Ribeiro (2002) em seu estudo na comunidade do Grotão e Maria do Nazaré em João Pessoa-PB, que relatou dificuldades em realizar atividades de promoção da saúde e prevenção, visto a grande demanda por tratamento e reabilitação da região, tornando a atuação do fisioterapeuta mais focado nesse nível de atenção com, conseqüente, detrimento dos demais.

Em contrapartida, Silva et al. (2006), em uma pesquisa com membros de ESF de Florianópolis sobre a possibilidade de inclusão de outros profissionais nessas equipes, constataram que, para alguns entrevistados, o fisioterapeuta realiza assistência mais específica, que necessita de espaços físicos e equipamentos não adequados à atenção básica. Para esses, seria suficiente a existência de um fisioterapeuta de referência para atender de três a cinco equipes.

Há necessidade de estudos e relatos de experiências da inserção do fisioterapeuta no NASF, principalmente no tocante a proporção de profissionais e número de equipes assistidas, para analisar se a quantidade proposta garantirá o acesso da população aos serviços, sem comprometer a qualidade dos mesmos. Também é preciso analisar a possibilidade de formação do vínculo entre o profissional de saúde e a população adscrita, já que esses são requisitos básicos para o bom funcionamento da EsSF.

Diante do exposto, percebe-se que a atuação do fisioterapeuta, tanto em um núcleo de apoio, quanto na equipe mínima, exige priorização das ações de atenção básica. Assim, é necessária a existência de estrutura física adequada e quantidade de profissionais suficiente para suprir a demanda reprimida que necessita de tratamento e reabilitação, para que o fisioterapeuta possa dirigir suas atividades, prioritariamente, para ações de prevenção e promoção da saúde.

\subsection{A Fisioterapia na EsSF do Município de Ribeirão Preto}

A implantação da EsSF em Ribeirão Preto é datada em 1999, ano em que surgiu a primeira USF, cujos recursos humanos e materiais foram disponibilizados pelo Centro de Saúde Escola da Faculdade de Medicina de Ribeirão Preto da Universidade de São Paulo. Em 2001 cinco USF foram oficialmente habilitados junto ao Ministério de Saúde. Hoje, essa estratégia abrange, além dos médicos residentes de medicina de família e comunidade do Hospital das Clínicas e os acadêmicos de medicina do $5^{\circ}$ ano, as áreas de Enfermagem, Farmácia, Psicologia, Nutrição, Fonoaudiologia, Fisioterapia, Terapia Ocupacional, 
Odontologia e Técnicos e Auxiliares de Enfermagem (CACCIA-BAVA; MATTOS; ROCHA, 2007).

O município está dividido em cinco Distritos de Saúde e conta, também, com diversas unidades de serviços especializados. A rede Municipal de Saúde de Ribeirão Preto apresenta a atuação de apenas sete fisioterapeutas, distribuídos de forma que o mesmo profissional trabalha em mais de um posto de serviço. Assim, o Centro de Referência em Saúde do Trabalhador/Prof. Dr. Roberto Meirelles Salles apresenta dois fisioterapeutas; o Núcleo de Atenção à Pessoa Deficiente - NADEF tem três; o Núcleo de Gestão Assistencial conta com dois; o Ambulatório de Especialidades Pediátricas - PAM II apresenta três e, os Programas de Saúde contam, somente, com a atuação de um fisioterapeuta (RIBEIRÃO PRETO, 2008a).

Aguiar (2005) mencionou que em algumas USF vinculadas à distrital do bairro Sumarezinho houve atuação de um fisioterapeuta, mas de forma voluntária, em média, apenas uma vez na semana, e com ações voltadas para reabilitação, realizando, principalmente, atividades domiciliares e individuais.

Assim, tratando-se de um dos municípios mais ricos do estado, com elevado padrão de vida e um dos principais centros universitários e de pesquisa do país, com destaque nas áreas médicas (RIBEIRÃO PRETO, 2005), apresenta um reduzido número de fisioterapeutas contratados e atuando na rede própria e conveniada do município.

Além disso, nesse município ocorre fato descrito por Ribeiro (2002), em que o atendimento fisioterápico encontra-se restrito a centros de reabilitação e outros serviços de atenção secundária, originando uma demanda reprimida nesses locais e, conseqüentemente, longa fila de espera. Em Ribeirão Preto, o tempo médio para se obter consulta fisioterápica atinge um ano, conforme tem mostrado a prática assistencial nas Unidades de Saúde (informação verbal) ${ }^{1}$.

A ausência de fisioterapeuta, junto à comunidade, também dificulta o acesso de acamados e portadores de deficiência, assim como gera grande custo com transporte, visto que esse tipo de atendimento, geralmente, necessita de várias sessões durante longo período de tempo (RIBEIRO, 2002).

Caccia-Bava; Mattos e Rocha (2007) destacam que nesse município, aproximadamente, $88 \%$ dos serviços de saúde ainda são organizados sob a lógica do modelo biomédico, tornando árduo o deslocamento do foco da assistência da saúde para o território e

\footnotetext{
${ }^{1}$ Informação fornecida por Maria Dulcilei Faria, setor de agendamento da UBDS do Sumarezinho, em Ribeirão Preto, 2008.
} 
para os grupos sociais e, conseqüentemente, para a instituição de novas relações de poder, coresponsabilidade e estímulo à participação dos atores sociais.

\section{JUSTIFICATIVA}

A Fisioterapia é um campo profissional relativamente novo, quando comparada às demais profissões da área de saúde. Apresenta, ainda, âmbito de atuação pouco conhecido pela população em geral, fazendo com que os indivíduos procurem a Fisioterapia tardiamente, apenas visando ao tratamento e à reabilitação e, conseqüentemente, aumentando gastos com a saúde.

Esse conhecimento restrito é ainda mais agravante, quando se refere à atuação do fisioterapeuta na atenção básica, já que o SUS, ao preconizar a participação de diversos atores sociais (usuários, profissionais e gestores), transforma o conhecimento sobre a saúde e sobre a importância dos diferentes saberes profissionais em ferramenta decisiva para a democratização da gestão da saúde e para a qualificação da assistência.

A pesquisa desenvolvida por Brasil et al. (2005) demonstrou esse fato, ao constatar que o desconhecimento a respeito da atuação do fisioterapeuta é um motivo de limitação do acesso da comunidade ao serviço de Fisioterapia na EsSF. Assim, para superar esse entrave, torna-se necessário avaliar o conhecimento da população usuária dos serviços da EsSF, dos profissionais da ESF e dos gestores, a respeito da Fisioterapia e sua importância para a saúde da comunidade.

Aguiar (2005) deu início a estudo dessa natureza, pesquisando sobre os conhecimentos e as atitudes da ESF em relação à Fisioterapia nas USF que cobrem a área de abrangência da Unidade Básica Distrital de Saúde (UBDS) do Sumarezinho, em Ribeirão Preto-SP. Obteve resultados satisfatórios, uma vez que, dentre os membros das ESF, 48,6\% consideraram necessária a participação do fisioterapeuta na EsSF; um em cada três dos entrevistados apresentou bom grau de conhecimento sobre a atuação do fisioterapeuta e 99,1\% demonstraram um conjunto de atitudes positivas em relação à atuação fisioterápica.

O estudo que desenvolvemos pode complementar o de Aguiar (2005), já que abordou o conhecimento da população usuária da EsSF à respeito da Fisioterapia. Sua importância é justificada pelo incentivo que os serviços de atenção básica atribuem à participação popular, transformando-a em estratégia de enfrentamento dos problemas de saúde, fazendo com que a população adquira maior consciência política e compartilhe a responsabilidade e as 
informações, buscando, assim, melhorar a autonomia e a qualidade de vida das pessoas (MARIN et al., 2007).

Também foram investigadas as percepções desses usuários quanto às suas principais necessidades em relação à atuação do fisioterapeuta. Esse dado é importante, uma vez que a composição das ESF que atuam na EsSF depende da localização e da necessidade da população quanto aos serviços de saúde a ela destinada.

A percepção dessa necessidade pelos próprios usuários tem sua relevância constatada por Stortz (1991), ao afirmar que a investigação sobre as necessidades de saúde não podem limitar-se aos indicadores epidemiológicos, devendo considerar importante o ponto de vista dos sujeitos reais, na definição das suas necessidades, conforme percepções e situações diferenciadas. A ausência dessa perspectiva pode causar fracasso no planejamento em saúde. 


\section{OBJETIVOS}

Diante do exposto, esta pesquisa apresenta os seguintes objetivos.

\subsection{Objetivo Geral}

$\checkmark$ Investigar os conhecimentos dos usuários de uma USF sobre a Fisioterapia, e as percepções dos mesmos quanto às suas principais necessidades em relação à atuação do fisioterapeuta.

\subsection{Objetivos Específicos}

$\checkmark$ Caracterizar o perfil sócio-familiar e demográfico dos usuários de uma USF.

$\checkmark$ Identificar os conhecimentos desses usuários em relação à Fisioterapia: conhecimentos básicos, recursos utilizados e âmbito de atuação.

$\checkmark$ Identificar as percepções desses usuários quanto à inclusão do fisioterapeuta na equipe multiprofissional da USF em que estão cadastrados.

$\checkmark$ Identificar as percepções desses usuários quanto às suas principais necessidades em relação à atuação do fisioterapeuta. 


\section{MATERIAL E MÉTODO}

\subsection{Delineamento do Estudo}

Trata-se de estudo com delineamento transversal e descritivo, de abordagem quantitativa. Para Gil (2002), a pesquisa descritiva apresenta como objetivo primordial a descrição das características de determinada população ou fenômeno, utilizando técnicas padronizadas de coleta de dados, tais como o questionário e a observação sistemática. Destacam-se, também, na pesquisa descritiva, aquelas que visam descrever opiniões, atitudes e crenças de uma população.

A abordagem quantitativa permite quantificar opiniões e dados por meio de coleta de informações, utilizando recursos e técnicas estatísticas desde as mais simples, como porcentagem, média, moda, mediana e desvio padrão, até as de uso mais complexos (OLIVEIRA, 2000). Essa abordagem apresenta objetividade e rigor peculiar e emprega procedimentos que permitem a previsão de etapas que caracterizam a investigação e a representatividade estatística da população investigada, ampliando a credibilidade das conclusões alcançadas (LIMA, 2004).

\subsection{Campo de Estudo}

Ribeirão Preto localiza-se na região nordeste do estado de São Paulo, a 313 km da capital, com uma população, com base nos dados do Censo Demográfico de 2000, de 504.923 habitantes, em um território de $651 \mathrm{Km}^{2}$. Trata-se de um dos municípios mais ricos do estado, com elevado padrão de vida. Também é considerado um dos principais centros universitários e de pesquisa do país, com destaque nas áreas médicas, situando-se entre os primeiros do Brasil no ranking nacional, na proporção médico por habitante, dispondo de um médico para cada 160 habitantes. Destaca-se, ainda, quanto à oferta de ações e serviços de saúde, cujo setor é constituído pela Rede Pública Municipal e por serviços filantrópicos e particulares de atenção à saúde (RIBEIRÃO PRETO, 2005).

A Rede Municipal de Saúde de Ribeiro Preto é constituída por cinco Distritos de Saúde e Unidades específicas: Núcleo de Gestão Assistencial - NGA 59, Ambulatório Regional de Saúde Mental, Núcleo de Atenção Psico Social - NAPS-1, Núcleo de Atenção Psico Social para Alcoolistas e Farmacodependentes - NAPS-F e, Ambulatório de Especialidades Pediátricas - PAM II (CACCIA-BAVA, 2004). 
Os Distritos de Saúde foram constituídos com o objetivo de compatibilizar as necessidades provindas do crescimento do município com o aumento do acesso da população aos serviços de saúde. São eles: norte (Quintino), sul (Vila Virgínia), leste (Castelo Branco), oeste (Sumarezinho) e centro (CACCIA-BAVA, 2004).

Cada distrito apresenta áreas e populações definidas de acordo com os aspectos geográficos, econômicos e sociais, que agrupam várias Unidades de Saúde e outros equipamentos sociais. Esses Distritos contam com uma Unidade Básica Distrital de Saúde (UBDS), que oferece atendimento básico para sua área de abrangência, além de ser referência de algumas especialidades para todo o distrito (RIBEIRÃO PRETO, 2006a).

Dessa forma, atualmente, a área de abrangência da UBDS Sumarezinho, no Distrito Oeste de Ribeirão Preto, é constituída por cinco Unidades de Saúde da Família (USF) que fazem o atendimento básico, contando com médicos generalistas, Agentes Comunitários de Saúde (ACS), enfermeiros e auxiliares de enfermagem, desenvolvendo seus trabalhos em proximidade com a comunidade (RIBEIRÃO PRETO, 2006b).

\subsection{Local de Estudo}

A USF em que foi desenvolvida esta pesquisa conta com uma Equipe de Saúde da Família (ESF) constituída por: um médico generalista, uma enfermeira, duas auxiliares de enfermagem, cinco ACS, um auxiliar de serviço e um aprendiz da Fundação de Educação para o Trabalho (FUNDET). Nesse núcleo, também, atuam: quatro residentes de medicina de família e comunidade do Hospital das Clínicas da Faculdade de Medicina de Ribeirão Preto (HCFMRP), alunos de graduação em medicina, enfermagem, odontologia, além de pesquisadores (RIBEIRÃO PRETO, 2006c).

Essa Unidade desenvolve atendimento ambulatorial de atenção básica e de baixa complexidade, visando à assistência da demanda espontânea da população. As atividades desenvolvidas englobam: atividades em grupos (com gestantes, de atividade física, de reeducação alimentar, de saúde da mulher); ações coletivas em espaços sociais; consultas médicas, odontológicas e de enfermagem; consultorias; discussões a respeito de planejamento familiar e de casos clínicos; seminários de educação permanente; ações de vigilância epidemiológica e visitas domiciliares (UNIVERSIDADE DE SÃO PAULO, 2008).

A USF selecionada foi considerada um local adequado para realizar esse estudo por diversos motivos. Essa Unidade segue as diretrizes do Ministério da Saúde e realiza atividades em todos os níveis de atenção, com promoção da saúde, prevenção de doenças, 
tratamento e reabilitação, dado importante, visto que foi investigado o conhecimento sobre a atuação do fisioterapeuta em todos esses seguimentos. Constitui uma área diversificada, com pessoas de diferentes níveis sócio-econômicos, essencial para o estudo da relação entre essas características, o conhecimento dos pesquisados sobre a Fisioterapia e as suas necessidades de atuação do fisioterapeuta.

Além disso, foi local de estudo para três trabalhos que obtiveram dados importantes para o tema abordado nessa pesquisa. Ferri (2006) pesquisou sobre a qualidade da assistência prestada por essa Unidade e a satisfação da população a ela cadastrada, e constatou que 85\% dos entrevistados já foram atendidos, nesse local, em três ou mais ocasiões e que esses indivíduos consideraram a Unidade como porta de entrada do Sistema de Saúde. Gaioso (2007), em uma pesquisa com usuários das quatro USF do Sumarezinho, constatou um alto porcentual de satisfação em relação aos serviços prestados, mas com alguns pontos de insatisfação, como a exemplo da infra-estrutura dos mesmos. Como já referido, Aguiar (2005), também, realizou uma pesquisa nessa Unidade, abordando o conhecimento e a atitude da ESF sobre a Fisioterapia.

\subsection{População Alvo}

A população-alvo dessa pesquisa foi constituída pelos usuários de uma USF existente na área da UBDS do Sumarezinho, em Ribeirão Preto-SP.

Para tornar viável a operacionalização, os usuários foram selecionados, tendo como base as famílias cadastradas na Unidade em estudo, de forma a ser entrevistada uma pessoa de cada família sorteada.

Esta Unidade apresenta 954 famílias cadastradas segundo o relatório "Relação de Famílias por Microáreas”, emitido pelo Sistema de Informação da Atenção Básica (SIAB) de 29 de agosto de 2008 (RIBEIRÃO PRETO, 2008b). Para o cálculo do tamanho da amostra foi considerada uma população finita de 954 indivíduos, uma proporção de 50\% de acertos nas perguntas do questionário, e grau de confiança de 95\%. Assim, a amostra desse estudo foi constituída por 275 pessoas (Anexo A).

A Unidade em questão, para melhor cumprimento dos princípios que regem a EsSF, teve sua área de abrangência dividida em cinco Microáreas de bases geográficas bem delimitadas, com diferentes números de famílias cadastradas em cada uma e com outras características peculiares, dentre as quais pode-se citar a Microárea II, que se encontra totalmente inserida em uma favela. 
Em consonância com essa divisão, utilizou-se a amostragem estratificada proporcional ao tamanho populacional de cada um dos estratos. Esses dados encontram-se expostos na tabela abaixo:

Tabela 1 - População cadastrada em cada microárea e amostra estratificada proporcional da população cadastrada em cada área, Sumarezinho, Ribeirão Preto (SP), 2008

\begin{tabular}{c|c|c}
\hline Microáreas & $\begin{array}{c}\text { População cadastrada } \\
\text { em cada microárea }\end{array}$ & $\begin{array}{c}\text { Amostra estratificada } \\
\text { proporcional da população } \\
\text { cadastrada em cada } \\
\text { microárea }\end{array}$ \\
\hline I & 199 & 57 \\
II & 201 & 58 \\
III & 158 & 46 \\
IV & 199 & 57 \\
V & 197 & 57 \\
\hline Total & $\mathbf{9 5 4}$ & $\mathbf{2 7 5}$ \\
\hline
\end{tabular}

Os entrevistados dessa pesquisa foram selecionados com base no relatório do SIAB, de forma aleatória e sistemática. Inicialmente, foi efetuado um sorteio dentre as dez primeiras famílias desse documento e, a partir desse sorteio, as outras famílias foram selecionadas seguindo um intervalo de três em três, de acordo com a disposição vertical da tabela, até se obter o número desejado de entrevistados de cada Microárea.

Foi estabelecido que o indivíduo a ser entrevistado tivesse obrigatoriamente idade superior a 18 anos; estivesse presente na residência no momento da coleta de dados; tivesse sido atendido, pelo menos, uma vez na USF estudada; e concordasse em participar do estudo mediante a assinatura do Termo de Consentimento Livre e Esclarecido (Apêndice A). Na presença, no domicílio, de mais de uma pessoa que se enquadre nesses critérios, seria solicitado que os mesmos indicassem entre eles a pessoa que iria participar.

$\mathrm{Na}$ hipótese de que na família sorteada não houvesse nenhum indivíduo que preenchesse os critérios de inclusão, a família residente no domicílio mais próximo à esquerda, que cumpra as exigências, seria automaticamente, incluída nesse estudo. 


\subsection{Coleta de Dados}

\subsubsection{Instrumentos para a Coleta de Dados}

O estudo utilizou como técnica de coleta de dados um questionário aplicado a um indivíduo de cada família, selecionada aleatoriamente, dentre as cadastradas à Unidade referida.

Segundo Gil (2002), questionário é a técnica de investigação composta por questões, tendo como objetivo o conhecimento de opiniões, crenças, sentimentos, interesses, expectativas, situações vivenciadas, etc.

Mediante a literatura a respeito do tema, esse instrumento foi elaborado (Apêndice B), fazendo-se necessário tecer algumas considerações.

Apresentou dois tipos de questões do ponto de vista do examinador: fechadas e abertas. Essas últimas foram abordadas de duas formas distintas: abertas sem préagrupamento, nas quais o examinador transcrevia as falas do entrevistado, na íntegra. E abertas com pré-agrupamento, em que o examinador fazia as perguntas sem oferecer opções de respostas; no entanto, essas questões apresentavam uma categorização pré-estabelecida que serviu como base para que o examinador classificasse, posteriormente, as respostas obtidas.

Algumas das questões do tipo fechadas ou abertas com pré-agrupamento apresentaram a opção “outras”, junto a um espaço para que o examinador transcrevesse a resposta dada, quando essa não se enquadrava em nenhuma das alternativas existentes.

O questionário foi de uso restrito dos entrevistadores e, por isso, há no mesmo algumas orientações para que eles pudessem guiar-se durante a aplicação. As questões dos módulos II e III foram elaboradas em forma de roteiro, sendo algumas vezes, a reposta de uma questão considerada pré-requisito para que fosse feita a pergunta seguinte.

O questionário foi dividido em módulos, de acordo com o tema que se objetivou investigar e cuja descrição segue abaixo.

\section{$\checkmark$ Módulo I - Caracterização sócio-familiar e demográfica dos entrevistados}

Apresentou questões fechadas referentes às seguintes características dos entrevistados: sexo (1.2); cor/raça (1.3); religião (1.4), situação conjugal (1.5); grau de escolaridade (1.7), baseado na organização empregada pelo Ministério da Educação, em Brasil (2009), presença, na família, de portador de deficiência física ou doença grave (1.11).

A classificação da cor ou raça foi realizada de acordo com a auto-classificação do entrevistado, baseada no Instituto Brasileiro de Geografia e Estatística (IBGE, 2000), que abrangia as seguintes opções: branca; preta; amarela; parda e indígena. 
A classificação econômica, questões 1.8 e 1.9, foi realizada com base no Critério de Classificação Econômica Brasil (CCEB).

O módulo I, ainda, apresentou questões abertas sem pré-agrupamentos, referentes à: idade, em anos (1.1); ocupação (1.6); e tempo em que moram na área adstrita à USF em que são cadastrados (1.10).

\section{$\checkmark$ Módulo II - Conhecimentos dos entrevistados sobre a Fisioterapia}

Apresentou questões fechadas que abordaram: o fato de o entrevistado já ter ouvido falar em Fisioterapia (2.1); a auto-avaliação sobre o conhecimento dele a respeito da Fisioterapia (2.3); a opinião do entrevistado sobre o grau de importância dos serviços de Fisioterapia para a saúde da população (2.5); e tipo de atividades que o fisioterapeuta realiza: domiciliar, individual, em grupo ou ações de educação em saúde (2.10).

As questões do tipo abertas com pré-agrupamentos foram às referentes ao: meio(s) através do qual o entrevistado ouviu falar da Fisioterapia (2.2); recursos que o fisioterapeuta utiliza (2.6); demanda de pacientes para assistência fisioterápica, ou seja, quem são ou o que apresentam as pessoas que precisam dos serviços de Fisioterapia (2.8); lugar (es) onde o fisioterapeuta trabalha (2.9).

O módulo II também apresentou duas questões abertas que abordaram: “o que é Fisioterapia?” (2.4), e “para que serve a Fisioterapia?” (2.7).

\section{$\checkmark$ Módulo III - Percepções dos entrevistados quanto às suas principais necessidades em relação à atuação do fisioterapeuta}

Abordou, de forma fechada, questões referentes à: necessidade de inclusão do fisioterapeuta à equipe da USF em que o entrevistado está cadastrado (3.1); prévio atendimento fisioterápico prestado ao entrevistado (3.3); natureza do atendimento fisioterápico, anteriormente, prestado ao entrevistado, ou seja, se foi realizado na Rede Pública de Saúde (3.4); presença, na família, de alguém que já foi ou está sendo atendido por fisioterapeuta (3.6) necessidade atual do entrevistado de utilizar os serviços de Fisioterapia (3.9).

As questões abertas com pré-agrupamentos foram às referentes aos: motivos que levaram o entrevistado a ser atendido por fisioterapeuta, anteriormente (3.5), ou algum familiar seu utilizar esse serviço (3.7). 
Esse módulo também apresentou questões abertas sem pré-agrupamento referentes à: justificativa da necessidade/ou não necessidade de inclusão do fisioterapeuta à equipe da USF em que o entrevistado está cadastrado (3.2); experiência do entrevistado e/ou familiares com a Fisioterapia (3.8) e; justificativa do entrevistado em, atualmente, precisar/ou não precisar dos serviços de Fisioterapia (3.10).

\subsubsection{Procedimentos para a Coleta de Dados}

A fase preparatória para a realização dos procedimentos de coleta de dados, visando à familiarização com o local de estudo, teve início no ano de 2007, quando a pesquisadora estagiou na USF e apresentou lá a proposta da pesquisa. Na ocasião, pôde conhecer a rotina do seu funcionamento, os membros que compõem a ESF, os instrumentos de cadastramento familiar utilizados, a organização por Microáreas e demais aspectos presentes no processo de trabalho da equipe, incluindo a participação da investigadora, como ouvinte, em reunião dos membros da ESF.

Após a aprovação por Comitê de Ética em Pesquisa, iniciou-se a segunda fase da presente pesquisa com a realização de um pré-teste para avaliar o instrumento de que o estudo faria uso, com enfoque na sua eficácia em relação ao conteúdo, adequação semântica e facilidade de entendimento por parte do entrevistado, como também para estimar o tempo de aplicação do mesmo. Para isso, o questionário foi aplicado em três famílias de cada uma das cinco Microáreas da Unidade em estudo, totalizando 15 entrevistas, no período de 18 a 25 de julho de 2008.

O teste apontou dificuldade de compreensão da linguagem em algumas questões, e resultou em reformulações nos módulos 1 e 2, com exclusão de uma questão do módulo 2 que se dirigia às atividades existentes na Unidade em estudo, uma vez que os entrevistados demonstraram não conhecer essas atividades.

Após as reformulações, o questionário foi reaplicado em cinco famílias da Unidade referida, tendo demonstrado que as dificuldades anteriores haviam sido superadas e sendo considerado adequado para os objetivos propostos.

As entrevistas foram realizadas pelos cinco ACS da Unidade em estudo devido ao número de questionários a serem aplicados, de forma a otimizar e reduzir o tempo de coleta e cumprir com o cronograma acadêmico; como, também, pelo fato de conhecerem melhor o território e contarem com uma receptividade maior de respostas ao estudo. As visitas foram realizadas durante os finais de semana, com a finalidade de encontrar, no domicílio, não só a 
população feminina e do lar, mas, também, a população trabalhadora e de ambos os sexos. Dessa forma, o horário da realização das entrevistas não coincidiu com o de trabalho dos agentes.

Para garantir a adequada aplicação do questionário, a pesquisadora realizou um treinamento com os entrevistados no dia 23/08/2008, quando apresentou os objetivos da pesquisa, o instrumento utilizado, orientando a correta aplicação de cada questão, esclarecendo as dúvidas e estimulando a aplicação do questionário entre eles. Também foram estabelecidas as datas e horários da sua realização. No dia 28/08/2008, foi realizada outra reunião para esclarecimentos de dúvidas remanescentes.

\subsection{Considerações Éticas}

Antes da aplicação do questionário, o entrevistado foi informado da pesquisa e de seus objetivos, tiveram suas dúvidas esclarecidas e, assim, foi assinado, espontaneamente, o Termo de Consentimento Livre e Esclarecido, visto que essa pesquisa foi desenvolvida resguardando os preceitos éticos e as Diretrizes e Normas Regulamentadoras de Pesquisas em Seres Humanos, através da Resolução n 196 do Conselho Nacional da Saúde (CNS), de dez de outubro de 1996 (BRASIL, 1996). O presente estudo foi aprovado pelo Comitê de Ética em Pesquisa (CEP) do Centro de Saúde Escola - CSE da FMRP/USP (Anexo B).

A pesquisadora responsabilizou-se em tornar público os resultados encontrados no estudo, independente de quais sejam esses resultados.

\subsection{Análise dos Dados}

Os dados foram categorizados e tabulados e os resultados foram expressos em freqüências relativas e absolutas das variáveis em relação as cinco Microáreas. Para algumas variáveis foi empregado, também, medidas de tendência central. Para realizar a análise descrita foi utilizado o procedimento Proc Corresp do programa de computador SAS versão 9.1. 


\section{RESULTADOS}

Neste capítulo, são apresentados os resultados da pesquisa. Ele está composto de três tópicos, de acordo com a divisão estabelecida no questionário aplicado, e com a seguinte seqüência: caracterização sócio-familiar e demográfica dos entrevistados, conhecimentos dos entrevistados sobre a Fisioterapia, e percepções dos entrevistados quanto às suas principais necessidades em relação à atuação do fisioterapeuta. Para facilitar a compreensão, utilizou-se tabelas com a distribuição das respostas dos entrevistados por freqüências relativas e absolutas das variáveis em relação a cada micro área estudada.

É importante salientar que para melhor apreensão, algumas questões abertas necessitaram de uma forma peculiar de apresentação. Uma vez que em cada resposta dos entrevistados foram identificados vários conceitos-chave, optou-se por categorizá-las de forma que uma resposta possa ser distribuída em mais de uma categoria, contemplando todos os conceitos que apresentavam. Assim, os conceitos-chave identificados nas respostas foram apresentados em tabelas e, para cada resposta, todos esses conceitos foram respondidos com sim ou não.

Nas questões em que os entrevistados podiam citar mais de uma alternativa como resposta, optou-se por desenhar uma tabela discriminando-as e, para cada uma dessas opções, foram respondidos sim ou não. Dessa forma, foi possível saber quantas pessoas citaram cada alternativa.

\subsection{Caracterização Sócio-Familiar e Demográfica dos Entrevistados}

\section{1) Idade}

Esta foi uma questão aberta cujas categorias foram construídas com base nas empregadas no relatório do SIAB de consolidação das famílias cadastradas do ano de 2008 da ESF, para posterior confronto com esses dados. Salienta-se, ainda, que, como critério de inclusão, a idade mínima do entrevistado era de 18 anos.

Observou-se que a faixa etária entre 18 e 39 anos foi predominante em todas as microáreas, correspondendo a 50\% dentre os entrevistados. Os indivíduos da Microárea III demonstraram ser mais velhos em relação às demais, com 55\% deles com mais de 50 anos (Tabela 2). A média de idade dos entrevistados foi de, aproximadamente, 43 anos, e o desvio padrão, de 16. A idade mínima foi 18 anos, e a máxima, 79 anos. 
Tabela 2 - Distribuição dos usuários das cinco microáreas de uma Unidade de Saúde da Família por faixa etária, Sumarezinho, Ribeirão Preto (SP), 2008

\begin{tabular}{|c|c|c|c|c|c|c|c|c|c|c|c|c|}
\hline \multirow{3}{*}{ Faixa etária } & \multicolumn{10}{|c|}{ Microáreas } & \multirow{2}{*}{\multicolumn{2}{|c|}{ Total }} \\
\hline & \multicolumn{2}{|c|}{ I } & \multicolumn{2}{|c|}{ II } & \multicolumn{2}{|c|}{ III } & \multicolumn{2}{|c|}{ IV } & \multicolumn{2}{|c|}{ V } & & \\
\hline & $\mathrm{n}$ & $\%$ & $n$ & $\%$ & $n$ & $\%$ & $\mathrm{n}$ & $\%$ & $\mathbf{n}$ & $\%$ & $\mathbf{n}$ & $\%$ \\
\hline $18-39$ & 30 & 53 & 30 & 52 & 14 & 30 & 32 & 56 & 31 & 54 & 137 & 50 \\
\hline $40-49$ & 10 & 17 & 08 & 14 & 07 & 15 & 09 & 16 & 12 & 21 & 46 & 17 \\
\hline $50-59$ & 04 & 07 & 09 & 15 & 11 & 25 & 10 & 18 & 09 & 16 & 43 & 15 \\
\hline 60 ou mais & 13 & 23 & 11 & 19 & 14 & 30 & 06 & 10 & 05 & 09 & 49 & 18 \\
\hline Total & 57 & 100 & 58 & 100 & 46 & 100 & 57 & 100 & 57 & 100 & 275 & 100 \\
\hline
\end{tabular}

\section{2) Sexo}

Verificou-se uma predominância do sexo feminino superior a $70 \%$ em todas as microáreas da Unidade em estudo, somando 82\% dentre o total dos entrevistados.

\section{3) Cor/raça}

Em relação ao total dos entrevistados, 59,6\% declararam-se pardos; e essa categoria prevaleceu em todas as microáreas, com exceção da Microárea III, em que a predominância foi da cor branca, com 73,9\% (Tabela 3).

Tabela 3 - Distribuição dos usuários das cinco microáreas de uma Unidade de Saúde da Família por cor/raça, Sumarezinho, Ribeirão Preto (SP), 2008

\begin{tabular}{|c|c|c|c|c|c|c|c|c|c|c|c|c|}
\hline \multirow{3}{*}{ Cor/Raça } & \multicolumn{10}{|c|}{ Microáreas } & \multirow{2}{*}{\multicolumn{2}{|c|}{ Total }} \\
\hline & \multicolumn{2}{|c|}{ I } & \multicolumn{2}{|c|}{ II } & \multicolumn{2}{|c|}{ III } & \multicolumn{2}{|c|}{ IV } & \multicolumn{2}{|c|}{$\mathbf{V}$} & & \\
\hline & $\mathbf{n}$ & $\%$ & n & $\%$ & $\mathbf{n}$ & $\%$ & n & $\%$ & $\mathbf{n}$ & $\%$ & $\mathbf{n}$ & $\%$ \\
\hline Branca & 15 & 26,3 & 04 & 6,9 & 34 & 73,9 & 23 & 40,4 & 15 & 26,3 & 91 & 33,1 \\
\hline Preta & 05 & 8,8 & 05 & 8,6 & - & - & 04 & 07 & - & - & 14 & 5,1 \\
\hline Amarela & 03 & 5,3 & 02 & 3,5 & - & - & - & - & - & - & 05 & 1,8 \\
\hline Parda & 34 & 59,6 & 47 & 81 & 12 & 26,1 & 30 & 52,6 & 41 & 71,9 & 164 & 59,6 \\
\hline Indígena & - & - & - & - & - & - & - & - & 01 & 1,8 & 01 & 0,4 \\
\hline Total & 57 & 100 & 58 & 100 & 46 & 100 & 57 & 100 & 57 & 100 & 275 & 100 \\
\hline
\end{tabular}




\section{4) Religião}

Em todas as microáreas, as religiões mais citadas foram a católica e a evangélica com, respectivamente, 54,2\% e 38,2\% do número total de entrevistados (Tabela 4).

Tabela 4 - Distribuição dos usuários das cinco microáreas de uma Unidade de Saúde da Família por religião, Sumarezinho, Ribeirão Preto (SP), 2008

\begin{tabular}{|c|c|c|c|c|c|c|c|c|c|c|c|c|}
\hline \multirow{3}{*}{ Religião } & \multicolumn{10}{|c|}{ Microáreas } & \multirow{2}{*}{\multicolumn{2}{|c|}{ Total }} \\
\hline & \multicolumn{2}{|c|}{ I } & \multicolumn{2}{|c|}{ II } & \multicolumn{2}{|c|}{ III } & \multicolumn{2}{|c|}{ IV } & \multicolumn{2}{|c|}{$\mathbf{V}$} & & \\
\hline & $\mathbf{n}$ & $\%$ & $\mathbf{n}$ & $\%$ & $\mathrm{n}$ & $\%$ & $\mathbf{n}$ & $\%$ & $\mathbf{n}$ & $\%$ & $\mathbf{n}$ & $\%$ \\
\hline Católico & 25 & 43,8 & 24 & 41,4 & 29 & 63 & 42 & 73,6 & 29 & 50,9 & 149 & 54,2 \\
\hline Evangélico & 26 & 45,6 & 27 & 46,6 & 15 & 32,6 & 13 & 22,8 & 24 & 42,1 & 105 & 38,2 \\
\hline Espírita & 01 & 1,8 & - & - & - & - & - & - & - & - & 01 & 0,4 \\
\hline Testemunha de Jeová & - & - & 01 & 1,7 & 01 & 2,2 & 01 & 1,8 & - & - & 03 & 01 \\
\hline Budista & 01 & 1,8 & - & - & - & - & - & - & - & - & 01 & 0,4 \\
\hline Não Tem & 04 & 07 & 06 & 10,3 & 01 & 2,2 & 01 & 1,8 & 04 & 07 & 16 & 5,8 \\
\hline Total & 57 & 100 & 58 & 100 & 46 & 100 & 57 & 100 & 57 & 100 & 275 & 100 \\
\hline
\end{tabular}

\section{5) Situação conjugal}

Em todas as microáreas prevaleceram pessoas que moravam com companheiros, sendo casados ou amasiados, correspondendo a mais da metade dos entrevistados (58\%) (Tabela 5).

Tabela 5 - Distribuição dos usuários das cinco microáreas de uma Unidade de Saúde da Família por situação conjugal, Sumarezinho, Ribeirão Preto (SP), 2008

\begin{tabular}{|c|c|c|c|c|c|c|c|c|c|c|c|c|}
\hline \multirow{3}{*}{ Situação conjugal } & \multicolumn{10}{|c|}{ Microáreas } & \multirow{2}{*}{\multicolumn{2}{|c|}{ Total }} \\
\hline & \multicolumn{2}{|c|}{ I } & \multicolumn{2}{|c|}{ II } & \multicolumn{2}{|c|}{ III } & \multicolumn{2}{|c|}{ IV } & \multicolumn{2}{|c|}{$\mathbf{V}$} & & \\
\hline & $\mathbf{n}$ & $\%$ & $\mathbf{n}$ & $\%$ & $\mathbf{n}$ & $\%$ & $\mathbf{n}$ & $\%$ & $\mathbf{n}$ & $\%$ & $\mathbf{n}$ & $\%$ \\
\hline Solteiro & 06 & 10 & 09 & 16 & 07 & 15 & 10 & 18 & 13 & 23 & 45 & 16 \\
\hline Casado & 28 & 49 & 14 & 24 & 20 & 43 & 12 & 21 & 14 & 25 & 88 & 32 \\
\hline Amasiado & 10 & 18 & 16 & 28 & 07 & 15 & 18 & 32 & 20 & 35 & 70 & 26 \\
\hline Separado/Divorciado & 05 & 09 & 10 & 17 & 04 & 09 & 06 & 11 & 20 & 35 & 28 & 10 \\
\hline Viúvo & 08 & 14 & 09 & 16 & 81 & 07 & 11 & 19 & 07 & 12 & 43 & 16 \\
\hline Total & 57 & 100 & 58 & 100 & 46 & 100 & 57 & 100 & 57 & 100 & 275 & 100 \\
\hline
\end{tabular}




\section{6) Ocupação}

A questão referente à ocupação dos entrevistados foi do tipo aberta e as respostas foram agrupadas nas seguintes categorias: serviço de nível superior; do lar; prestadores de serviços, em geral; comerciante; subocupações; aposentado; desempregado e não informada.

A categoria "prestadores de serviços, em geral” incluiu as ocupações a seguir: diarista, lavadeira, cozinheira, faxineira, auxiliar de cozinha/limpeza, jardineiro, secretária, telefonista, atendente, recepcionista, balconista, pedreiro, pintor, vigilante, zelador, ferreiro. $\mathrm{O}$ termo "subocupações” englobou catador de papelão e reciclagem.

As ocupações “do lar” e “prestadores de serviços, em geral”, foram as mais mencionadas em todas as microáreas, representando 74\% dos entrevistados (Tabela 6).

Tabela 6 - Distribuição dos usuários das cinco microáreas de uma Unidade de Saúde da Família por ocupação, Sumarezinho, Ribeirão Preto (SP), 2008

\begin{tabular}{|c|c|c|c|c|c|c|c|c|c|c|c|c|}
\hline \multirow{3}{*}{ Ocupação } & \multicolumn{10}{|c|}{ Microáreas } & \multirow{2}{*}{\multicolumn{2}{|c|}{ Total }} \\
\hline & \multicolumn{2}{|c|}{ I } & \multicolumn{2}{|c|}{ II } & \multicolumn{2}{|c|}{ III } & \multicolumn{2}{|c|}{ IV } & \multicolumn{2}{|c|}{ V } & & \\
\hline & $\mathbf{n}$ & $\%$ & $\mathbf{n}$ & $\%$ & $\mathbf{n}$ & $\%$ & $\mathbf{n}$ & $\%$ & $\mathbf{n}$ & $\%$ & $\mathbf{n}$ & $\%$ \\
\hline $\begin{array}{l}\text { Serviço de Nível } \\
\text { Superior }\end{array}$ & - & - & - & - & - & - & - & - & 02 & 04 & 02 & 01 \\
\hline Do Lar & 21 & 37 & 25 & 43 & 16 & 35 & 36 & 63 & 16 & 28 & 114 & 41 \\
\hline $\begin{array}{l}\text { Prestadores de } \\
\text { Serviços, em Geral }\end{array}$ & 22 & 39 & 14 & 24 & 18 & 39 & 13 & 23 & 25 & 44 & 92 & 33 \\
\hline Comerciante & 02 & 04 & 05 & 09 & 01 & 02 & 02 & 04 & 06 & 11 & 16 & 06 \\
\hline Subocupações & - & - & 03 & 05 & - & - & 01 & 02 & 06 & 11 & 04 & 01 \\
\hline Aposentado & 09 & 16 & 04 & 07 & 09 & 20 & 02 & 04 & 05 & 09 & 29 & 11 \\
\hline Desempregado & 01 & 02 & 03 & 05 & 02 & 04 & 03 & 05 & 02 & 04 & 11 & 04 \\
\hline Não Informada & 02 & 04 & 04 & 07 & - & - & - & - & 01 & 02 & 07 & 03 \\
\hline Total & 57 & 100 & 58 & 100 & 46 & 100 & 57 & 100 & 57 & 100 & 275 & 100 \\
\hline
\end{tabular}

\section{7) Grau de escolaridade}

Em todas as microáreas, prevaleceram os entrevistados que tinham, no máximo, o primário incompleto ou o ginasial incompleto (78\%). O nível superior completo só foi referido na Microárea I, com 4\% e na V, com 2\% (Tabela 7). 
Tabela 7 - Distribuição dos usuários das cinco microáreas de uma Unidade de Saúde da Família por grau de escolaridade, Sumarezinho, Ribeirão Preto (SP), 2008

\begin{tabular}{|c|c|c|c|c|c|c|c|c|c|c|c|c|}
\hline \multirow{2}{*}{$\begin{array}{c}\text { Grau de } \\
\text { Escolaridade }\end{array}$} & \multicolumn{2}{|c|}{ I } & \multicolumn{2}{|c|}{ II } & \multicolumn{2}{|c|}{$\begin{array}{l}\text { Microáreas } \\
\text { III }\end{array}$} & \multicolumn{2}{|c|}{ IV } & \multicolumn{2}{|c|}{ V } & \multicolumn{2}{|c|}{ Total } \\
\hline & $\mathbf{n}$ & $\%$ & $\mathbf{n}$ & $\%$ & $\mathbf{n}$ & $\%$ & $\mathbf{n}$ & $\%$ & $\mathbf{n}$ & $\%$ & $\mathbf{n}$ & $\%$ \\
\hline $\begin{array}{l}\text { Analfabeto } / 4^{\circ} \text { ano do } \\
\text { Ensino Fundamental }\end{array}$ & 20 & 35 & 32 & 55 & 08 & 17 & 21 & 37 & 24 & 42 & 105 & 38 \\
\hline $\begin{array}{l}5^{\circ} \text { a } 8^{\circ} \text { ano do Ensino } \\
\text { Fundamental }\end{array}$ & 25 & 44 & 17 & 29 & 24 & 53 & 24 & 42 & 21 & 37 & 111 & 40 \\
\hline $\begin{array}{l}\text { Ensino Fundamental } \\
\text { completo/Ensino } \\
\text { Médio incompleto }\end{array}$ & 03 & 05 & 05 & 09 & 06 & 13 & 12 & 21 & 07 & 12 & 33 & 12 \\
\hline $\begin{array}{l}\text { Ensino Médio } \\
\text { completo/Ensino } \\
\text { Superior incompleto }\end{array}$ & 07 & 12 & 04 & 07 & 08 & 17 & - & - & 04 & 07 & 23 & 09 \\
\hline $\begin{array}{l}\text { Ensino Superior } \\
\text { completo }\end{array}$ & 02 & 04 & - & - & - & - & - & - & 01 & 02 & 03 & 01 \\
\hline Total & 57 & 100 & 58 & 100 & 46 & 100 & 57 & 100 & 57 & 100 & 275 & 100 \\
\hline
\end{tabular}

\section{8) Classificação Econômica}

O Critério de Classificação Econômica Brasil (CCEB), utilizada nesta pesquisa, é usado para estimar o poder de compra das pessoas e famílias urbanas. Para isso, é composto de duas questões: uma referente à posse de itens de conforto na residência do entrevistado e outra, sobre a escolaridade do chefe da família. A partir desses dados, classificaram-se os entrevistados em termos de classes econômicas (ABEP, 2008).

$\mathrm{Na}$ Tabela 8, percebe-se que as classes $\mathrm{C}$ e $\mathrm{D}$ foram predominantes em todas as microáreas, configurando, respectivamente, 44\% e 42\% dos entrevistados. Em contrapartida, a classe A só foi observada nas Microáreas I, com 4\% e, na V, com 2\%. 
Tabela 8 - Distribuição dos usuários das cinco microáreas de uma Unidade de Saúde da Família por Critério de Classificação Econômica Brasil (CCEB), Sumarezinho, Ribeirão Preto (SP), 2008

\begin{tabular}{|c|c|c|c|c|c|c|c|c|c|c|c|c|}
\hline \multirow{3}{*}{$\begin{array}{c}\text { Classificação } \\
\text { Econômica }\end{array}$} & \multicolumn{10}{|c|}{ Microáreas } & \multirow{2}{*}{\multicolumn{2}{|c|}{ Total }} \\
\hline & \multicolumn{2}{|c|}{ I } & \multicolumn{2}{|c|}{ II } & \multicolumn{2}{|c|}{ III } & \multicolumn{2}{|c|}{ IV } & \multicolumn{2}{|c|}{$\mathbf{V}$} & & \\
\hline & $n$ & $\%$ & $\mathrm{n}$ & $\%$ & $\mathbf{n}$ & $\%$ & $\mathrm{n}$ & $\%$ & $n$ & $\%$ & $\mathrm{n}$ & $\%$ \\
\hline A & 02 & 04 & - & - & - & - & - & - & 01 & 02 & 03 & 01 \\
\hline B & 06 & 11 & 03 & 05 & 06 & 13 & 01 & 02 & 02 & 04 & 18 & 07 \\
\hline C & 27 & 47 & 20 & 34 & 23 & 50 & 20 & 35 & 32 & 56 & 122 & 44 \\
\hline $\mathrm{D}$ & 21 & 37 & 28 & 48 & 14 & 30 & 32 & 56 & 21 & 37 & 116 & 42 \\
\hline $\mathrm{E}$ & 01 & 02 & 07 & 12 & 03 & 07 & 04 & 07 & 01 & 02 & 16 & 06 \\
\hline Total & 57 & 100 & 58 & 100 & 46 & 100 & 57 & 100 & 57 & 100 & 275 & 100 \\
\hline
\end{tabular}

\section{9) Tempo em que moram na área adstrita à Unidade de Saúde da Família}

A maioria dos entrevistados de todas as microáreas morava de 6 a 10 anos na área adstrita à unidade estudada (28\%). A única exceção foi a Microárea III, em que prevaleceram os que moravam há 20 anos ou mais (48\%). Considerando a amostra total do estudo, o tempo médio em que moravam nessa área foi de 10,5 anos, com desvio padrão de 9,4 (Tabela 9).

Tabela 9 - Distribuição dos usuários das cinco microáreas de uma Unidade de Saúde da Família (USF) por tempo em que moram na área adstrita a esta USF, Sumarezinho, Ribeirão Preto (SP), 2008

\begin{tabular}{|c|c|c|c|c|c|c|c|c|c|c|c|c|}
\hline \multirow{3}{*}{$\begin{array}{llr}\text { Tempo } & \text { em } & \text { que } \\
\text { moram } & \text { na } & \text { área } \\
\text { adstrita à } & \text { USF, em } \\
\text { anos } & & \\
\end{array}$} & \multicolumn{10}{|c|}{ Microáreas } & \multirow{2}{*}{\multicolumn{2}{|c|}{ Total }} \\
\hline & \multicolumn{2}{|c|}{ I } & \multicolumn{2}{|c|}{ II } & \multicolumn{2}{|c|}{ III } & \multicolumn{2}{|c|}{ IV } & \multicolumn{2}{|c|}{$\mathbf{V}$} & & \\
\hline & $\mathbf{n}$ & $\%$ & $\mathbf{n}$ & $\%$ & $\mathbf{n}$ & $\%$ & $\mathbf{n}$ & $\%$ & $\mathbf{n}$ & $\%$ & $\mathbf{n}$ & $\%$ \\
\hline 1 ou menos & 07 & 12 & 11 & 19 & 05 & 11 & 09 & 16 & 02 & 04 & 34 & 12 \\
\hline 2- 5 & 08 & 14 & 16 & 28 & 09 & 20 & 09 & 16 & 19 & 33 & 61 & 22 \\
\hline $6-10$ & 12 & 21 & 16 & 28 & 07 & 15 & 21 & 36 & 20 & 35 & 76 & 28 \\
\hline $11-15$ & 09 & 16 & 05 & 8 & - & - & 09 & 16 & 09 & 16 & 32 & 12 \\
\hline $16-20$ & 08 & 14 & 06 & 10 & 03 & 06 & 03 & 05 & - & - & 20 & 07 \\
\hline 20 ou mais & 11 & 19 & 01 & 02 & 22 & 48 & 05 & 09 & 03 & 05 & 42 & 15 \\
\hline Não sabe & 02 & 04 & 03 & 05 & - & - & 01 & 02 & 04 & 07 & 10 & 04 \\
\hline Total & 57 & 100 & 58 & 100 & 46 & 100 & 57 & 100 & 57 & 100 & 275 & 100 \\
\hline
\end{tabular}


10) Presença, na família, de pessoa portadora de deficiência física ou doença grave

Este dado só foi observado em 7\% dos entrevistados, com maior índice na Microárea III, representando 17\% (Tabela 10).

Tabela 10 - Distribuição dos usuários das cinco microáreas de uma Unidade de Saúde da Família por presença, na família, de pessoa portadora de deficiência física ou doença grave, Sumarezinho, Ribeirão Preto (SP), 2008

\begin{tabular}{|c|c|c|c|c|c|c|c|c|c|c|c|c|}
\hline \multirow{3}{*}{$\begin{array}{l}\text { Presença, na família, } \\
\text { de pessoa portadora } \\
\text { de deficiência física } \\
\text { ou doença grave }\end{array}$} & \multicolumn{10}{|c|}{ Microáreas } & \multirow{2}{*}{\multicolumn{2}{|c|}{ Total }} \\
\hline & \multicolumn{2}{|c|}{$\mathbf{I}$} & \multicolumn{2}{|c|}{ II } & \multicolumn{2}{|c|}{ III } & \multicolumn{2}{|c|}{ IV } & \multicolumn{2}{|c|}{$\mathbf{V}$} & & \\
\hline & $\mathbf{n}$ & $\%$ & $\mathbf{n}$ & $\%$ & $\mathbf{n}$ & $\%$ & $\mathbf{n}$ & $\%$ & $\mathbf{n}$ & $\%$ & $\mathbf{n}$ & $\%$ \\
\hline Sim & 01 & 02 & 02 & 03 & 08 & 17 & 05 & 09 & 02 & 04 & 18 & 07 \\
\hline Não & 56 & 98 & 56 & 97 & 38 & 83 & 52 & 91 & 55 & 96 & 257 & 93 \\
\hline Total & 57 & 100 & 58 & 100 & 46 & 100 & 57 & 100 & 57 & 100 & 275 & 100 \\
\hline
\end{tabular}

\subsection{Conhecimentos dos entrevistados sobre a Fisioterapia}

\section{1) Ter ouvido falar em Fisioterapia}

Destacou-se em todas as microáreas que a maioria dos entrevistados já ouviu falar em Fisioterapia, representando 90\% das respostas (Tabela 11).

Tabela 11 - Distribuição dos usuários das cinco microáreas de uma Unidade de Saúde da Família por já ter ouvido falar em Fisioterapia, Sumarezinho, Ribeirão Preto (SP), 2008

\begin{tabular}{|c|c|c|c|c|c|c|c|c|c|c|c|c|}
\hline \multirow{2}{*}{$\begin{array}{c}\text { Já ouviram falar em } \\
\text { Fisioterapia? }\end{array}$} & \multicolumn{2}{|c|}{ I } & \multicolumn{4}{|c|}{$\begin{array}{c}\text { Microáreas } \\
\text { III }\end{array}$} & \multicolumn{2}{|c|}{ IV } & \multicolumn{2}{|c|}{$\mathbf{V}$} & \multicolumn{2}{|c|}{ Total } \\
\hline & $\mathbf{n}$ & $\%$ & $\mathbf{n}$ & $\%$ & $\mathbf{n}$ & $\%$ & $\mathbf{n}$ & $\%$ & $\mathbf{n}$ & $\%$ & $\mathbf{n}$ & $\%$ \\
\hline Sim & 53 & 93 & 52 & 90 & 42 & 91 & 50 & 88 & 50 & 88 & 247 & 90 \\
\hline Não & 04 & 07 & 06 & 10 & 04 & 09 & 07 & 12 & 07 & 12 & 28 & 10 \\
\hline Total & 57 & 100 & 58 & 100 & 46 & 100 & 57 & 100 & 57 & 100 & 275 & 100 \\
\hline
\end{tabular}

Percebemos essa questão como um fator decisivo e excludente na continuidade dessa entrevista. Dessa forma, do próximo tópico em diante serão consideradas apenas as respostas dos 247 indivíduos que já ouviram falar em Fisioterapia.

2) Meios através dos quais se ouviu falar em Fisioterapia 
Em relação aos meios através dos quais se ouviu falar em Fisioterapia, o profissional de saúde foi o mais citado por todos os entrevistados (51\%), seguido pelos meios de comunicação, com 41\% (Tabela 12).

Tabela 12 - Distribuição dos usuários das cinco microáreas de uma Unidade de Saúde da Família por meios através dos quais se ouviu falar em Fisioterapia, Sumarezinho, Ribeirão Preto (SP), 2008

\begin{tabular}{|c|c|c|c|c|c|c|c|c|c|c|c|c|c|}
\hline \multirow{3}{*}{\multicolumn{2}{|c|}{$\begin{array}{c}\text { Meio através dos } \\
\text { quais se ouviu falar } \\
\text { em Fisioterapia }\end{array}$}} & \multicolumn{10}{|c|}{ Microáreas } & \multirow{2}{*}{\multicolumn{2}{|c|}{ Total }} \\
\hline & & \multicolumn{2}{|c|}{ I } & \multicolumn{2}{|c|}{ II } & \multicolumn{2}{|c|}{ III } & \multicolumn{2}{|c|}{ IV } & \multicolumn{2}{|c|}{$\mathbf{V}$} & & \\
\hline & & n & $\%$ & $\mathbf{n}$ & $\%$ & $\mathbf{n}$ & $\%$ & $\mathbf{n}$ & $\%$ & $\mathbf{n}$ & $\%$ & \multicolumn{2}{|r|}{$\%$} \\
\hline \\
\hline \multirow[t]{2}{*}{ Saúde } & $\begin{array}{l}\text { Sim } \\
\text { Não }\end{array}$ & $\begin{array}{l}35 \\
18\end{array}$ & $\begin{array}{l}66 \\
34\end{array}$ & $\begin{array}{l}18 \\
34\end{array}$ & $\begin{array}{l}35 \\
65\end{array}$ & $\begin{array}{l}25 \\
17\end{array}$ & $\begin{array}{l}60 \\
40\end{array}$ & $\begin{array}{l}19 \\
31\end{array}$ & $\begin{array}{l}38 \\
62\end{array}$ & $\begin{array}{l}30 \\
20\end{array}$ & $\begin{array}{l}60 \\
40\end{array}$ & $\begin{array}{l}127 \\
120\end{array}$ & $\begin{array}{l}51 \\
49\end{array}$ \\
\hline & Total & 53 & 100 & 52 & 100 & 42 & 100 & 50 & 100 & 50 & 100 & 247 & 100 \\
\hline \multicolumn{14}{|l|}{ Parente/amigo } \\
\hline & Sim & 19 & 36 & 17 & 33 & 12 & 29 & 13 & 26 & 8 & 16 & 69 & 28 \\
\hline & Não & 34 & 64 & 35 & 67 & 30 & 71 & 37 & 74 & 42 & 84 & 178 & 72 \\
\hline & Total & 53 & 100 & 52 & 100 & 42 & 100 & 50 & 100 & 50 & 100 & 247 & 100 \\
\hline \multirow{4}{*}{$\begin{array}{l}\text { Meios de } \\
\text { Comunicação }\end{array}$} & & & & & & & & & & & & & \\
\hline & Sim & 09 & 17 & 34 & 18 & 10 & 24 & 24 & 48 & 24 & 48 & 101 & 41 \\
\hline & Não & 44 & 83 & 65 & 35 & 32 & 76 & 26 & 52 & 26 & 52 & 146 & 59 \\
\hline & Total & 53 & 100 & 52 & 100 & 42 & 100 & 50 & 100 & 50 & 100 & 247 & 100 \\
\hline
\end{tabular}

\section{3) Auto-avaliação do conhecimento sobre Fisioterapia}

Uma grande parcela dos entrevistados de todas as microáreas afirmou querer saber mais sobre esse tema, representando $70 \%$ do total. Em contrapartida, 13\% desses demonstraram não ter conhecimento algum sobre o assunto (Tabela 13). 
Tabela 13 - Distribuição dos usuários das cinco microáreas de uma Unidade de Saúde da Família por auto-avaliação do conhecimento sobre Fisioterapia, Sumarezinho, Ribeirão Preto (SP), 2008

\begin{tabular}{|c|c|c|c|c|c|c|c|c|c|c|c|c|}
\hline \multirow{3}{*}{$\begin{array}{c}\text { Auto-avaliação do } \\
\text { conhecimento sobre } \\
\text { Fisioterapia } \\
\end{array}$} & \multicolumn{10}{|c|}{ Microáreas } & \multirow{2}{*}{\multicolumn{2}{|c|}{ Total }} \\
\hline & \multicolumn{2}{|c|}{ I } & \multicolumn{2}{|c|}{ II } & \multicolumn{2}{|c|}{ III } & \multicolumn{2}{|c|}{ IV } & \multicolumn{2}{|c|}{$\mathbf{V}$} & & \\
\hline & $\mathbf{n}$ & $\%$ & $\mathbf{n}$ & $\%$ & n & $\%$ & $\mathbf{n}$ & $\%$ & $\mathbf{n}$ & $\%$ & $\mathbf{n}$ & $\%$ \\
\hline Sabe o suficiente & 06 & 11 & - & - & 11 & 26 & 03 & 06 & 02 & 04 & 22 & 09 \\
\hline Gostaria de saber mais & 43 & 81 & 40 & 77 & 20 & 48 & 36 & 72 & 35 & 70 & 174 & 70 \\
\hline $\begin{array}{l}\text { Não tem } \\
\text { conhecimento algum }\end{array}$ & 02 & 04 & 03 & 06 & 08 & 19 & 07 & 14 & 12 & 24 & 32 & 13 \\
\hline $\begin{array}{l}\text { Não acha necessário } \\
\text { saber sobre isso }\end{array}$ & 02 & 04 & 02 & 04 & 02 & 05 & 02 & 04 & - & - & 08 & 03 \\
\hline Não sabe responder & - & - & 07 & 13 & 01 & 02 & 02 & 04 & 01 & 02 & 11 & 05 \\
\hline Total & 57 & 100 & 58 & 100 & 46 & 100 & 57 & 100 & 57 & 100 & 247 & 100 \\
\hline
\end{tabular}

\section{4) O que é Fisioterapia?}

A metade dos entrevistados vinculou a Fisioterapia a uma "forma de reabilitação, recuperação e/ou tratamento”. Em seguida, prevaleceu o vínculo da Fisioterapia com os termos “exercício, movimento, relaxamento e/ou massagem”, com 34\%. Os que não sabiam responder configuraram 18\% total (Tabela 14).

Dos entrevistados, 13\% relacionaram a Fisioterapia aos benefícios, de forma geral, que esta proporciona. Incluindo as seguintes respostas: melhora a saúde, melhora o corpo, melhora a vida, é bom para saúde, ajuda as pessoas. A relação da Fisioterapia com a prevenção foi citada por apenas $4 \%$

A resposta categorizada como "outros" abrangeu: estuda o metabolismo do organismo, é um aparelho, é uma medicação, é um exame, e respostas semelhantes. Essa categoria foi mencionada por apenas $2 \%$ dos entrevistados. 
Tabela 14 - Distribuição dos usuários das cinco microáreas de uma Unidade de Saúde da Família por conceito de Fisioterapia, Sumarezinho, Ribeirão Preto (SP), 2008

\begin{tabular}{|c|c|c|c|c|c|c|c|c|c|c|c|c|}
\hline \multirow{3}{*}{ O que é Fisioterapia? } & \multicolumn{10}{|c|}{ Microáreas } & \multirow{2}{*}{\multicolumn{2}{|c|}{ Total }} \\
\hline & \multicolumn{2}{|c|}{ I } & \multicolumn{2}{|c|}{ II } & \multicolumn{2}{|c|}{ III } & \multicolumn{2}{|c|}{ IV } & \multicolumn{2}{|c|}{$\mathbf{V}$} & & \\
\hline & $\mathbf{n}$ & $\%$ & $\mathbf{n}$ & $\%$ & $\mathbf{n}$ & $\%$ & $\mathbf{n}$ & $\%$ & $\mathbf{n}$ & $\%$ & $\mathbf{n}$ & $\%$ \\
\hline \multicolumn{13}{|l|}{ Forma de reabilitação } \\
\hline e/ou Sim & 36 & 68 & 23 & 44 & 16 & 38 & 18 & 36 & 31 & 62 & 124 & 50 \\
\hline tratamento & 17 & 32 & 29 & 56 & 26 & 62 & 32 & 64 & 19 & 38 & 123 & 50 \\
\hline Total & 53 & 100 & 52 & 100 & 42 & 100 & 50 & 100 & 50 & 100 & 247 & 100 \\
\hline \multicolumn{13}{|l|}{$\begin{array}{l}\text { Exercício,movimento, } \\
\text { Relaxamento e/ou Sim }\end{array}$} \\
\hline massagem Não & 36 & 68 & 35 & 67 & 24 & 57 & 32 & 64 & 36 & 72 & 163 & 66 \\
\hline Total & 53 & 100 & 52 & 100 & 42 & 100 & 50 & 100 & 50 & 100 & 247 & 100 \\
\hline
\end{tabular}

\begin{tabular}{|c|c|c|c|c|c|c|c|c|c|c|c|c|c|}
\hline \multicolumn{14}{|l|}{ Prevenção } \\
\hline & Sim & 01 & 02 & 03 & 06 & 03 & 07 & 02 & 04 & 01 & 02 & 10 & 04 \\
\hline & Não & 52 & 98 & 49 & 94 & 39 & 93 & 48 & 96 & 49 & 98 & 237 & 96 \\
\hline & Total & 53 & 100 & 52 & 100 & 42 & 100 & 50 & 100 & 50 & 100 & 247 & 100 \\
\hline \multicolumn{14}{|l|}{ Relacionada aos } \\
\hline Benefícios da & Sim & 05 & 09 & 02 & 04 & 03 & 07 & 08 & 16 & 15 & 30 & 33 & 13 \\
\hline Fisioterapia & Não & 48 & 91 & 50 & 96 & 39 & 93 & 42 & 84 & 35 & 70 & 214 & 87 \\
\hline em geral & Total & 53 & 100 & 52 & 100 & 42 & 100 & 50 & 100 & 50 & 100 & 247 & 100 \\
\hline \multicolumn{14}{|l|}{ Psicoterapia } \\
\hline & Sim & 02 & 04 & 02 & 04 & 02 & 05 & - & - & - & - & 06 & 02 \\
\hline & Não & 51 & 96 & 50 & 96 & 40 & 95 & 50 & 100 & 50 & 100 & 241 & 98 \\
\hline & Total & 53 & 100 & 52 & 100 & 42 & 100 & 50 & 100 & 50 & 100 & 247 & 100 \\
\hline \multicolumn{14}{|l|}{ Outros } \\
\hline & Sim & 01 & 02 & 03 & 06 & 02 & 05 & - & - & - & - & 06 & 02 \\
\hline & Não & 52 & 98 & 49 & 94 & 40 & 95 & 50 & 100 & 50 & 100 & 241 & 98 \\
\hline & Total & 53 & 100 & 52 & 100 & 42 & 100 & 50 & 100 & 50 & 100 & 247 & 100 \\
\hline \multicolumn{14}{|c|}{ Não sabe responder } \\
\hline & Sim & 02 & 04 & 12 & 23 & 06 & 14 & 13 & 26 & 12 & 24 & 45 & 18 \\
\hline & Não & 51 & 96 & 40 & 77 & 36 & 86 & 37 & 74 & 38 & 76 & 202 & 82 \\
\hline & Total & 53 & 100 & 52 & 100 & 42 & 100 & 50 & 100 & 50 & 100 & 247 & 100 \\
\hline
\end{tabular}

\section{5) Grau de importância dos serviços de Fisioterapia para a saúde da população}

Observou-se que a maioria de todas as microáreas considerou a Fisioterapia muito importante, representando 90\% dentre os entrevistados. Salienta-se, ainda, que as junções dos índices sem importância e pouco importantes somaram apenas 3\% do total (Tabela 15). 
Tabela 15 - Distribuição dos usuários das cinco microáreas de uma Unidade de Saúde da Família por grau de importância dos serviços de Fisioterapia para a saúde da população, Sumarezinho, Ribeirão Preto (SP), 2008

\begin{tabular}{|c|c|c|c|c|c|c|c|c|c|c|c|c|}
\hline \multirow{3}{*}{$\begin{array}{l}\text { Grau de importância } \\
\text { da Fisioterapia }\end{array}$} & \multicolumn{10}{|c|}{ Microáreas } & \multirow{2}{*}{\multicolumn{2}{|c|}{ Total }} \\
\hline & \multicolumn{2}{|c|}{ I } & \multicolumn{2}{|c|}{ II } & \multicolumn{2}{|c|}{ III } & \multicolumn{2}{|c|}{ IV } & \multicolumn{2}{|c|}{$\mathbf{V}$} & & \\
\hline & $\mathbf{n}$ & $\%$ & $\mathbf{n}$ & $\%$ & $\mathbf{n}$ & $\%$ & $\mathbf{n}$ & $\%$ & $\mathbf{n}$ & $\%$ & $\mathbf{n}$ & $\%$ \\
\hline Sem importância & - & - & 01 & 02 & 01 & 02 & - & - & - & - & 02 & 01 \\
\hline Pouco importante & 01 & 02 & 01 & 02 & 02 & 06 & - & - & 02 & 04 & 06 & 02 \\
\hline Muito importante & 50 & 94 & 42 & 81 & 38 & 90 & 48 & 96 & 44 & 88 & 222 & 90 \\
\hline Não sabe responder & 02 & 04 & 08 & 15 & 01 & 02 & 02 & 04 & 04 & 08 & 17 & 07 \\
\hline Total & 57 & 100 & 58 & 100 & 46 & 100 & 57 & 100 & 57 & 100 & 247 & 100 \\
\hline
\end{tabular}

\section{6) Recursos que o fisioterapeuta utiliza}

Constatou-se que a maioria dos entrevistados de todas as microáreas considerou como principais recursos que o fisioterapeuta utiliza: o exercício e/ou massagem (45\%) e os aparelhos e agentes elétricos e/ou térmicos (44\%). As bolas foram citadas por 23\% dos pesquisados. Percebeu-se, ainda, que 31\% dos entrevistados afirmaram não saber responder essa questão. As demais categorias foram poucas vezes mencionadas. Salienta-se que a categoria “outros” incluiu as seguintes respostas: esteira, aparelho de pressão e medicamentos (Tabela 16). 
Tabela 16 - Distribuição dos usuários das cinco microáreas de uma Unidade de Saúde da Família por recursos que o fisioterapeuta utiliza, Sumarezinho, Ribeirão Preto (SP), 2008

\begin{tabular}{|c|c|c|c|c|c|c|c|c|c|c|c|c|c|}
\hline \multirow{3}{*}{\multicolumn{2}{|c|}{$\begin{array}{c}\text { Recursos que o } \\
\text { fisioterapeuta utiliza }\end{array}$}} & \multicolumn{10}{|c|}{ Microáreas } & \multirow{2}{*}{\multicolumn{2}{|c|}{ Total }} \\
\hline & & \multicolumn{2}{|c|}{ I } & \multicolumn{2}{|c|}{ II } & \multicolumn{2}{|c|}{ III } & \multicolumn{2}{|c|}{ IV } & \multicolumn{2}{|c|}{$\mathbf{V}$} & & \\
\hline & & $\mathbf{n}$ & $\%$ & $\mathbf{n}$ & $\%$ & $\mathbf{n}$ & $\%$ & $\mathbf{n}$ & $\%$ & $\mathbf{n}$ & $\%$ & $\mathbf{n}$ & $\%$ \\
\hline \multicolumn{14}{|c|}{ Aparelhos e agentes } \\
\hline elétricos & Sim & 35 & 66 & 18 & 35 & 16 & 38 & 16 & 32 & 23 & 46 & 108 & 44 \\
\hline \multirow[t]{2}{*}{ e/ou térmicos } & Não & 18 & 34 & 34 & 65 & 26 & 62 & 34 & 68 & 27 & 54 & 139 & 56 \\
\hline & Total & 53 & 100 & 52 & 100 & 42 & 100 & 50 & 100 & 50 & 100 & 247 & 100 \\
\hline \multicolumn{14}{|l|}{ Exercícios e/ou } \\
\hline \multirow[t]{3}{*}{ Massagens } & Sim & 39 & 74 & 13 & 25 & 09 & 21 & 22 & 44 & 29 & 58 & 112 & 45 \\
\hline & Não & 14 & 26 & 39 & 75 & 33 & 79 & 28 & 56 & 21 & 42 & 135 & 55 \\
\hline & Total & 53 & 100 & 52 & 100 & 42 & 100 & 50 & 100 & 50 & 100 & 247 & 100 \\
\hline
\end{tabular}

Pesos

\begin{tabular}{rcccccccccccc} 
Sim & - & - & 03 & 06 & 01 & 02 & 01 & 02 & 01 & 02 & 06 & 02 \\
Não & 53 & 100 & 49 & 94 & 41 & 98 & 49 & 98 & 49 & 98 & 241 & 98 \\
Total & $\mathbf{5 3}$ & $\mathbf{1 0 0}$ & $\mathbf{5 2}$ & $\mathbf{1 0 0}$ & $\mathbf{4 2}$ & $\mathbf{1 0 0}$ & $\mathbf{5 0}$ & $\mathbf{1 0 0}$ & $\mathbf{5 0}$ & $\mathbf{1 0 0}$ & $\mathbf{2 4 7}$ & $\mathbf{1 0 0}$ \\
\hline
\end{tabular}

Bolas

\begin{tabular}{rcccccccccccc} 
Sim & 09 & 17 & 03 & 06 & 13 & 31 & 08 & 16 & 24 & 48 & 57 & 23 \\
Não & 44 & 83 & 49 & 94 & 29 & 69 & 42 & 84 & 26 & 52 & 190 & 77 \\
Total & $\mathbf{5 3}$ & $\mathbf{1 0 0}$ & $\mathbf{5 2}$ & $\mathbf{1 0 0}$ & $\mathbf{4 2}$ & $\mathbf{1 0 0}$ & $\mathbf{5 0}$ & $\mathbf{1 0 0}$ & $\mathbf{5 0}$ & $\mathbf{1 0 0}$ & $\mathbf{2 4 7}$ & $\mathbf{1 0 0}$ \\
\hline
\end{tabular}

Auxílio/Marcha

\begin{tabular}{rcccccccccccc} 
Sim & - & - & - & - & 03 & 07 & 02 & 04 & - & - & 05 & 02 \\
Não & 53 & 100 & 52 & 100 & 39 & 93 & 48 & 96 & 50 & 100 & 242 & 98 \\
Total & $\mathbf{5 3}$ & $\mathbf{1 0 0}$ & $\mathbf{5 2}$ & $\mathbf{1 0 0}$ & $\mathbf{4 2}$ & $\mathbf{1 0 0}$ & $\mathbf{5 0}$ & $\mathbf{1 0 0}$ & $\mathbf{5 0}$ & $\mathbf{1 0 0}$ & $\mathbf{2 4 7}$ & $\mathbf{1 0 0}$ \\
\hline
\end{tabular}

Outros

\begin{tabular}{rcccccccccccc} 
Sim & - & - & 07 & 13 & 06 & 14 & 02 & 04 & 02 & 04 & 17 & 07 \\
Não & 53 & 100 & 45 & 87 & 36 & 86 & 48 & 96 & 48 & 96 & 230 & 93 \\
Total & $\mathbf{5 3}$ & $\mathbf{1 0 0}$ & $\mathbf{5 2}$ & $\mathbf{1 0 0}$ & $\mathbf{4 2}$ & $\mathbf{1 0 0}$ & $\mathbf{5 0}$ & $\mathbf{1 0 0}$ & $\mathbf{5 0}$ & $\mathbf{1 0 0}$ & $\mathbf{2 4 7}$ & $\mathbf{1 0 0}$ \\
\hline
\end{tabular}

Não sabe responder

\begin{tabular}{rcccccccccccc} 
Sim & 03 & 06 & 26 & 50 & 16 & 38 & 18 & 36 & 13 & 26 & 76 & 31 \\
Não & 50 & 94 & 26 & 50 & 26 & 62 & 32 & 64 & 37 & 74 & 171 & 69 \\
Total & $\mathbf{5 3}$ & $\mathbf{1 0 0}$ & $\mathbf{5 2}$ & $\mathbf{1 0 0}$ & $\mathbf{4 2}$ & $\mathbf{1 0 0}$ & $\mathbf{5 0}$ & $\mathbf{1 0 0}$ & $\mathbf{5 0}$ & $\mathbf{1 0 0}$ & $\mathbf{2 4 7}$ & $\mathbf{1 0 0}$ \\
\hline
\end{tabular}

\section{7) Para que serve a Fisioterapia?}

A função da Fisioterapia no tratamento e reabilitação de doenças específicas destacou-se em relação ao número total de entrevistados, com 43\%. Em seguida, prevaleceu à categoria que englobou: “realizar exercícios, recuperar movimento e/ou andar”, com 40\%. Os benefícios à saúde em geral obteve 16\% e a prevenção 4\%. Mas essas duas categorias se destacaram na Microárea III, com respectivamente 33\% e 12\% (Tabela 17). 
Tabela 17 - Distribuição dos usuários das cinco microáreas de uma Unidade de Saúde da Família por função da Fisioterapia, Sumarezinho, Ribeirão Preto (SP), 2008

\begin{tabular}{|c|c|c|c|c|c|c|c|c|c|c|c|c|}
\hline \multirow{3}{*}{$\begin{array}{c}\text { Para que serve a } \\
\text { Fisioterapia? }\end{array}$} & \multicolumn{10}{|c|}{ Microáreas } & \multirow{2}{*}{\multicolumn{2}{|c|}{ Total }} \\
\hline & \multicolumn{2}{|c|}{ I } & \multicolumn{2}{|c|}{ II } & \multicolumn{2}{|c|}{ III } & \multicolumn{2}{|c|}{ IV } & \multicolumn{2}{|c|}{$\mathbf{V}$} & & \\
\hline & $\mathbf{n}$ & $\%$ & $n$ & $\%$ & $\mathrm{n}$ & $\%$ & $\mathbf{n}$ & $\%$ & $\mathbf{n}$ & $\%$ & $\mathbf{n}$ & $\%$ \\
\hline \multicolumn{13}{|l|}{ Tratamento/Reabilitação } \\
\hline Doenças $\quad$ Sim & 26 & 49 & 28 & 54 & 23 & 55 & 10 & 20 & 19 & 38 & 106 & 43 \\
\hline específicas & 27 & 51 & 24 & 46 & 19 & 45 & 40 & 80 & 31 & 62 & 141 & 57 \\
\hline Total & 53 & 100 & 52 & 100 & 42 & 100 & 50 & 100 & 50 & 100 & 247 & 100 \\
\hline \multicolumn{13}{|l|}{ Realizar exercícios, re- } \\
\hline cuperar movimento Sim & 26 & 49 & 17 & 33 & 12 & 29 & 25 & 50 & 19 & 38 & 99 & 40 \\
\hline e/ou andar $\quad$ Não & 27 & 51 & 35 & 67 & 30 & 71 & 25 & 50 & 31 & 62 & 148 & 60 \\
\hline $\begin{array}{ll}\text { Total } \\
\text {. }\end{array}$ & 53 & 100 & 52 & 100 & 42 & 100 & 50 & 100 & 50 & 100 & 247 & 100 \\
\hline
\end{tabular}

Prevenção

\begin{tabular}{rcccccccccccc} 
Sim Não & 03 & 06 & 03 & 06 & 05 & 12 & - & - & - & - & 11 & 04 \\
Não & 50 & 94 & 49 & 94 & 37 & 88 & 50 & 100 & 50 & 100 & 236 & 96 \\
Total & $\mathbf{5 3}$ & $\mathbf{1 0 0}$ & $\mathbf{5 2}$ & $\mathbf{1 0 0}$ & $\mathbf{4 2}$ & $\mathbf{1 0 0}$ & $\mathbf{5 0}$ & $\mathbf{1 0 0}$ & $\mathbf{5 0}$ & $\mathbf{1 0 0}$ & $\mathbf{2 4 7}$ & $\mathbf{1 0 0}$ \\
\hline
\end{tabular}

Benefícios à saúde em

\begin{tabular}{lccccccccccccc} 
Geral & Sim & 05 & 09 & 04 & 08 & 14 & 33 & 7 & 14 & 10 & 20 & 40 & 16 \\
& Não & 48 & 91 & 48 & 92 & 28 & 67 & 43 & 86 & 40 & 80 & 207 & 84 \\
& Total & $\mathbf{5 3}$ & $\mathbf{1 0 0}$ & $\mathbf{5 2}$ & $\mathbf{1 0 0}$ & $\mathbf{4 2}$ & $\mathbf{1 0 0}$ & $\mathbf{5 0}$ & $\mathbf{1 0 0}$ & $\mathbf{5 0}$ & $\mathbf{1 0 0}$ & $\mathbf{2 4 7}$ & $\mathbf{1 0 0}$ \\
\hline
\end{tabular}

Aspectos emocionais/

\begin{tabular}{lccccccccccccc} 
Psicológicos & Sim & 05 & 09 & 01 & 02 & - & - & - & - & 01 & 02 & 07 & 03 \\
& Não & 48 & 91 & 51 & 98 & 42 & 100 & 50 & 100 & 49 & 98 & 240 & 97 \\
& Total & $\mathbf{5 3}$ & $\mathbf{1 0 0}$ & $\mathbf{5 2}$ & $\mathbf{1 0 0}$ & $\mathbf{4 2}$ & $\mathbf{1 0 0}$ & $\mathbf{5 0}$ & $\mathbf{1 0 0}$ & $\mathbf{5 0}$ & $\mathbf{1 0 0}$ & $\mathbf{2 4 7}$ & $\mathbf{1 0 0}$ \\
\hline
\end{tabular}

Tratamento da dor

\begin{tabular}{rcccccccccccc} 
Sim & 03 & 06 & - & - & 01 & 02 & 03 & 11 & 01 & 02 & 08 & 03 \\
Não & 50 & 94 & 52 & 100 & 41 & 98 & 47 & 94 & 49 & 98 & 239 & 97 \\
Total & $\mathbf{5 3}$ & $\mathbf{1 0 0}$ & $\mathbf{5 2}$ & $\mathbf{1 0 0}$ & $\mathbf{4 2}$ & $\mathbf{1 0 0}$ & $\mathbf{5 0}$ & $\mathbf{1 0 0}$ & $\mathbf{5 0}$ & $\mathbf{1 0 0}$ & $\mathbf{2 4 7}$ & $\mathbf{1 0 0}$ \\
\hline
\end{tabular}

Não sabe

\begin{tabular}{rcccccccccccc} 
Sim & - & - & 12 & 23 & 01 & 02 & 10 & 20 & 04 & 08 & 27 & 11 \\
Não & 53 & 100 & 40 & 77 & 41 & 98 & 40 & 80 & 46 & 92 & 220 & 89 \\
Total & $\mathbf{5 3}$ & $\mathbf{1 0 0}$ & $\mathbf{5 2}$ & $\mathbf{1 0 0}$ & $\mathbf{4 2}$ & $\mathbf{1 0 0}$ & $\mathbf{5 0}$ & $\mathbf{1 0 0}$ & $\mathbf{5 0}$ & $\mathbf{1 0 0}$ & $\mathbf{2 4 7}$ & $\mathbf{1 0 0}$ \\
\hline
\end{tabular}

\section{8) Pessoas ou situações que precisam dos serviços de Fisioterapia}

Em todas as microáreas, as pessoas que precisavam dos serviços de Fisioterapia que mais foram mencionadas pertenciam à categoria "deficientes físicos, lesões e/ou algias músculo-esquelética”, com 76\% dos entrevistados. A categoria “acamados, idosos e doenças geriátricas” obteve 31\%. As pessoas sadias só foram referidas na Microárea III, correspondendo a $2 \%$ do total. As demais categorias também obtiveram pouco destaque (Tabela 18). 
Tabela 18 - Distribuição dos usuários das cinco microáreas de uma Unidade de Saúde da Família por pessoas ou situações que precisam dos serviços de Fisioterapia, Sumarezinho, Ribeirão Preto (SP), 2008

\begin{tabular}{|c|c|c|c|c|c|c|c|c|c|c|c|c|}
\hline \multirow{3}{*}{$\begin{array}{c}\text { Pessoas ou situações que } \\
\text { precisam dos serviços de } \\
\text { Fisioterapia } \\
\end{array}$} & \multicolumn{10}{|c|}{ Microáreas } & \multirow{2}{*}{\multicolumn{2}{|c|}{ Total }} \\
\hline & \multicolumn{2}{|c|}{$\mathbf{I}$} & \multicolumn{2}{|c|}{ II } & \multicolumn{2}{|c|}{ III } & \multicolumn{2}{|c|}{ IV } & \multicolumn{2}{|c|}{$\mathbf{V}$} & & \\
\hline & $n$ & $\%$ & $n$ & $\%$ & $\mathbf{n}$ & $\%$ & $\mathbf{n}$ & $\%$ & $\mathbf{n}$ & $\%$ & \multicolumn{2}{|r|}{$\%$} \\
\hline \multicolumn{13}{|l|}{ Pessoas Sadias } \\
\hline Sim & - & - & - & - & 04 & 10 & - & - & - & - & 04 & 02 \\
\hline Não & 53 & 100 & 52 & 100 & 38 & 90 & 50 & 100 & 50 & 100 & 243 & 98 \\
\hline Total & 53 & 100 & 52 & 100 & 42 & 100 & 50 & 100 & 50 & 100 & 247 & 100 \\
\hline \multicolumn{13}{|l|}{ Acamados, Idosos e } \\
\hline Doenças $\quad$ Sim & 24 & 45 & 14 & 27 & 09 & 21 & 05 & 10 & 25 & 50 & 77 & 31 \\
\hline \multirow[t]{2}{*}{ Geriátricas } & 29 & 55 & 38 & 73 & 33 & 79 & 45 & 90 & 25 & 50 & 170 & 69 \\
\hline & 53 & 100 & 52 & 100 & 42 & 100 & 50 & 100 & 50 & 100 & 247 & 100 \\
\hline \multicolumn{13}{|l|}{ Deficientes físicos/ lesões } \\
\hline e/ou algias músculo- Sim & 48 & 91 & 36 & 69 & 27 & 64 & 39 & 78 & 37 & 74 & 187 & 76 \\
\hline esquelético $\quad$ Não & 05 & 09 & 16 & 31 & 15 & 36 & 11 & 22 & 13 & 26 & 60 & 24 \\
\hline Total & 53 & 100 & 52 & 100 & 42 & 100 & 50 & 100 & 50 & 100 & 247 & 100 \\
\hline \multicolumn{13}{|l|}{ Doenças Neurológicas } \\
\hline Sim & 03 & 06 & 03 & 06 & 06 & 14 & 02 & 04 & 05 & 10 & 19 & 08 \\
\hline Não & 50 & 94 & 49 & 94 & 36 & 86 & 48 & 96 & 45 & 90 & 228 & 92 \\
\hline Total & 53 & 100 & 52 & 100 & 42 & 100 & 50 & 100 & 50 & 100 & 247 & 100 \\
\hline \multicolumn{13}{|l|}{ Doenças Respiratórias } \\
\hline \multirow[t]{3}{*}{ e Cardíacas } & 07 & 13 & 01 & 02 & 03 & 07 & 07 & 14 & 06 & 12 & 24 & 10 \\
\hline & 46 & 87 & 51 & 98 & 39 & 93 & 43 & 86 & 44 & 88 & 223 & 90 \\
\hline & 53 & 100 & 52 & 100 & 42 & 100 & 50 & 100 & 50 & 100 & 247 & 100 \\
\hline \multicolumn{13}{|l|}{ Necessidades Estéticas } \\
\hline Sim & - & - & 01 & 02 & - & - & 02 & 04 & - & - & 03 & 01 \\
\hline Não & 53 & 100 & 51 & 98 & 42 & 100 & 48 & 96 & 50 & 100 & 244 & 99 \\
\hline Total & 53 & 100 & 52 & 100 & 42 & 100 & 50 & 100 & 50 & 100 & 247 & 100 \\
\hline \multicolumn{13}{|l|}{ Outros } \\
\hline Sim & 01 & 02 & 02 & 04 & 07 & 17 & 02 & 04 & 01 & 02 & 13 & 05 \\
\hline Não & 52 & 98 & 50 & 96 & 35 & 83 & 48 & 96 & 49 & 98 & 234 & 95 \\
\hline Total & 53 & 100 & 52 & 100 & 42 & 100 & 50 & 100 & 50 & 100 & 247 & 100 \\
\hline \multicolumn{13}{|l|}{ Não sabe } \\
\hline Sim & - & - & 12 & 23 & 02 & 05 & 05 & 10 & 07 & 14 & 26 & 11 \\
\hline Não & 53 & 100 & 40 & 77 & 40 & 95 & 45 & 90 & 43 & 86 & 221 & 89 \\
\hline Total & 53 & 100 & 52 & 100 & 42 & 100 & 50 & 100 & 50 & 100 & 247 & 100 \\
\hline
\end{tabular}

\section{9) Lugares onde o fisioterapeuta trabalha}

O lugar onde o fisioterapeuta trabalha, mais mencionado, foi o hospital, com 59\% dos entrevistados. Em seguida, encontra-se a clínica, com 42\%. O posto de saúde foi citado por $38 \%$ dos pesquisados. A atividade domiciliar foi a menos referida, com apenas $15 \%$ (Tabela 19). 
Tabela 19 - Distribuição dos usuários das cinco microáreas de uma Unidade de Saúde da Família por lugares onde fisioterapeuta trabalha, Sumarezinho, Ribeirão Preto (SP), 2008

\begin{tabular}{|c|c|c|c|c|c|c|c|c|c|c|c|c|}
\hline \multirow{3}{*}{$\begin{array}{l}\text { Lugares onde o } \\
\text { fisioterapeuta trabalha }\end{array}$} & \multicolumn{10}{|c|}{ Microáreas } & \multirow{2}{*}{\multicolumn{2}{|c|}{ Total }} \\
\hline & \multicolumn{2}{|c|}{ I } & \multicolumn{2}{|c|}{ II } & \multicolumn{2}{|c|}{ III } & \multicolumn{2}{|c|}{ IV } & \multicolumn{2}{|c|}{$\mathbf{V}$} & & \\
\hline & $\mathbf{n}$ & $\%$ & n & $\%$ & $\mathbf{n}$ & $\%$ & n & $\%$ & $\mathbf{n}$ & $\%$ & \multicolumn{2}{|r|}{$\%$} \\
\hline \multicolumn{13}{|l|}{ Clínica } \\
\hline Sim & 32 & 60 & 17 & 33 & 17 & 40 & 12 & 24 & 26 & 52 & 104 & 42 \\
\hline Não & 21 & 40 & 35 & 67 & 25 & 60 & 38 & 76 & 24 & 48 & 143 & 58 \\
\hline Total & 53 & 100 & 52 & 100 & 42 & 100 & 50 & 100 & 50 & 100 & 247 & 100 \\
\hline \multicolumn{13}{|l|}{ Domiciliar } \\
\hline Sim & 05 & 09 & 07 & 13 & 09 & 21 & 08 & 16 & 07 & 14 & 36 & 15 \\
\hline Não & 48 & 91 & 45 & 87 & 33 & 79 & 42 & 84 & 43 & 86 & 211 & 85 \\
\hline Total & 53 & 100 & 52 & 100 & 42 & 100 & 50 & 100 & 50 & 100 & 247 & 100 \\
\hline \multicolumn{13}{|l|}{ Posto de saúde } \\
\hline Sim & 28 & 53 & 19 & 37 & 12 & 29 & 15 & 30 & 20 & 40 & 94 & 38 \\
\hline Não & 25 & 47 & 33 & 63 & 30 & 72 & 35 & 70 & 30 & 60 & 153 & 62 \\
\hline Total & 53 & 100 & 52 & 100 & 42 & 100 & 50 & 100 & 50 & 100 & 247 & 100 \\
\hline \multicolumn{13}{|l|}{ Hospital } \\
\hline Sim & 26 & 49 & 28 & 54 & 30 & 71 & 25 & 50 & 36 & 72 & 145 & 59 \\
\hline Não & 27 & 51 & 24 & 46 & 12 & 29 & 25 & 50 & 14 & 28 & 102 & 41 \\
\hline Total & 53 & 100 & 52 & 100 & 42 & 100 & 50 & 100 & 50 & 100 & 247 & 100 \\
\hline \multicolumn{13}{|l|}{ Não sabe responder } \\
\hline Sim & 01 & 02 & 10 & 19 & 01 & 02 & 08 & 16 & 02 & 04 & 22 & 09 \\
\hline Não & 52 & 98 & 42 & 81 & 41 & 98 & 42 & 84 & 48 & 96 & 225 & 91 \\
\hline Total & 53 & 100 & 52 & 100 & 42 & 100 & 50 & 100 & 50 & 100 & 247 & 100 \\
\hline
\end{tabular}

10) Tipo de atividades que $o$ fisioterapeuta realiza

A atividade mais mencionada foi a realizada individualmente, com 51\% dos entrevistados. No entanto, as atividades de grupo adquiriram 48\%. A atividade domiciliar foi citada por 36\% dos entrevistados e as ações de educação em saúde, por apenas 9\% (Tabela 20). 
Tabela 20 - Distribuição dos usuários das cinco microáreas de uma Unidade de Saúde da Família por tipo de atividades que o fisioterapeuta realiza, Sumarezinho, Ribeirão Preto (SP), 2008

\begin{tabular}{|c|c|c|c|c|c|c|c|c|c|c|c|c|}
\hline \multirow{3}{*}{$\begin{array}{c}\text { Tipo de atividades que o } \\
\text { fisioterapeuta realiza }\end{array}$} & \multicolumn{10}{|c|}{ Microáreas } & \multirow{2}{*}{\multicolumn{2}{|c|}{ Total }} \\
\hline & \multicolumn{2}{|c|}{ I } & \multicolumn{2}{|c|}{ II } & \multicolumn{2}{|c|}{ III } & \multicolumn{2}{|c|}{ IV } & \multicolumn{2}{|c|}{$\mathbf{V}$} & & \\
\hline & $\mathbf{n}$ & $\%$ & $\mathbf{n}$ & $\%$ & $\mathbf{n}$ & $\%$ & $\mathbf{n}$ & $\%$ & $\mathbf{n}$ & $\%$ & $\mathbf{n}$ & $\%$ \\
\hline \multicolumn{13}{|l|}{ Domiciliar } \\
\hline Sim & 26 & 49 & 16 & 31 & 17 & 40 & 11 & 22 & 20 & 40 & 90 & 36 \\
\hline Não & 27 & 51 & 36 & 69 & 25 & 60 & 39 & 78 & 30 & 60 & 157 & 64 \\
\hline Total & 53 & 100 & 52 & 100 & 42 & 100 & 50 & 100 & 50 & 100 & 247 & 100 \\
\hline \multicolumn{13}{|l|}{ Individual } \\
\hline Sim & 32 & 60 & 14 & 27 & 29 & 69 & 22 & 44 & 30 & 60 & 127 & 51 \\
\hline Não & 21 & 40 & 38 & 73 & 13 & 31 & 28 & 56 & 20 & 40 & 120 & 49 \\
\hline Total & 53 & 100 & 52 & 100 & 42 & 100 & 50 & 100 & 50 & 100 & 247 & 100 \\
\hline \multicolumn{13}{|l|}{ De grupo } \\
\hline Sim & 31 & 58 & 21 & 40 & 19 & 45 & 27 & 54 & 21 & 42 & 119 & 48 \\
\hline Não & 22 & 42 & 31 & 60 & 23 & 55 & 23 & 46 & 29 & 58 & 128 & 52 \\
\hline Total & 53 & 100 & 52 & 100 & 42 & 100 & 50 & 100 & 50 & 100 & 247 & 100 \\
\hline
\end{tabular}

Ações de educação em saúde

\begin{tabular}{rcccccccccccc} 
Sim & 07 & 13 & 02 & 04 & 05 & 12 & 06 & 12 & 02 & 04 & 22 & 09 \\
Não & 46 & 87 & 50 & 96 & 37 & 88 & 44 & 88 & 48 & 96 & 225 & 91 \\
Total & $\mathbf{5 3}$ & $\mathbf{1 0 0}$ & $\mathbf{5 2}$ & $\mathbf{1 0 0}$ & $\mathbf{4 2}$ & $\mathbf{1 0 0}$ & $\mathbf{5 0}$ & $\mathbf{1 0 0}$ & $\mathbf{5 0}$ & $\mathbf{1 0 0}$ & $\mathbf{2 4 7}$ & $\mathbf{1 0 0}$ \\
\hline
\end{tabular}

Não sabe

\begin{tabular}{rcccccccccccc} 
Sim & 02 & 04 & 19 & 37 & 04 & 10 & 10 & 20 & 05 & 10 & 40 & 16 \\
Não & 51 & 96 & 33 & 63 & 38 & 90 & 40 & 80 & 45 & 90 & 207 & 84 \\
Total & $\mathbf{5 3}$ & $\mathbf{1 0 0}$ & $\mathbf{5 2}$ & $\mathbf{1 0 0}$ & $\mathbf{4 2}$ & $\mathbf{1 0 0}$ & $\mathbf{5 0}$ & $\mathbf{1 0 0}$ & $\mathbf{5 0}$ & $\mathbf{1 0 0}$ & $\mathbf{2 4 7}$ & $\mathbf{1 0 0}$ \\
\hline
\end{tabular}

\subsection{Percepções dos entrevistados quanto às suas principais necessidades em relação à} atuação do fisioterapeuta

1) Necessidade de inclusão do fisioterapeuta à equipe da USF em que os entrevistados estão cadastrados

Verificou-se que a grande maioria dos entrevistados de todas as microáreas considerou necessária a inclusão do fisioterapeuta à equipe da Unidade de Saúde da Família em que está cadastrada, correspondendo a 98\%. A resposta negativa a essa questão foi referida por apenas 1\%, presentes, apenas, nas Microáreas I e na V (Tabela 21). 
Tabela 21 - Distribuição dos usuários das cinco microáreas de uma Unidade de Saúde da Família (USF) por necessidade de inclusão do fisioterapeuta à equipe da USF em que eles estão cadastrados, Sumarezinho, Ribeirão Preto (SP), 2008

\begin{tabular}{|c|c|c|c|c|c|c|c|c|c|c|c|c|}
\hline \multirow{3}{*}{$\begin{array}{c}\text { Há necessidade de } \\
\text { inclusão do } \\
\text { fisioterapeuta à } \\
\text { equipe da USF em } \\
\text { que estão } \\
\text { cadastrados? }\end{array}$} & \multicolumn{10}{|c|}{ Microáreas } & \multirow{2}{*}{\multicolumn{2}{|c|}{ Total }} \\
\hline & \multicolumn{2}{|c|}{ I } & \multicolumn{2}{|c|}{ II } & \multicolumn{2}{|c|}{ III } & \multicolumn{2}{|c|}{ IV } & \multicolumn{2}{|c|}{ V } & & \\
\hline & $\mathbf{n}$ & $\%$ & $\mathbf{n}$ & $\%$ & $\mathbf{n}$ & $\%$ & $\mathbf{n}$ & $\%$ & $\mathbf{n}$ & $\%$ & $\mathbf{n}$ & $\%$ \\
\hline Sim & 52 & 98 & 52 & 100 & 41 & 98 & 49 & 98 & 49 & 98 & 243 & 98 \\
\hline Não & 01 & 02 & - & - & - & - & - & - & 01 & 02 & 02 & 01 \\
\hline Não sabe responder & - & - & - & - & 01 & 02 & 01 & 02 & - & - & 02 & 01 \\
\hline Total & 53 & 100 & 52 & 100 & 42 & 100 & 50 & 100 & 50 & 100 & 247 & 100 \\
\hline
\end{tabular}

2) Justificativa dos entrevistados sobre a necessidade/ou não necessidade de inclusão do fisioterapeuta à equipe da USF em que eles estão cadastrados

Foi solicitada aos entrevistados uma justificativa para a resposta do item anterior. As mesmas estão descritas a seguir, de forma que as respostas positivas correspondem ao item a, e a negativa, ao b.

\section{a) Por que é necessária a inclusão do fisioterapeuta à equipe da USF em que os entrevistados estão cadastrados?}

A Tabela 22 demonstra as justificativas dos entrevistados para a necessidade de inclusão do fisioterapeuta, mas salienta-se que, nessa tabela, a população total corresponde aos 243 indivíduos que responderam considerarem necessária essa inclusão, conforme o tópico anterior.

É importante destacar que, nessa questão, a categoria "suprir necessidades presentes na população e facilitar acesso e acessibilidade” inclui: as dificuldades geográficas, sócioculturais e organizacionais que influenciam o acesso aos serviços de Fisioterapia. Foram classificadas como "benefícios à saúde", as respostas a seguir: porque é bom, melhora a saúde, ajuda as pessoas, é importante. Como "local que oferece assistência diferenciada”, foram incluídas as respostas que afirmaram que o profissional da Unidade conhece a realidade do paciente e que esse é um local em que os usuários são bem recebidos. A categoria “outros” englobou respostas consideradas mais vagas, em que não foi possível identificar a idéiacentral do entrevistado sobre o assunto. 
A categoria "suprir necessidade presente na população e/ou facilitar o acesso e acessibilidade” obteve vasta predominância, sendo mencionada por $84 \%$ dos entrevistados. Os benefícios à saúde adquiriram 9\%. E as demais categorias foram poucas vezes citadas (Tabela 22).

Tabela 22 - Distribuição dos usuários das cinco microáreas de uma Unidade de Saúde da Família (USF) por justificativas da necessidade de inclusão do fisioterapeuta à equipe da USF em que eles estão cadastrados, Sumarezinho, Ribeirão Preto (SP), 2008

\begin{tabular}{|c|c|c|c|c|c|c|c|c|c|c|c|c|}
\hline \multirow{3}{*}{$\begin{array}{c}\text { Por que é necessária } \\
\text { a inclusão do } \\
\text { fisioterapeuta à } \\
\text { equipe da USF em } \\
\text { que estão } \\
\text { cadastrados? } \\
\end{array}$} & \multicolumn{10}{|c|}{ Microáreas } & \multirow{2}{*}{\multicolumn{2}{|c|}{ Total }} \\
\hline & \multicolumn{2}{|c|}{$\mathbf{I}$} & \multicolumn{2}{|c|}{ II } & \multicolumn{2}{|c|}{ III } & \multicolumn{2}{|c|}{ IV } & \multicolumn{2}{|c|}{$\mathbf{V}$} & & \\
\hline & $\mathbf{n}$ & $\%$ & $\mathbf{n}$ & $\%$ & $\mathbf{n}$ & $\%$ & $\mathbf{n}$ & $\%$ & $\mathbf{n}$ & $\%$ & $\mathbf{n}$ & $\%$ \\
\hline $\begin{array}{lr}\text { Suprir } & \text { necessidades } \\
\text { presentes } & \text { na } \\
\text { população e } & \text { Facilitar } \\
\text { acesso e acessibilidade }\end{array}$ & 44 & 84 & 44 & 85 & 37 & 90 & 38 & 78 & 40 & 82 & 203 & 84 \\
\hline Benefícios à saúde & 03 & 06 & 08 & 15 & - & - & 04 & 08 & 07 & 14 & 22 & 09 \\
\hline $\begin{array}{l}\text { Informar ou orientar a } \\
\text { população sobre a } \\
\text { Fisioterapia }\end{array}$ & 02 & 04 & - & - & - & - & 03 & 06 & 01 & 02 & 06 & 02 \\
\hline $\begin{array}{ll}\text { Local que oferece } \\
\text { assistência } \\
\text { diferenciada }\end{array}$ & 02 & 04 & - & - & 01 & 03 & 02 & 04 & - & - & 05 & 02 \\
\hline Outros & 01 & 02 & - & - & 03 & 07 & 02 & 04 & 01 & 02 & 07 & 03 \\
\hline Total & 52 & 100 & 52 & 100 & 41 & 100 & 49 & 100 & 49 & 100 & 243 & 100 \\
\hline
\end{tabular}

b) Porque não é necessária a inclusão do fisioterapeuta à equipe da Unidade de Saúde da

\section{Família em que os entrevistados estão cadastrados?}

Como demonstrado na Tabela 21, apenas dois indivíduos, um da Microárea I, e outro da $\mathrm{V}$, não consideraram necessária a inclusão do fisioterapeuta à equipe da USF em que eles estão cadastrados. Ambos justificaram essa opinião pela limitação do espaço físico da unidade estudada. 


\section{3) Prévio atendimento fisioterápico prestado aos entrevistados}

O prévio atendimento fisioterápico prestado aos entrevistados foi identificado ao questioná-los se já tinham sido atendidos por fisioterapeuta. Apenas 19\% desses responderam positivamente (Tabela 23).

Tabela 23 - Distribuição dos usuários das cinco microáreas de uma Unidade de Saúde da Família por prévio atendimento fisioterápico prestado a eles, Sumarezinho, Ribeirão Preto (SP), 2008

\begin{tabular}{|c|c|c|c|c|c|c|c|c|c|c|c|c|}
\hline \multirow{3}{*}{$\begin{array}{l}\text { Já foram atendidos } \\
\text { por fisioterapeuta? }\end{array}$} & \multicolumn{10}{|c|}{ Microáreas } & \multirow{2}{*}{\multicolumn{2}{|c|}{ Total }} \\
\hline & \multicolumn{2}{|c|}{ I } & \multicolumn{2}{|c|}{ II } & \multicolumn{2}{|c|}{ III } & \multicolumn{2}{|c|}{ IV } & \multicolumn{2}{|c|}{$\mathbf{V}$} & & \\
\hline & $\mathbf{n}$ & $\%$ & $\mathbf{n}$ & $\%$ & $\mathbf{n}$ & $\%$ & $\mathbf{n}$ & $\%$ & $\mathbf{n}$ & $\%$ & $\mathrm{n}$ & $\%$ \\
\hline Sim & 10 & 19 & 05 & 10 & 14 & 33 & 14 & 28 & 04 & 08 & 47 & 19 \\
\hline Não & 43 & 81 & 47 & 90 & 28 & 67 & 36 & 72 & 46 & 92 & 200 & 81 \\
\hline Total & 53 & 100 & 52 & 100 & 42 & 100 & 50 & 100 & 50 & 100 & 247 & 100 \\
\hline
\end{tabular}

Os itens 4 e 5, descritos a seguir, são restritos aos entrevistados que já foram atendidos por fisioterapeuta anteriormente a essa pesquisa, ou seja, 47 indivíduos conforme Tabela 22 .

\section{4) Natureza dos atendimentos fisioterápicos prestados aos entrevistados}

A natureza dos atendimentos fisioterápicos prestado aos entrevistados foi detectada ao perguntar se o atendimento fisioterápico que eles tiveram foi na Rede Pública de Saúde. Na Tabela 24, observa-se que $81 \%$ dos entrevistados tiveram atendimento dessa natureza. Em contrapartida, apenas nas Microáreas III e IV, observaram-se indivíduos que tenham tido atendimento fisioterápico de forma particular ou por convênio, representando 19\% do total. 
Tabela 24 - Distribuição dos usuários das cinco microáreas de uma Unidade de Saúde da Família por natureza dos atendimentos fisioterápicos prestados a eles, Sumarezinho, Ribeirão Preto (SP), 2008

\begin{tabular}{|c|c|c|c|c|c|c|c|c|c|c|c|c|c|}
\hline \multirow{3}{*}{$\begin{array}{l}\text { Natureza dos } \\
\text { atendimentos } \\
\text { fisioterápicos }\end{array}$} & & \multicolumn{10}{|c|}{ Microáreas } & \multirow{2}{*}{\multicolumn{2}{|c|}{ Total }} \\
\hline & & \multicolumn{2}{|c|}{ I } & \multicolumn{2}{|c|}{ II } & \multicolumn{2}{|c|}{ III } & \multicolumn{2}{|c|}{ IV } & \multicolumn{2}{|c|}{ V } & & \\
\hline & & $\mathrm{n}$ & $\%$ & $\mathbf{n}$ & $\%$ & $\mathrm{n}$ & $\%$ & $\mathrm{n}$ & $\%$ & $\mathbf{n}$ & $\%$ & $\mathbf{n}$ & $\%$ \\
\hline $\begin{array}{l}\text { Rede Pública } \\
\text { Saúde }\end{array}$ & de & 10 & 100 & 05 & 100 & 09 & 64 & 10 & 71 & 04 & 100 & 38 & 81 \\
\hline $\begin{array}{l}\text { Atendimento } \\
\text { Particular/convênio }\end{array}$ & & - & - & - & - & 05 & 36 & 04 & 29 & - & - & 09 & 19 \\
\hline Total & & 10 & 100 & 05 & 100 & 14 & 100 & 14 & 100 & 04 & 100 & 47 & 100 \\
\hline
\end{tabular}

\section{5) Motivos dos atendimentos fisioterápicos prestados aos entrevistados}

Os motivos do atendimento fisioterápico prestados aos entrevistados foram dispostos em duas categorias: a primeira, “deficientes físicos, lesão e/ou algias músculo-esquelético”, corresponde à quase totalidade das respostas, com 96\%; a segunda, “doenças respiratórias e/ou cardíacas”, só foi mencionada por duas pessoas na Microárea III, configurando 4\% do total (Tabela 25).

Tabela 25 - Distribuição dos usuários das cinco microáreas de uma Unidade de Saúde da Família por motivos dos atendimentos fisioterápicos prestados a eles, Sumarezinho, Ribeirão Preto (SP), 2008

\begin{tabular}{|c|c|c|c|c|c|c|c|c|c|c|c|c|}
\hline \multirow{3}{*}{$\begin{array}{c}\text { Motivos dos } \\
\text { atendimentos } \\
\text { fisioterápicos dos } \\
\text { entrevistados }\end{array}$} & \multicolumn{10}{|c|}{ Microáreas } & \multirow{2}{*}{\multicolumn{2}{|c|}{ Total }} \\
\hline & \multicolumn{2}{|c|}{$\mathbf{I}$} & \multicolumn{2}{|c|}{ II } & \multicolumn{2}{|c|}{ III } & \multicolumn{2}{|c|}{ IV } & \multicolumn{2}{|c|}{$\mathbf{V}$} & & \\
\hline & $\mathbf{n}$ & $\%$ & n & $\%$ & $\mathbf{n}$ & $\%$ & n & $\%$ & n & $\%$ & n & $\%$ \\
\hline $\begin{array}{l}\text { Deficientes físicos, } \\
\text { lesão e/ou algias } \\
\text { músculo-esquelético }\end{array}$ & 10 & 100 & 05 & 100 & 12 & 86 & 14 & 100 & 04 & 100 & 45 & 96 \\
\hline $\begin{array}{l}\text { Doenças respiratórias } \\
\text { e/ou cardíacas }\end{array}$ & - & - & - & - & 02 & 14 & - & - & - & - & 02 & 04 \\
\hline Total & 10 & 100 & 05 & 100 & 14 & 100 & 14 & 100 & 04 & 100 & 47 & 100 \\
\hline
\end{tabular}




\section{6) Prévio atendimento fisioterápico prestado aos familiares dos entrevistados}

Ao ser questionado se alguém da sua família já tinha sido atendido por um fisioterapeuta antes dessa pesquisa, apenas 19\% dos entrevistados responderam que sim. $\mathrm{Na}$ Microárea III, este índice foi de 36\% (Tabela 26).

Tabela 26 - Distribuição dos usuários das cinco microáreas de uma Unidade de Saúde da Família por prévio atendimento fisioterápico prestado aos familiares deles, Sumarezinho, Ribeirão Preto (SP), 2008

\begin{tabular}{|c|c|c|c|c|c|c|c|c|c|c|c|c|}
\hline \multirow{3}{*}{$\begin{array}{l}\text { Alguém da sua } \\
\text { família já foi } \\
\text { atendido por } \\
\text { fisioterapeuta? }\end{array}$} & \multicolumn{10}{|c|}{ Microáreas } & \multirow{2}{*}{\multicolumn{2}{|c|}{ Total }} \\
\hline & \multicolumn{2}{|c|}{ I } & \multicolumn{2}{|c|}{ II } & \multicolumn{2}{|c|}{ III } & \multicolumn{2}{|c|}{ IV } & \multicolumn{2}{|c|}{$\mathbf{V}$} & & \\
\hline & $\mathbf{n}$ & $\%$ & $\mathbf{n}$ & $\%$ & $\mathbf{n}$ & $\%$ & $\mathbf{n}$ & $\%$ & $\mathbf{n}$ & $\%$ & $\mathbf{n}$ & $\%$ \\
\hline Sim & 13 & 24 & 03 & 06 & 15 & 36 & 10 & 20 & 06 & 12 & 47 & 19 \\
\hline Não & 39 & 74 & 49 & 94 & 26 & 62 & 39 & 78 & 43 & 86 & 196 & 79 \\
\hline Não sabe responder & 01 & 02 & - & - & 01 & 02 & 01 & 02 & 01 & 02 & 04 & 02 \\
\hline Total & 53 & 100 & 52 & 100 & 42 & 100 & 50 & 100 & 50 & 100 & 247 & 100 \\
\hline
\end{tabular}

Foi perguntado aos 47 entrevistados cujos familiares já tinham sido atendidos pelo fisioterapeuta, qual foi o motivo desse atendimento. E as respostas encontram-se descritas no item a seguir.

\section{7) Motivos dos atendimentos fisioterápicos prestados aos familiares dos entrevistados}

Observa-se, na Tabela 27, que os principais motivos que levaram os familiares dos entrevistados de todas as microáreas a serem atendidos por fisioterapeuta foram ser deficiente físico ou apresentar lesão e/ou algias músculo-esquelético, com 78,7\%. 
Tabela 27 - Distribuição dos usuários das cinco microáreas de uma Unidade de Saúde da Família por motivos dos atendimentos fisioterápicos prestados aos familiares deles, Sumarezinho, Ribeirão Preto (SP), 2008

\begin{tabular}{|c|c|c|c|c|c|c|c|c|c|c|c|c|}
\hline \multirow{3}{*}{$\begin{array}{c}\text { Motivos dos } \\
\text { atendimentos } \\
\text { fisioterápicos dos } \\
\text { familiares dos } \\
\text { entrevistados }\end{array}$} & \multicolumn{10}{|c|}{ Microáreas } & \multirow{2}{*}{\multicolumn{2}{|c|}{ Total }} \\
\hline & \multicolumn{2}{|c|}{ I } & \multicolumn{2}{|c|}{ II } & \multicolumn{2}{|c|}{ III } & \multicolumn{2}{|c|}{ IV } & \multicolumn{2}{|c|}{$\mathbf{V}$} & & \\
\hline & $\mathbf{n}$ & $\%$ & $\mathbf{n}$ & $\%$ & $\mathbf{n}$ & $\%$ & $\mathbf{n}$ & $\%$ & $\mathbf{n}$ & $\%$ & $\mathbf{n}$ & $\%$ \\
\hline $\begin{array}{l}\text { Acamados/ Doenças } \\
\text { Geriátricas }\end{array}$ & - & - & - & - & 01 & 6,7 & 01 & 10,0 & 01 & 16,7 & 03 & 6,4 \\
\hline $\begin{array}{l}\text { Deficientes físicos e } \\
\text { lesão e/ou algias } \\
\text { músculo-esquelético }\end{array}$ & 11 & 84,6 & 03 & 100 & 12 & 80,0 & 08 & 80,0 & 03 & 50,0 & 37 & 78,7 \\
\hline Doenças Neurológicas & 01 & 7,7 & - & - & 02 & 13,3 & - & - & 16,7 & 01 & 04 & 8,5 \\
\hline $\begin{array}{l}\text { Doenças } \\
\text { Respiratórias/Cardíacas }\end{array}$ & 01 & 7,7 & - & - & - & - & 01 & 10,0 & 01 & 16,7 & 03 & 6,4 \\
\hline Total & 13 & 100 & 03 & 100 & 15 & 100 & 10 & 100 & 06 & 100 & 47 & 100 \\
\hline
\end{tabular}

\section{8) Experiência dos entrevistado e/ou familiares com a Fisioterapia}

Essa questão está relacionada com os itens anteriores e foi restrita aos entrevistados que já foram atendidos e/ou tiveram familiares atendidos por fisioterapeuta. Dentre a amostra de 247 indivíduos que já ouviram falar em Fisioterapia, verificou-se que 32 pessoas já foram atendidas por um fisioterapeuta e 32 pessoas tiveram algum familiar atendido por fisioterapeuta. Outras 15 pessoas tanto já foram atendidas, quanto já tiveram familiar atendido. Assim, concluiu-se que 79 indivíduos, dentre os entrevistados, estavam aptos a responder sobre a sua experiência com a Fisioterapia.

As respostas obtidas foram classificadas nas seguintes categorias: “ótima”, incluiu as expressões: ótima, excelente, muito boa, melhorou muito; "boa”, que englobou: bom, ajudou, melhorou; e "ruim”, que abrangeu: não gostei, não teve resultado.

A distribuição das respostas está disposta na Tabela 28, em que se percebe que as respostas predominantes em todas as microáreas foram as que consideraram a experiência com a Fisioterapia ótima ou boa. A soma dessas duas categorias ratifica que essa é a opinião de $90,1 \%$ de todos os entrevistados. 
Tabela 28 - Distribuição dos usuários das cinco microáreas de uma Unidade de Saúde da Família por experiência dos mesmos e/ou familiares com a Fisioterapia, Sumarezinho, Ribeirão Preto (SP), 2008

\begin{tabular}{|c|c|c|c|c|c|c|c|c|c|c|c|c|}
\hline \multirow{3}{*}{$\begin{array}{l}\text { Experiência com a } \\
\text { Fisioterapia }\end{array}$} & \multicolumn{10}{|c|}{ Microáreas } & \multirow{2}{*}{\multicolumn{2}{|c|}{ Total }} \\
\hline & \multicolumn{2}{|c|}{ I } & \multicolumn{2}{|c|}{ II } & \multicolumn{2}{|c|}{ III } & \multicolumn{2}{|c|}{ IV } & \multicolumn{2}{|c|}{$\mathbf{V}$} & & \\
\hline & $n$ & $\%$ & $n$ & $\%$ & $\mathrm{n}$ & $\%$ & $\mathrm{n}$ & $\%$ & $n$ & $\%$ & $\mathrm{n}$ & $\%$ \\
\hline Ótima & 08 & 42,1 & - & - & 10 & 45,5 & 05 & 22,7 & 03 & 33,3 & 26 & 32,9 \\
\hline Boa & 11 & 57,9 & 06 & 85,7 & 10 & 45,5 & 13 & 59,1 & 05 & 55,6 & 45 & 57,0 \\
\hline Ruim & - & - & 01 & 14,3 & 02 & 9,0 & - & - & - & - & 03 & 3,8 \\
\hline Não sabe & - & - & - & - & - & - & 04 & 18,2 & 01 & 11,1 & 05 & 6,3 \\
\hline Total & 19 & 100 & 07 & 100 & 22 & 100 & 22 & 100 & 09 & 100 & 79 & 100 \\
\hline
\end{tabular}

\section{9) Necessidade atual dos entrevistados em relação aos serviços de Fisioterapia}

As respostas obtidas detectaram que 72 indivíduos dentre os entrevistados (29\%) afirmaram necessitar, atualmente, dos serviços de Fisioterapia (Tabela 29).

Tabela 29 - Distribuição dos usuários das cinco microáreas de uma Unidade de Saúde da Família por precisarem, atualmente, dos serviços de Fisioterapia, Sumarezinho, Ribeirão Preto (SP), 2008

\begin{tabular}{|c|c|c|c|c|c|c|c|c|c|c|c|c|}
\hline \multirow{3}{*}{$\begin{array}{l}\text { Precisam dos } \\
\text { serviços de } \\
\text { Fisioterapia? }\end{array}$} & \multicolumn{10}{|c|}{ Microáreas } & \multirow{2}{*}{\multicolumn{2}{|c|}{ Total }} \\
\hline & \multicolumn{2}{|c|}{ I } & \multicolumn{2}{|c|}{ II } & \multicolumn{2}{|c|}{ III } & \multicolumn{2}{|c|}{ IV } & \multicolumn{2}{|c|}{$\mathbf{V}$} & & \\
\hline & $\mathbf{n}$ & $\%$ & $\mathbf{n}$ & $\%$ & $\mathbf{n}$ & $\%$ & $\mathbf{n}$ & $\%$ & $\mathbf{n}$ & $\%$ & $\mathbf{n}$ & $\%$ \\
\hline Sim & 22 & 42 & 11 & 21 & 15 & 36 & 13 & 26 & 11 & 22 & 72 & 29 \\
\hline Não & 31 & 58 & 41 & 79 & 27 & 64 & 37 & 74 & 39 & 78 & 175 & 71 \\
\hline Total & 53 & 100 & 52 & 100 & 42 & 100 & 50 & 100 & 50 & 100 & 247 & 100 \\
\hline
\end{tabular}

10) Justificativa da necessidade/ou não necessidade atual dos entrevistados em relação aos serviços de Fisioterapia

Após responderem se precisavam dos serviços de Fisioterapia, os entrevistados justificaram as suas respostas. Para melhor compreensão, essas respostas foram divididas nos itens seguintes: 


\section{a) Por que precisam dos serviços de Fisioterapia atualmente?}

A Tabela 30 demonstra a distribuição das justificativas dos 72 entrevistados que consideraram precisar, atualmente, dos serviços de Fisioterapia. Desses, a resposta predominante em todas as microáreas foi a presença de dor, com 56,9\% dos entrevistados. Em seguida, enquadra-se a resposta referente à presença de doenças e/ou em situações específicas, com $18,1 \%$.

Tabela 30 - Distribuição dos usuários das cinco microáreas de uma Unidade de Saúde da Família por justificativas de que precisam, atualmente, dos serviços de Fisioterapia, Sumarezinho, Ribeirão Preto (SP), 2008

\begin{tabular}{|c|c|c|c|c|c|c|c|c|c|c|c|c|}
\hline \multirow{3}{*}{$\begin{array}{c}\text { Por que precisam } \\
\text { dos serviços de } \\
\text { Fisioterapia? }\end{array}$} & \multicolumn{10}{|c|}{ Microáreas } & \multirow{2}{*}{\multicolumn{2}{|c|}{ Total }} \\
\hline & \multicolumn{2}{|c|}{ I } & \multicolumn{2}{|c|}{ II } & \multicolumn{2}{|c|}{ III } & \multicolumn{2}{|c|}{ IV } & \multicolumn{2}{|c|}{ V } & & \\
\hline & $\mathbf{n}$ & $\%$ & $n$ & $\%$ & $\mathrm{n}$ & $\%$ & $\mathrm{n}$ & $\%$ & $\mathbf{n}$ & $\%$ & $n$ & $\%$ \\
\hline Melhorar movimento & 04 & 18,2 & - & - & 01 & 6,7 & 04 & 30,8 & - & - & 09 & 12,5 \\
\hline $\begin{array}{l}\text { Apresenta doença e/ou } \\
\text { situação específica }\end{array}$ & 05 & 22,7 & 03 & 27,3 & 02 & 13,3 & 02 & 15,4 & 01 & 9,1 & 13 & 18,1 \\
\hline Apresenta dor & 12 & 54,5 & 05 & 45,4 & 10 & 66,7 & 04 & 30,8 & 10 & 90,9 & 41 & 56,9 \\
\hline $\begin{array}{l}\text { Apresenta } \\
\text { estresses/tonturas }\end{array}$ & 01 & 4,6 & 03 & 27,3 & 02 & 13,3 & 03 & 23,0 & - & - & 09 & 12,5 \\
\hline Total & 22 & 100 & 11 & 100 & 15 & 100 & 13 & 100 & 11 & 100 & 72 & 100 \\
\hline
\end{tabular}

\section{b) Por que não precisam dos serviços de Fisioterapia atualmente?}

A Tabela 29 demonstra que 175 entrevistados consideraram não precisar, atualmente, dos serviços de Fisioterapia. As justificativas para 91\% desses foram não ter problemas de saúde. O fato de desconhecer a Fisioterapia foi citado por 5\% dos entrevistados (Tabela 30). 
Tabela 31 - Distribuição dos usuários das cinco microáreas de uma Unidade de Saúde da Família por justificativas de que não precisam, atualmente, dos serviços de Fisioterapia, Sumarezinho, Ribeirão Preto (SP), 2008

\begin{tabular}{|c|c|c|c|c|c|c|c|c|c|c|c|c|}
\hline \multirow{3}{*}{$\begin{array}{c}\text { Por que não } \\
\text { precisam dos } \\
\text { serviços de } \\
\text { Fisioterapia? }\end{array}$} & \multicolumn{10}{|c|}{ Microáreas } & \multirow{2}{*}{\multicolumn{2}{|c|}{ Total }} \\
\hline & \multicolumn{2}{|c|}{ I } & \multicolumn{2}{|c|}{ II } & \multicolumn{2}{|c|}{ III } & \multicolumn{2}{|c|}{ IV } & \multicolumn{2}{|c|}{$\mathbf{V}$} & & \\
\hline & $\mathbf{n}$ & $\%$ & $\mathbf{n}$ & $\%$ & $\mathbf{n}$ & $\%$ & $\mathbf{n}$ & $\%$ & $\mathbf{n}$ & $\%$ & $\mathbf{n}$ & $\%$ \\
\hline $\begin{array}{l}\text { Não tem problemas de } \\
\text { saúde }\end{array}$ & 31 & 100 & 35 & 85 & 24 & 89 & 31 & 84 & 38 & 97 & 159 & 91 \\
\hline $\begin{array}{l}\text { Desconhece a } \\
\text { Fisioterapia }\end{array}$ & - & - & 01 & 03 & 02 & 07 & 05 & 13 & 01 & 03 & 09 & 05 \\
\hline Outros & - & - & 05 & 12 & 01 & 04 & 01 & 03 & - & - & 07 & 04 \\
\hline Total & 31 & 100 & 41 & 100 & 27 & 100 & 37 & 100 & 39 & 100 & 175 & 100 \\
\hline
\end{tabular}




\section{DISCUSSÃO}

De forma similar à apresentação dos resultados dessa pesquisa e visando tornar a leitura mais facilitada, esse capítulo é composto de três tópicos: caracterização sócio-familiar e demográfica dos entrevistados, conhecimentos dos entrevistados sobre a Fisioterapia, e percepções dos entrevistados quanto às suas principais necessidades em relação à atuação do fisioterapeuta.

\subsection{Caracterização sócio-familiar e demográfica dos entrevistados}

As pessoas entrevistadas concentraram-se na faixa etária de 18 a 39 anos, em todas as Microáreas dessa pesquisa, correspondendo a 50\% dentre os pesquisados e estando em conformidade com os dados encontrados nos relatórios do SIAB de consolidação das famílias cadastradas do ano de 2008. Nesse documento, todas as Microáreas apresentaram mais de $30 \%$ dos seus indivíduos nessa faixa etária. Também foi verificado que 66,5\% dos entrevistados apresentavam de 20 a 50 anos, número que é semelhante ao do estudo de Ferri (2006), realizada nessa mesma USF, ao constatar que 68\% da população adscrita tinham essa faixa de idade.

Nessa mesma direção, vem a constatação de que os indivíduos da Microárea III demonstraram ser mais velhos em relação às demais, com 55\% deles com mais de 50 . Esse dado pode ser confirmado através do documento da SIAB, em que, também, se verifica essa relação, apresentando 26\% da população dessa Microárea, com mais de 50 anos.

No tocante ao sexo, a população entrevistada foi essencialmente feminina, configurando $82 \%$ dos entrevistados, valor semelhante aos $80 \%$ encontrados na pesquisa de Ferri (2006), embora o documento do SIAB demonstre equilibro entre a presença de ambos os sexos em todas as Microáreas, com cerca de 50\% para cada opção. Nesse particular, vale à pena salientar que, no intuito de apresentar uma população mais próxima da realidade, a aplicação do questionário ocorreu nos fins de semana, quando haveria maior chance de se encontrar todos os membros da família em casa. Mesmo assim, apresentou-se esse predomínio do sexo feminino, que foi referido à pesquisadora pelos próprios entrevistadores, que afirmaram que as mulheres se mostraram mais solícitas em responder as entrevistas e em se ocupar das questões da saúde familiar.

Dessa mesma forma, a pesquisa de Jorge et al. (2007) não só demonstrou maior demanda de pessoas do sexo feminino nas USF dos municípios do Ceará, como também 
atribuiu às mulheres maior responsabilidade em procurar atendimento para seus familiares e/ou amigos na sua comunidade, considerando-as boas avaliadoras de serviços de saúde.

Os entrevistados, em sua maioria, se declararam pardos (59,6\%), de religião católica (54,2\%) ou evangélica (38,2\%), moravam com companheiros (58\%) e trabalhavam no próprio lar (41\%) ou como prestadores de serviços, em geral (33\%). Essas ocupações não exigiam alto grau de escolaridade, já que 78\% desses apresentavam no máximo, o ginásio incompleto. A baixa escolaridade e o tipo de ocupação da maioria dos entrevistados são aspectos que reafirmam a predominância de pessoas das classes econômicas C e D nesse estudo (86\%). Ressalta-se que nessa pesquisa, 4\% e 2\% dos entrevistados, respectivamente, da Microárea I e V foram categorizados como pertencentes à classe econômica A. No entanto, na população da área de abrangência da UBDS do Sumarezinho não consta indivíduos que ocupem essa classificação econômica (informação verbal) ${ }^{2}$. Uma vez que não se trata de uma porcentagem pequena, essa discrepância se torna irrelevante, já que em ABEP (2008) está descrito a possibilidade de ocorrer erro de classificação, mas pouco numeroso de forma a não distorcer significativamente os resultados investigados.

Dos entrevistados, o tempo de moradia na área adstrita a USF predominou entre 6 e 10 anos (28\%), novamente com exceção da Microárea III, onde prevaleceu os que moravam na área há 20 anos ou mais (48\%). Através dos dados, pôde-se, ainda, verificar que 66\% dos entrevistados moravam nesse local há, no mínimo, seis anos. Considerando que a Unidade estudada foi implantada em 2001, há sete anos, concluí-se que a maioria dos entrevistados acompanhou o seu desenvolvimento e, por isso, agregam condições favoráveis para responder corretamente essa e outras pesquisas lá desenvolvidas.

A presença de pessoas portadoras de deficiência física ou doenças graves na família foi mencionada por apenas 7\% dos entrevistados, com maior índice na Microárea III (17\%). A Organização Mundial de Saúde (OMS) estima que 10\% da população de qualquer país é constituída de pessoas com deficiência, e atribui $2 \%$ desses aos deficientes físicos (BRASIL, 2003). Assim, percebe-se que, em todas as microáreas, essa porcentagem é igual ou superior ao estimado. No entanto, salientamos que, em nosso estudo, nesse percentual estão, também, incluídas pessoas com doenças graves.

Especificamente em relação a Ribeirão Preto, o Estudo de Prevalência de Deficiências, Incapacidades e Desvantagens realizadas em 1996, constatou que 4,3\% das

\footnotetext{
2 Informação fornecida pelo Professor Doutor Altacílio Aparecido Nunes, atual Coordenador do Núcleo de Saúde da Família IV da UBDS Sumarezinho, em Ribeirão Preto, em 2008.
} 
pessoas pesquisadas são suspeitas de apresentar deficiências ou incapacidades. No bairro do Sumarezinho, onde está localizada a Unidade estudada, a prevalência de deficiência constatada por uma equipe multiprofissional foi de 1,8\% (RIBEIRÃO PRETO, 2008c). O fato da presente pesquisa ter obtido percentuais maiores pode ser justificada pelo uso do método de deficiência auto-referida, por incluir doenças graves e, também, porque aquele estudo não retrata a realidade atual, já que foi realizado há 12 anos.

Os entrevistados da Microárea III apresentaram algumas características peculiares e que podem ser importantes para a discussão nos próximos tópicos desse capítulo. Contaram com indivíduos de idade mais avançada, moravam a mais tempo na área adstrita à unidade estudada, e apresentavam maior número de familiares portadores de deficiência física ou doenças graves.

\subsection{Conhecimentos dos entrevistados sobre a Fisioterapia}

A maioria dos entrevistados, em todas as Microáreas, já ouviu falar em Fisioterapia (90\%), fato bastante importante, visto tratar-se de uma profissão relativamente nova, embora não suficiente para garantir a qualidade dos conhecimentos construídos sobre a Fisioterapia.

Nessa divulgação, os profissionais de saúde tiveram um importante papel (51\% dos entrevistados ouviram por meio desses), o que aponta para um dado essencial, visto que os profissionais da ESF necessitam ter conhecimentos sobre Fisioterapia para que possam detectar, na população, situações que exijam a atuação do fisioterapeuta e, assim, encaminhar as pessoas para os serviços existentes. A pesquisa de Aguiar (2005) constatou que um em cada três dos profissionais das ESF da área da UBDS do Sumarezinho apresenta um bom grau de conhecimento sobre a atuação do fisioterapeuta.

Essa mesma pesquisa de Aguiar (2005) mencionou, também, que a Unidade em estudo já contou com a atuação de um fisioterapeuta, mas de forma voluntária, em média de apenas uma vez na semana, e voltada para reabilitação, realizando, principalmente, atividades domiciliares e individuais. Mesmo com atuação descontínua, esse pode ser um aspecto importante para que os entrevistados já tenham ouvido falar em Fisioterapia e por meio de profissionais de saúde. No entanto, o tipo de atividade realizada também pode ter influenciado uma idéia restrita do campo de atuação do fisioterapeuta.

Os meios de comunicação, também, representaram um aspecto importante na disseminação de informações sobre a Fisioterapia, visto que foram mencionados por $41 \%$ dos entrevistados. Para nós, esse dado foi surpreendente, ao considerarmos que ainda não há uma 
mobilização efetiva dos Conselhos e Órgãos responsáveis pela divulgação da Fisioterapia para a sociedade, havendo poucas campanhas publicitárias veiculadas nos meios de comunicação. No entanto, o número de cursos de Fisioterapia é crescente em todo o país. Em Ribeirão Preto, há uma faculdade estadual e quatro particulares que oferecem esse curso e, portanto, o divulgam diretamente, pelos meios de comunicação; ou indiretamente, através de eventos em praças públicas, shoppings, etc. com ações sociais em que são realizados exames simples (pressão, diabetes, etc.), exercícios e orientações.

A maioria dos entrevistados referiu que gostaria de saber mais sobre a Fisioterapia, (70\%). Provavelmente, esse fato relaciona-se à divulgação sobre a Fisioterapia que ainda é superficial e, muitas vezes, de caráter mais comercial, como a relacionada aos eventos das faculdades. Ao mesmo tempo, ratifica-se o interesse da população sobre o assunto, já que apenas 3\% dos entrevistados demonstraram não achar necessário saber sobre o tema. A soma dos entrevistados que auto-avaliaram não ter qualquer conhecimento sobre a Fisioterapia com os que não souberam responder esta questão equivale a 18\%, sendo inferior ao encontrado na pesquisa de Blascovi-Assis e Peixoto (2002), que constataram que 35,2\% dos pacientes de Fisioterapia não tinham conhecimento algum sobre esse assunto, antes de iniciar o tratamento.

$\mathrm{Na}$ apresentação dos resultados, constatamos a grande semelhança nas respostas das questões “o que é Fisioterapia?” e “para que serve a Fisioterapia?”, tanto em relação às categorias existentes, quanto às respectivas porcentagens. Por isso, optamos em abordá-las juntas.

Nessas duas questões, a categoria mais mencionada foi a que vinculou a Fisioterapia a uma forma de reabilitação e/ou tratamento. Em contrapartida, a prevenção foi citada, apenas, por $4 \%$ dos entrevistados em ambas as questões. Esses dados retomam o estigma essencialmente reabilitador que acompanha a Fisioterapia desde sua origem. Na pesquisa de Blascovi-Assis e Peixoto (2002), também, foi constatado que 53,9\% dos usuários de um serviço de Fisioterapia a relacionavam à reabilitação, recuperação, recursos para evitar cirurgias, exercícios ou forma de tratamento. No entanto, salientamos que o conceito atual de Fisioterapia é bem mais amplo e não se restringe ao tratamento e reabilitação, considerando-a como uma Ciência da Saúde que estuda, previne e trata os distúrbios cinéticos funcionais intercorrentes em órgãos e sistemas do corpo humano, causados por alterações genéticas, traumas e doenças adquiridas (COFFITO, 2008). Contudo, destacamos que ações preventivas podem ser feitas, também, junto a atividades de tratamento e reabilitação.

Ainda sobre essas duas questões, a segunda categoria mais mencionada pelos entrevistados foi a que incluía exercício e/ou massagens. Viana et al. (2003) também 
constataram essa associação em um estudo em que 54\% dos pacientes atendidos em um serviço de Fisioterapia associaram o tratamento fisioterápico à utilização de exercícios, ginástica e movimento. No entanto, esses pesquisados se referiram à Fisioterapia como um trabalho de nível técnico.

Esse vínculo da Fisioterapia com o exercício está fundamentado, já que para Hall e Brody (2001), o exercício terapêutico é um elemento central presente na maioria das atividades fisioterápicas, com o objetivo de aprimorar a função e reduzir uma incapacidade. Kisner e Colby (2005) acrescentam que o exercício é uma das ferramentas-chave utilizadas pelo fisioterapeuta para restaurar e melhorar o bem-estar musculoesquelético ou cardiopulmonar do paciente.

A terceira categoria mais mencionada relacionou a Fisioterapia aos benefícios à saúde em geral, destacando que para esses entrevistados a Fisioterapia apresenta impacto positivo nas condições físicas ou mesmo de vida.

A relação da Fisioterapia com a psicoterapia ou aspectos similares foi pouco cotada. No entanto, optamos por discuti-la já que é um indicativo de que alguns entrevistados confundam o papel do fisioterapeuta com o do psicólogo, necessitando, portanto, de maior esclarecimento sobre essas duas profissões. Outra hipótese leva em consideração o grande vínculo que existe entre o fisioterapeuta e seus clientes ou pacientes, uma vez que os serviços de Fisioterapia necessitam de regularidade e continuidade para serem eficazes, permitindo o estabelecimento de vínculos positivos entre profissionais e usuários.

Verificou-se que 90\% dentre os pesquisados consideraram a Fisioterapia muito importante. Fato esse que, provavelmente, justifica o interesse dos mesmos em saber mais sobre a Fisioterapia, como constatado anteriormente.

A maioria dos entrevistados de todas as Microáreas considerou o exercício e/ou massagem (45\%) e os aparelhos e agentes elétricos e/ou térmicos (44\%) como principais recursos que o fisioterapeuta utiliza. Possivelmente, foi esse conhecimento sobre o constante uso do exercício como recurso fisioterápico que influenciou os entrevistados a responderem “o que é Fisioterapia?”, abordando-o. Na ausência de pesquisa similar, citamos o estudo de Blascovi-Assis e Peixoto (2002) que se diferenciou por entrevistar indivíduos que estavam em atendimento fisioterápico. Nesse estudo, verificou-se que o recurso mais utilizado também foi o exercício, categorizado como cinesioterapia (73,3\%), seguido da eletroterapia (60,52\%). Diante da semelhança das respostas, podemos inferir que o conhecimento dos entrevistados da presente pesquisa sobre os recursos da Fisioterapia são equivalentes aos recursos utilizados na prática do atendimento. 
No tocante às pessoas ou situações que precisam de Fisioterapia, a maioria dos entrevistados (76\%) mencionou a categoria de “deficientes físicos, lesão e/ou algias músculoesquelético”. Essa resposta pode ser justificada, de forma generalizada, pelos estudos que indicam a superior demanda de encaminhamento fisioterápico dos pacientes de ortopedia. As pesquisas de Viana et al. (2003) indicaram que 43\% dos pacientes atendidos em um serviço de Fisioterapia apresentavam diagnóstico de ortopedia. No estudo de Blascovi-Assis e Peixoto (2002), em Sorocaba, esse número correspondeu a 94,7\%. Para esses autores, a ortopedia inclui: traumatismos, lesões músculo-ligamentares, alterações posturais, etc.

A segunda categoria mais mencionada das pessoas ou situações que precisam de Fisioterapia foi a que abrangia “acamados, idosos, ou doenças geriátricas” (31\%). Supõe-se que esse fato seja resultante de uma visão cultural do idoso como um indivíduo doente. No entanto, Cianciarullo et al. (2002) indicam que a velhice não pode ser considerada como sinônimo de doença, mesmo sabendo que o aumento da idade é diretamente proporcional ao aumento do risco de comprometimento funcional e a conseqüente perda de qualidade de vida.

Salientamos ainda que a categoria de pessoas sadias só foi referida por $2 \%$ dos entrevistados, retomando o grande vínculo da Fisioterapia com o tratamento e a reabilitação, já mencionado. Para Botomé e Rebellato (1999), a origem dessa profissão fez com que a Fisioterapia não apresentasse uma nítida definição do seu objeto de estudo ou de sua intervenção, gerando um foco de atenção maior na doença e suas seqüelas, e conseqüentemente, limitando a atuação fisioterápica ao tratamento e à reabilitação do indivíduo.

Em relação ao lugar ode fisioterapeuta trabalha, o hospital foi o mais mencionado (59\%), seguido pela clínica (42\%). Esses são locais em que predominam a demanda por tratamento e reabilitação, novamente estabelecendo a ligação entre a Fisioterapia e ações com essa finalidade. O posto de saúde foi citado por 38\% dos pesquisados. Essa resposta surpreende porque a atuação do fisioterapeuta nas USF ainda encontra-se em consolidação e, atualmente, no município de Ribeirão Preto, não há presença desse profissional atuando diretamente nessas unidades. É valido lembrar que na área pesquisada já houve atuação de um fisioterapeuta de forma voluntária e que os entrevistadores desse estudo eram os agentes de saúde da família, fatores que podem ter influenciado a resposta.

O tipo de atividade, mais mencionada, que o fisioterapeuta realiza foi a de forma individual (51\%), mas com pouca diferença em relação às atividades de grupo (48\%). Essa resposta pode estar relacionada ao número de atividades dessa natureza empregada na Unidade em estudo (grupos com gestantes; de atividade física; de reeducação alimentar e de 
saúde da mulher) e a sua adesão pela população. Consideramos esse dado importante porque as atividades de grupo, muitas vezes, estão associadas à promoção da saúde e prevenção de agravos. Para essas finalidades, as atividades de grupo são estimuladas pela EsSF, sendo constantemente empregadas, também, por fisioterapeutas que atuam junto à comunidade, como demonstram algumas pesquisas.

Para Ribeiro (2002), o trabalho de grupo tem-se mostrado uma boa possibilidade de atuação da Fisioterapia na atenção básica, já que se adequa às necessidades dos usuários e à disponibilidade de profissionais e, por isso, representa uma estratégia de atender a uma demanda reprimida. Essa atuação foi verificada na pesquisa de Viana et al. (2003), realizada no Centro de Saúde São Gabriel, ao constatar que 67\% dos usuários dos serviços de Fisioterapia foram encaminhados para atividades de grupo.

A atividade domiciliar do fisioterapeuta foi citada por $36 \%$ dos entrevistados. Consideramos esta uma relação entre o atendimento domiciliar e a dificuldade de deslocamento que algumas doenças ou situações acarretam. Para Ragasson et al. (2006) o fisioterapeuta apresenta aptidões e competências inerentes à sua formação profissional, e uma delas é realizar atendimentos domiciliares em pacientes portadores de enfermidades crônicas e/ou degenerativas, pacientes acamados ou impossibilitados. Ribeiro (2002) também considera este tipo de atendimento imprescindível, principalmente, na atenção básica, para a assistência de pessoas que precisam da Fisioterapia e não podem se deslocar ao serviço. E acrescenta que esse atendimento requer do profissional uma maior disponibilidade de tempo, pois, além do tempo necessário ao deslocamento ao domicílio do indivíduo, há a necessidade de adaptação dos procedimentos às condições do ambiente.

As ações de educação em saúde foram mencionadas por apenas $9 \%$ dos entrevistados. Assim, pôde-se supor que a maioria dos pesquisados não consideraram que essas atividades façam parte do âmbito da Fisioterapia. No entanto, para Ragasson et al. (2006), a Fisioterapia apresenta missão essencial através da aplicação de meios terapêuticos físicos, na prevenção, eliminação ou melhora de estados patológicos do homem, na promoção e na educação em saúde.

Outra justificativa para esse baixo índice relativo às ações de educação em saúde é a pouca valorização dessas atividades por parte dos entrevistados. A pesquisa de Ferri (2006), realizada na mesma UFS desse estudo, constatou que 66,2\% dos usuários procuravam os serviços dessa unidade visando a uma consulta médica e 25\%, para acompanhamento, prevenção e promoção da saúde. Então concluímos que a maioria dos entrevistados dessa pesquisa ainda apresenta em sua concepção de saúde resquícios importantes do modelo 
hospitalocêntrico, curativo e reabilitador, ao mesmo tempo em que também observamos uma significativa adesão às ações de promoção e prevenção.

Embora os resultados dessa pesquisa tenham indicado que os usuários da Microárea III apresentaram algumas especificidades em relação às demais, o fato de apresentarem idade mais avançada e terem maior número de entrevistados com presença, na família, de portadores de deficiências físicas ou doenças graves, poderia levar a uma maior necessidade de atendimento visando ao tratamento e à reabilitação, mas observou-se, justamente, o contrário. Os entrevistados dessa Microárea, ao responderem à questão "para que serve a Fisioterapia”, enfocaram mais os benefícios à saúde, em geral, e prevenção, como também, foram os únicos a indicar indivíduos sadios como pessoas ou situações que precisam de Fisioterapia. Assim, consideramos que esses indivíduos, mesmo apresentando necessidades relacionadas ao tratamento e reabilitação, atribuem importância maior à prevenção de doenças ou agravos em relação aos indivíduos das outras Microáreas, que são mais jovens e apresentam menos familiares com deficiência física ou doença grave.

\subsection{Percepções dos entrevistados quanto às suas principais necessidades em relação à atuação do fisioterapeuta}

Os entrevistados, em sua maioria, (98\%) consideraram necessária a inclusão do fisioterapeuta na equipe da USF em que eles estão cadastrados. Vale destacar que, durante a entrevista, os entrevistadores, agentes comunitários de saúde, não citaram tratar-se de pesquisa realizada por fisioterapeuta.

A grande porcentagem de usuários que achou necessária a inclusão do fisioterapeuta

na EsSF pode estar relacionada à demanda existente, à grande dificuldade de acesso à esses serviços, à atuação anterior de um fisioterapeuta voluntário nessa unidade, e às atitudes dos demais profissionais da saúde que valorizam a atuação do fisioterapeuta, conforme mostraram os resultados da pesquisa de Aguiar (2005), onde 48,6\% dos profissionais das ESF do Sumarezinho acharam necessária essa inclusão e apresentaram bom conhecimento e atitudes em relação à Fisioterapia.

Silva et al. (2006), em estudo com ESF de Florianópolis, constataram que a inclusão de outros profissionais nessas equipes, depende, principalmente, das ações de educação em saúde realizadas por parte dos membros já inseridos, que teriam a função de mostrar para a população a necessidade de outras categorias profissionais, objetivando a realização de um atendimento integral. Para esses autores, o usuário não consegue identificar que profissional 
poderia melhor atender à sua necessidade e, por isso, procura os que estão ao seu alcance na USF. Dessa forma, a equipe mínima acaba executando funções que não lhe cabem especificamente e, assim, contribui para aumentar a opacidade em relação às limitações que sua atual composição acarreta para a população.

Entre os entrevistados que consideraram necessária a inclusão do fisioterapeuta na ESF, 84\% justificaram sua opinião, tendo em vista suprir as necessidades instaladas na população e facilitar o acesso e melhorar as condições de acessibilidade a esses serviços. Consideramos que essa seja uma justificativa plausível visto que a prática assistencial nas Unidades de Saúde de Ribeirão Preto indica que o tempo médio para se obter consulta de Fisioterapia atinge um ano.

Em relação a esse fato, a pesquisa de Lins (2003) realizada em Recife-PE constatou que dentre todos os usuários com necessidade real de assistência fisioterápica na comunidade, apenas 7\% tinham acesso a esses serviços. Para esse autor, a inserção do fisioterapeuta na EsSF poderia sanar essa dificuldade de acesso, ao superar entraves geralmente presentes nas comunidades carentes, como condições financeiras e físicas, empecilhos arquitetônicos ao deslocamento do paciente, superlotação nos centros de referência, além da rejeição do paciente em submeter-se ao tratamento.

Fato semelhante foi relatado por Véras et al. (2005) em Sobral-CE, ao verificarem que $47 \%$ dos usuários dos serviços de Fisioterapia na EsSF desse município nunca tinham sido atendido por esse profissional antes de ele ser inserido nessa estratégia.

No entanto, baseado em Starfield (2002), salientamos que a proximidade dos serviços de Fisioterapia é apenas um dos elementos necessários para facilitar o acesso da população, sendo essenciais, também, outros fatores, como informação, qualidade de atendimento e identificação da clientela com o serviço.

Dentre as demais categorias de respostas que justificaram a necessidade de inclusão do fisioterapeuta na ESF, duas merecem destaque por terem sido citadas, mesmo que tenham obtido poucas menções. A primeira refere-se a informar ou orientar a população sobre a Fisioterapia, pois indica o interesse que os entrevistados têm sobre esse tema. A segunda está relacionada à assistência diferenciada dos profissionais dessa Unidade, que conhecem a realidade da população e fazem com que os usuários sejam bem recebidos. Esse fato foi constatado na pesquisa de Ferri (2006), ao indicar que os usuários valorizavam e consideraram que são bem-tratados nessa USF. Jorge et al. (2007), referiram que os principais determinantes da satisfação dos usuários da EsSF estão relacionados ao bom atendimento, 
incluindo adequada escuta, acolhimento e bons profissionais, de forma que, até mesmo os aspectos técnicos dos profissionais e dos serviços, estão relegados a segundo plano

Apenas dois indivíduos não consideraram necessária a inclusão do fisioterapeuta à equipe da USF em que estão cadastrados e ambos justificaram essa opinião pela limitação do espaço físico do local. A necessidade de melhorias na infra-estrutura, incluindo o aumento de número de salas, foi citada também, na pesquisa Ferri (2006), por 20,6\% dos usuários, como sugestão para aprimorar os serviços prestados por essa Unidade.

A pesquisa de Centa e Almeida (2003) indicou a precariedade do ambiente de trabalho como obstáculo à implantação da EsSF. Em uma das entrevistas apresentadas, foi colocado que o espaço físico da UBS não acompanhou o desenvolvimento da demanda e, por isso, tornou-se incompatível com a exigência atual. Salienta-se que esse fato pode ter ocorrido na Unidade em estudo, já que essa funciona em uma casa alugada que foi adaptada para a prestação desse serviço, dificultando a realização de reformas para melhorar sua estrutura. Atualmente, essa Unidade apresenta: quatro consultórios; uma sala de aplicação de medicamento; uma sala de reunião; uma sala para os ACS; área de serviço; pátio coberto; cozinha e três banheiros.

A pesquisa de Kieling (2008) constatou dificuldades para o fisioterapeuta exercer seu trabalho, devido à falta de um espaço físico para atuar nas USF. Para superar essa dificuldade são feitos acordos entre os profissionais para utilização dos espaços existentes e as atividades coletivas são realizadas em diversos locais, como estacionamentos das unidades, igreja mais próxima ou escola. Essas são formas provisórias de resolver os problemas acarretados pela inadequação da estrutura física.

Apenas 19\% dos entrevistados já foram atendidos por um fisioterapeuta antes dessa pesquisa. Mesma porcentagem de entrevistados afirmou ter tido algum familiar atendido por esse profissional. Esses dados podem estar relacionados à dificuldade de acesso da população a esses serviços e à existência de uma demanda reprimida, já referida anteriormente.

Dentre os entrevistados que já tinham sido atendidos por um fisioterapeuta, 81\% utilizaram a Rede Pública de Saúde. Esse número é semelhante ao da pesquisa de Viana et al. (2003) do Centro de Saúde São Gabriel, em que cerca de 79\% dos entrevistados que haviam realizado tratamento fisioterápico, anteriormente, fizeram-no em alguma Unidade de Saúde do SUS.

Os principais motivos de atendimento fisioterápico, tanto do entrevistado como dos seus familiares, foi a presença de deficiência física, lesão e/ou algias músculo-esquelético. 
Respostas similares à obtida na questão referente às pessoas que precisam de Fisioterapia, e são justificadas pela grande demanda da Fisioterapia ortopédica.

A soma do número de entrevistados e de seus familiares que já foram atendidos por fisioterapeuta resulta em 79 indivíduos que responderam sobre a experiência com a Fisioterapia. Desses, 89,9\% consideraram essa experiência ótima ou boa. Esse número é superior ao constatado na pesquisa de Pereira (2004), em que 77,2\% dos usuários do serviço de Fisioterapia de Média Complexidade Ambulatorial do SUS em Sobral-CE avaliaram o atendimento como ótimo ou bom.

Atualmente, 72 indivíduos dentre os entrevistados (29\%) afirmaram necessitar dos serviços de Fisioterapia. Salienta-se que essa foi uma questão auto-referida, em que os entrevistados avaliaram essa necessidade com base, apenas, em seus conhecimentos prévios do campo de atuação da Fisioterapia que, como mencionado anteriormente, muitas vezes ainda está restrito ao tratamento e à reabilitação. Por isso, consideramos que o número de pessoas com necessidade real de assistência fisioterápica pode ser bem maior, mas para quantificar é necessária uma avaliação mais cautelosa.

Infelizmente, não se pode afirmar com precisão o tamanho da possível demanda reprimida para esse serviço, já que, no questionário aplicado, não foi perguntado se esses indivíduos que afirmaram necessitar dos serviços de Fisioterapia estão sendo atendidos.

Mas, podemos supor que os entrevistados que necessitam e, ao mesmo tempo, estão sendo atendidos atualmente por um fisioterapeuta, fazem parte do grupo das 47 pessoas que responderam positivamente à questão “já foi atendido por um fisioterapeuta?”. Assim, podemos calcular que de 72 indivíduos que precisam de Fisioterapia, no máximo, 47 estão ou foram atendidos, de forma que a demanda reprimida para o serviço de Fisioterapia é de, no mínimo, 35\%. Sabemos que esse cálculo não vai proporcionar a dimensão real da demanda reprimida, mas pode ser um indicativo importante da necessidade de melhorar a acessibilidade desse serviço à população em estudo.

Esses fatos foram mencionados no Estudo de Prevalência de Deficiências, Incapacidades e Desvantagens realizadas em 1996 a 1998, em Ribeirão Preto, ao constatar que dentre os diversos tipos de reabilitação, a que mais se mostrou necessária para os indivíduos pesquisados foi a reabilitação física, baseada, principalmente, na Fisioterapia. Assim, a demanda de portadores de deficiência para Fisioterapia nesse município, foi de 0,55\% da população que, em números absolutos, corresponde a cerca de 2.672 pessoas. No entanto, dentre esses, apenas a metade tem acesso aos serviços de Fisioterapia (RIBEIRÃO PRETO, 2008c). 
O número de pessoas que não apresentam condições de acesso ao tratamento fisioterápico, segundo Ribeiro (2002), demonstra a deficiência do Sistema de Saúde em proporcionar o acesso universal, equânime e integral à saúde, que é direito de todos os cidadãos, conforme a Constituição.

Em Ribeirão Preto, supõe-se que a demanda reprimida seja fruto do reduzido número de fisioterapeutas que trabalham na Rede Municipal de Saúde, já que há apenas sete desses profissionais contratados e que atuam na rede própria e conveniada do município.

Dentre os entrevistados que, atualmente, consideraram precisar dos serviços de Fisioterapia, a presença de dor foi a justificativa mais mencionada (56,9\%), seguida da resposta referente à presença de doenças e/ou em situações específicas, com 18,1\%. Esses dados assemelham-se aos da pesquisa de Silva et al. (2006), em que os próprios membros de equipes da EsSF de Florianópolis, consideraram a dor e as lesões como principais objetos de intervenção do fisioterapeuta.

Em relação aos entrevistados que, atualmente, consideraram não precisar dos serviços de Fisioterapia, 91\% justificaram sua resposta por não terem problemas de saúde instalados.

Novamente, essas respostas seguem o padrão, estabelecido em todo esse estudo, de que a Fisioterapia está associada fortemente ao tratamento e à reabilitação. Para Robalo e Silva (2005) a população, devido a aspectos sócio-culturais, muitas vezes, só recorre a Fisioterapia devido às necessidades consideradas urgentes e imediatas, tais como seqüelas de Acidente Vascular Cerebral ou dor lombar aguda. Véras et al. (2004) consideram esse fato uma demonstração do desconhecimento da população de meios de prevenção de doenças, enfatizando a necessidade de informá-la e conscientizá-la da importância dessa atuação.

Ainda nos reportando às especificidades da Microárea III, essa apresentou não só maior porcentagem de atendimento fisioterápico prestado aos entrevistados e a seus familiares, como também indicou grande necessidade atual por esse serviço. Podemos justificar esses dados pela idade mais avançada dos indivíduos dessa Microárea e pela maior presença, em suas famílias, de pessoas portadoras de deficiência física ou doença grave, que são possíveis demandas da Fisioterapia e que exigem assistência contínua.

Nessa discussão, devemos salientar a dificuldade imposta pela restrição do número de artigos científicos que abordassem a percepção da população sobre a Fisioterapia. 


\section{CONSIDERAÇÕES FINAIS}

O presente estudo desenvolveu-se com o intuito de investigar os conhecimentos dos usuários de uma USF sobre a Fisioterapia, e as percepções dos mesmos quanto às suas necessidades em relação à atuação do fisioterapeuta. Observou-se, nesse sentido, que essa percepção foi similar àquelas encontradas por algumas pesquisas realizadas acerca do mesmo tema, nas quais se identificou conhecimento restrito do campo de atuação da Fisioterapia.

Os resultados demonstraram que a metade dos usuários da Unidade estudada concentrava-se na faixa etária de 18 a 39 anos. Predominou: o sexo feminino (82\%); indivíduos que se declararam pardos (59,6\%); de religião católica $(54,2 \%)$ ou evangélica (38,2\%), indivíduos que moravam com companheiros (58\%); e trabalhavam no próprio lar (41\%) ou como prestadores de serviços, em geral, (33\%); de baixa escolaridade; pertencentes às classes econômicas C e D (86\%) e que moravam na área adstrita à Unidade, de 6 a 10 anos (28\%). A presença de pessoas portadoras de deficiência física ou doenças graves na família foi mencionada por 7\% dos entrevistados e obteve, em todas as microáreas, índice igual ou superior ao estimado pela OMS.

Quase a totalidade dos entrevistados (90\%) já ouviu falar em Fisioterapia, principalmente por meio dos profissionais de saúde (51\%). Os pesquisados também demonstraram que gostariam de saber mais sobre esse tema (70\%), e consideraram a Fisioterapia muito importante (90\%). Avaliamos o interesse da população sobre esse assunto essencial, visto que o conhecimento da mesma sobre a Fisioterapia mostrou-se limitado, sendo constantemente relacionada à reabilitação e/ou tratamento e, poucas vezes, mencionada nos aspectos referentes à promoção e à prevenção. Fato demonstrado também nas questões em que, $76 \%$ dos entrevistados mencionaram que as pessoas ou situações que precisam de Fisioterapia são os deficientes físicos, portadores de lesão e/ou algias músculo-esquelético; que o fisioterapeuta trabalha principalmente no hospital (59\%), e que poucas pessoas relacionaram a Fisioterapia às ações de educação em saúde (9\%). Mas destacamos que as ações de prevenção também podem ser realizadas junto às atividades reabilitadoras.

O vínculo da Fisioterapia com a reabilitação solidificou-se porque é fruto da sua gênese, do seu próprio nome, das leis que regem a sua atuação e do modelo de atenção centrado basicamente na doença. Contudo, o conceito atual da Fisioterapia já apresenta um amplo campo de atuação e desenvolve ações de promoção, prevenção, tratamento e recuperação da saúde, formando um profissional apto a atuar na atenção básica. 
A crescente expansão da EsSF no país, regida pela concepção da multidisciplinaridade, aumento da resolutividade e integralidade da assistência, fez surgir novos questionamentos que apontam para a importante colaboração de outras áreas de conhecimento, dentre elas a Fisioterapia, para o cumprimento desses objetivos.

Mesmo não havendo um conhecimento amplo sobre o papel da Fisioterapia, a maioria dos entrevistados (98\%) considerou necessária a inclusão do fisioterapeuta na equipe da USF em que está cadastrada. Provavelmente, esse fato está relacionado à reconhecida dificuldade de acesso a esses serviços, que foi apontado por $84 \%$ dos usuários. Igualmente, o pequeno número de entrevistados já atendidos por um fisioterapeuta, que somam 47 indivíduos, diante das 72 pessoas que afirmaram necessitar dos serviços de Fisioterapia, reforça a idéia da falta de acessibilidade.

Essa realidade identificada nos faz refletir que a necessidade dos entrevistados em relação à atuação do fisioterapeuta poderia vir a ser bastante superior à manifesta, se houvesse maior conhecimento sobre o amplo campo de atuação desse profissional.

Pesquisas trazidas no contexto desse trabalho demonstraram a importância da atuação integral do fisioterapeuta em todos os níveis de atenção à saúde, e que a inserção deste profissional junto à comunidade, especificamente na EsSF, na maioria das vezes pode ser a única possibilidade de acesso da população a estes serviços.

Especificamente no município de Ribeirão Preto, em que há um reduzido número de fisioterapeutas na Rede Municipal de Saúde, o aumento do número desses profissionais em atuação junto à comunidade iria contribuir para suprir as atuais dificuldades de acesso, tanto relacionado às condições financeiras e físicas e à grande demanda reprimida existente; além de estabelecer maior rigor e efetividade ao sistema de referência e contra-referência. Contudo, ratificamos que não basta apenas oferecer o serviço, mas, também, há necessidade de proporcionar boa qualidade de atendimento, com estrutura física adequada e quantidade suficiente de profissionais.

A criação dos NASF, que inclui a possibilidade de um fisioterapeuta vinculado a um número determinado de ESF, não se concretizou até o momento, valorizando um estudo em relação à experiência da atuação fisioterápica nesses núcleos. Por isso, surge a necessidade de pesquisas que apontem para a adequada proporção de fisioterapeutas por número de equipes, de forma a garantir o acesso da população aos serviços, com qualidade.

Este estudo apresentou algumas limitações inerentes, como a impossibilidade de generalizar os resultados obtidos a outras populações e localidades. O uso da abordagem 
quantitativa também limitou a realização de uma análise mais detalhada das respostas às questões abertas do questionário, como as relacionadas à: “o que é fisioterapia?” e "Porque, atualmente, precisa/não precisa dos serviços da fisioterapia?”. Para suprir essa limitação, sugerimos a realização de uma pesquisa de natureza qualitativa para que se possa compreender melhor a perspectiva dos participantes sobre o significado da fisioterapia e a percepção deles sobre o tema. Ao mesmo tempo, manifestamos nosso desejo de realizar um estudo qualitativo com base nos questionários aplicados na presente pesquisa.

Este estudo apresentou algumas limitações inerentes ao método e instrumento utilizado, como a impossibilidade de generalizar os resultados obtidos a outras populações e localidades. O uso da abordagem quantitativa, ao mesmo tempo em que ofereceu representatividade estatística à população estudada, limitou a realização de uma análise mais detalhada das respostas às questões abertas do questionário, como as relacionadas à: “o que é fisioterapia?” e “Porque, atualmente, precisa/não precisa dos serviços da fisioterapia?”. Salientamos que optamos pelo emprego de algumas questões abertas, mesmo que resultasse em um trabalho mais dispendioso e exaustivo, para evitar a indução de respostas dos entrevistados. Para suprir essa limitação, sugerimos a realização de pesquisas de natureza qualitativa para que se possa compreender melhor a perspectiva dos participantes sobre o significado da fisioterapia e a percepção deles sobre o tema. Ao mesmo tempo, manifestamos nosso desejo de realizar um estudo qualitativo com base nos questionários aplicados na presente pesquisa.

Acreditamos que o desconhecimento da população a respeito da atuação do fisioterapeuta, como demonstrado nessa pesquisa, é um importante motivo de limitação do acesso da comunidade a esses serviços. Mas acrescentamos que esse fato é agravado pela percepção, em uma esfera mais ampla, da saúde segundo o modelo hospitalocêntrico, de atenção centrado basicamente na doença, que se opõem aos princípios da Atenção Básica. Por isso, sugerimos o emprego de estratégias que visem conscientizar a população e os profissionais de saúde sobre a importância de ações de promoção e prevenção à saúde. E, também, o incentivo da educação continuada para os profissionais de saúde, com uma atenção especial aos ACS's, para que esses possam identificar as necessidades reais da população, visto se tratar do membro da equipe de interação mais próxima à comunidade.

Especificamente sobre a Fisioterapia, acreditamos que não havendo um valor dessa natureza arraigado na cultura, não serão geradas demandas nesse sentido, ao contrário da assistência médica, de reconhecimento consolidado e estimulado inclusive pelas superespecialidades. 
A valorização e o incentivo que os serviços de atenção primária, geralmente, oferecem à participação ativa da população, entretanto, podem gerar a produção de novos valores. Perante esse fato, ressaltamos a necessidade de ações conjuntas por parte dos diversos atores sociais envolvidos: Conselhos e órgãos representativos da profissão, instituições formadoras e profissionais fisioterapeutas, que visem à divulgação da fisioterapia à população, demais profissionais da área da saúde e gestores, e facilitem o acesso da população a esses serviços.

Em relação aos Conselhos Federais e Regionais, destacamos a importância de realizar macro e micro políticas bem estruturadas, ordenadas com base na realidade existente, capazes de elaborar e concretizar estratégias que visem divulgar a Fisioterapia e o seu amplo campo de atuação, especialmente às ações de promoção e de prevenção, para contestar o seu paradigma essencialmente reabilitador e aproximar a atuação do fisioterapeuta à comunidade.

No que diz respeito às Universidades e Faculdades, sugerimos: maiores incentivos à pesquisa científica, ênfase nas disciplinas relacionadas à Saúde Pública; inclusão de ações de prevenção e promoção em todas as disciplinas de sua grade curricular; incentivo a atividades em equipe multidisciplinares, com interação entre os diversos cursos e profissionais; além do estabelecimento de estratégias de interação entre as instituições formadoras e o Sistema de Saúde, de forma a aumentar o acesso ao atendimento fisioterápico à população e formar os futuros fisioterapeutas em novos campos de práticas hoje bastante restritos aos hospitais de ensino. Destacamos, ainda, que essa responsabilidade se estende a cada profissional fisioterapeuta, que deve contribuir com essa divulgação prestando atendimento de qualidade e desenvolvendo pesquisas que demonstrem a importância da atuação fisioterápica.

Estratégias como essas podem fazer com que o cidadão esteja cada vez mais apto a reconhecer suas próprias necessidades, e possa solicitar os serviços mais compatíveis a elas. Acreditamos que pessoas mais cientes dos benefícios da Fisioterapia na promoção da saúde e na prevenção de doenças e agravos, levariam a assistência antes da instalação de um quadro patológico, evitando muitos sintomas indesejáveis, doenças e seqüelas, mas para que isso ocorra, faz-se necessário lutarmos em prol da expansão e do fortalecimento da Fisioterapia.

Diante desse contexto, essa pesquisa buscou contribuir no sentido de abrir caminhos e despertar o interesse de novos estudos para discutir a atuação do fisioterapeuta na atenção básica, como possibilidade de promover melhorias na qualidade da assistência e garantir a saúde como direito social fundamental da pessoa humana. 


\title{
REFERÊNCIAS*
}

\author{
ASSOCIAÇÃO BRASILEIRA DE EMPRESAS DE PESQUISA (ABEP). Critério de \\ Classificação Econômica Brasil. \\ <http://www.abep.org/codigosguias/ABEP_CCEB.pdf>. Acesso em: 28 fev. 2008.
}

AFONSO, J. L. Fisioterapia na Atenção Primária à Saúde. Revista Ícone, Uberlândia, v. 2, n. 2, p. 47-75, jul./dez., 1994.

AGUIAR, R. G. Conhecimentos e atitude sobre a atuação do profissional fisioterapeuta entre os profissionais da Equipe mínima de Saúde da Família em Ribeirão Preto. 2005. 118 f. Dissertação (Mestrado em Saúde na Comunidade) - Faculdade de Medicina de Ribeirão Preto, Universidade de São Paulo, Ribeirão Preto, 2005.

GAIOSO, V. P. Satisfação do usuário na perspectiva da aceitabilidade no cenário da Saúde da Família no município de Ribeirão Preto-SP. 2007. 155 f. Dissertação (Mestrado em Saúde Pública) - Escola de Enfermagem de Ribeirão Preto, Universidade de São Paulo, Ribeirão Preto, 2007.

ALEIXO, J. L. M. A Atenção Primária à Saúde e o Programa de Saúde da Família: perspectivas de desenvolvimento no início do terceiro milênio. Revista Mineira de Saúde Pública, Belo Horizonte, ano 1, n. 1, p.1-16, jan./jun. 2002.

BARROS, F. B. M. Autonomia profissional do fisioterapeuta ao longo da história. Fisiobrasil, Rio de Janeiro, n. 59, p. 20-31, mai/jun. 2003.

BLASCOVI-ASSIS, S. M.; PEIXOTO, B. O. A visão dos pacientes no atendimento de Fisioterapia: dados para traçar um novo perfil profissional. Fisioterapia em movimento, Curitiba, v. 15, n. 1, p. 61-7, abr./set. 2002.

BRASIL, A. C. O. et al. O papel do fisioterapeuta do Programa Saúde da Família do município de Sobral-Ceará. Revista Brasileira em Promoção da Saúde, Fortaleza, v.18, n. 1, p. 3-6. 2005.

BRASIL. Ministério da Saúde. Dispõe sobre as condições para promoção, proteção e recuperação da saúde, a organização e o funcionamento dos serviços correspondentes, e dá outras providências. Lei 8.080, de 19 de setembro de 1990. Diário Oficial da União, Brasília, p. 18055, set. 1990.

\footnotetext{
* De acordo com:

ASSOCIAÇÃO BRASILEIRA DE NORMAS E TÉCNICAS. NBR 6023: informação e documentação: referências: elaboração. Rio de Janeiro, 2002.
} 
BRASIL. Conselho Nacional de Saúde. Aprova diretrizes e normas regulamentadoras de pesquisa envolvendo seres humanos. Resolução CNS n. 196, 10 de outubro de 1996. Diário Oficial da União, Brasília, n. 201, p. 21082, out. 1996. Seção I.

BRASIL. Ministério da Saúde. Secretaria de Assistência á saúde. Coordenação de Saúde da Comunidade. Saúde da Família: uma nova estratégia para a reorganização do modelo assistencial. Brasília: Ministério da Saúde, 1997.

BRASIL. Ministério da Saúde. Departamento de Atenção Básica. Guia prático do Programa Saúde da Família. Brasília: Ministério da Saúde, 2001.

BRASIL. Ministério da Saúde. Manual de legislação da pessoa portadora de deficiência física. Brasília: Ministério da Saúde, 2003.

BRASIL. Ministério da Saúde. Conselho Nacional de Secretários Municipais de Saúde. O SUS de A a Z: garantindo saúde nos municípios. Brasília: Ministério da Saúde, 2005.

BRASIL. Ministério da Saúde. Aprova a Política Nacional de Atenção Básica, estabelecendo a revisão de diretrizes e normas para a organização da Atenção Básica para o Programa Saúde da Família (PSF) e o Programa Agentes Comunitários de Saúde (PACSP). Portaria $\mathrm{n}^{0}$ 648/GM, 28 de março de 2006. Diário Oficial da União, Brasília, mar. 2006a.

BRASIL. Ministério da Saúde. Departamento de Atenção Básica: Atenção Básica e a Saúde da Família. Portal da Saúde. Brasília: Ministério da Saúde, 2006. Disponível em: $<$ http://dtr2004.saude.gov.br/dab/atencaobasica.php>. Acesso em: 23 out. 2006b.

BRASIL. Ministério da Saúde. Departamento de Atenção Básica: Atenção Básica e a Saúde da Família: Números da Saúde da Familia. Portal da Saúde. Brasília: Ministério da Saúde, 2007. Disponível em: <http://dtr2004.saude.gov.br/dab/abnumeros.php\#numeros>. Acesso em: 22 set. 2007.

BRASIL. Ministério da Saúde. Cria os Núcleos de Apoio à Saúde da Família - NASF. Portaria $n^{\circ}$ 154/GM, de 24 de janeiro de 2008. Diário Oficial da União, Brasília, p. 38-42, mar. 2008.

BRASIL. Ministério da Educação. Disponível em: < http://portal.mec.gov.br/index.php>. Acesso em: 28 jan. 2009.

BRAZ, M. M. Educação integral: um modelo de ensino da Fisioterapia baseado na física quântica. 2006. 208 f. Dissertação (Doutorado em Engenharia de Produção) - Universidade Federal de Santa Catarina, Florianópolis, 2006.

CACCIA-BAVA, M. C. G. G. (Coord.) Relatório do convênio Núcleos de Saúde da Família. Ribeirão Preto, 2004. Não publicado. 
CACCIA-BAVA, M. C. G. G.; MATTOS, A. T. R.; ROCHA, J. S. Y. Reflexões sobre a Atenção Primária à Saúde e o Programa de Saúde da Família. Relatório Técnico do Departamento de Medicina social. Universidade de São Paulo, Faculdade de Medicina de Ribeirão Preto, Ribeirão Preto, 2007.

CAMPOS, C. E. A. O desafio da integralidade segundo as perspectivas da vigilância da saúde e da saúde da família. Revista Ciência e Saúde Coletiva, Rio de Janeiro, v. 8, n. 2, p. 56984, mar./abr. 2003.

CAMPOS, G. W. S et al. (Orgs). Tratado de Saúde Coletiva. São Paulo: Hucitec; Rio de Janeiro: Ed. Fiocruz, 2007.

CARVALHO, S. T. R. F. A Fisioterapia na atenção básica: um olhar dos profissionais que atuam no PSF em Cabedelo/PB. 2005. 91 f. Monografia (Bacharelado em Fisioterapia) - Curso de Fisioterapia, Universidade de João Pessoa, João Pessoa, 2005.

CASTRO, S. S.; CIPRIANO JUNIOR, G; MARTINHO, A. Fisioterapia no Programa de Saúde da Família: Uma revisão e discussões sobre a inclusão. Fisioterapia em Movimento, Curitiba, v. 19, p. 55-62, out./dez. 2006.

CENTA, M. L.; ALMEIDA, B. M. M. O programa de saúde da família sob olhar da equipe multidisciplinar. Família, saúde e desenvolvimento, Curitiba, v. 5, n. 2, p. 103-13, mai./ago. 2003.

CHAZAN, L. F. Trabalhando com as famílias na atenção Primária. In: BURD, M.; MELO FILHO, J. (Org.). Doença e Família. São Paulo: Casa do Psicólogo, 2004, cap. 6, p. 111-21.

CIANCIARULlO, T. I. et al. Saúde na Família e na Comunidade. São Paulo: Robe, 2002.

CONSELHO FEDERAL DE FISIOTERAPIA E TERAPIA OCUPACIONAL (COFFITO). Aprova o código de Ética Profissional de Fisioterapia e Terapia Ocupacional. Resolução n ${ }^{\circ}$ 10, 22 de setembro de 1978. Diário Oficial da União 182, Brasília, p. 5265-8, set. 1978. Seção I, Parte II.

CONSELHO FEDERAL DE FISIOTERAPIA E TERAPIA OCUPACIONAL (COFFITO). Disponível em: <http://www.coffito.org.br/conteudo/con_view.asp?secao=27>. Acesso em: 17 jul. 2008.

CONSELHO NACIONAL DE EDUCAÇÃO (CNE). Câmara de Educação Superior. Institui Diretrizes Curriculares Nacionais do Curso de Graduação em Fisioterapia. Resolução CNE/CES nº 4, 19 de fevereiro de 2002. Diário Oficial da União, Brasília, p. 11, mar. 2002. Seção 1. 
CONSELHO REGIONAL DE FISIOTERAPIA E TERAPIA OCUPACIONAL DA $3^{\circ}$ REGIÃO (CREFITO-3). Exemplos que comprovam atuação conjunta de fisioterapeuta e terapeuta ocupacional em UBSs de Paulínia, no interior de São Paulo, reduziu ou eliminou a dor de quase $90 \%$ dos pacientes. Revista CREFITO-3. São Paulo, n. 5, ed. 1, p. 12-3, jan/fev. 2008.

COSTA, E. M. A. Sistema Único de Saúde. In: CABONE, M. H; COSTA, E. M. A. Saúde da Família: uma abordagem interdisciplinar. Rio de Janeiro: Rubio, 2004, cap. 2, p. 7-17.

DELIBERATO, P. C. P. Fisioterapia Preventiva: Fundamentos e Aplicações. São Paulo: Manole, 2002.

DOMINGUEZ, B. N. R. O programa de saúde da família: como fazer. São Paulo: Parma, 1998.

ELIAS, P. E. Estrutura e organização da atenção à Saúde no Brasil. In: COHN, A; ELIAS, P. E. Saúde no Brasil: Políticas e Organização de Serviços. 3. ed. São Paulo: Cortez, 1999. cap. 2, p. 59-120.

FERREIRA, F. N. et al. Intervenção Fisioterápica na comunidade: relato de caso de uma paciente com AVE. Revista Saúde da Comunidade. Bahia, v. 1, n. 1, p. 35-43. 2005. Disponível em: <http://www.uesb.br/revista/rsc/v1/v1n1a5.pdf>. Acesso em: 20 set. 2006.

FERRI, S. M. N. As tecnologias leves como geradoras de satisfação em usuários de uma Unidade de Saúde da Família - elemento analisador da qualidade do cuidado prestado? 2006. 125 f. Dissertação (Enfermagem em Saúde Pública) - Escola de Enfermagem de Ribeirão Preto, Universidade de São Paulo, Ribeirão Preto, 2006.

GAIOSO, Vanessa Pirani. Satisfação do usuário na perspectiva da aceitabilidade no cenário da Saúde da Família no município de Ribeirão Preto-SP. 2007. 155 f. Dissertação (Mestrado em Saúde Pública) - Escola de Enfermagem de Ribeirão Preto, Universidade de São Paulo, Ribeirão Preto, 2007.

GALLO, D. L. L. A Fisioterapia no Programa Saúde da Família: percepções em relação à atuação profissional e formação universitária. 2005. 180 f. Dissertação (Mestrado em Saúde Coletiva) - Universidade Estadual de Londrina, Londrina, 2005.

GIL, A. C. Como Elaborar Projetos de Pesquisas. 4. ed. São Paulo: Atlas, 2002.

GREENACRE, M. J. Theory and Applications of Correspondence Analysis. Editora Hardcover, 1984.

HALL, C. M.; BRODY, L. T.; TARANTO, G. Exercício terapêutico: na busca da função. São Paulo: Guanabara Koogan, 2001. 
INSTITUTO BRASILEIRO DE GEOGRAFIA E ESTATÍSTICA (IBGE). Censo Demográfico - 2000: Famílias e Domicílios: Resultados da amostra. Notas Metodológicas. 2000.

Disponível

em:

$<$ http://www.ibge.gov.br/home/estatistica/populacao/censo2000/familias/notas.pdf $>$. Acesso em: 28 set. 2006.

JORGE, M. S. B. et al. Avaliação da qualidade do Programa Saúde da Família no Ceará: a satisfação dos usuários. Revista Baiana de Saúde Pública, Salvador, v. 31, p. 258-268, 2007.

KELL, M. C. G. Integralidade da atenção à saúde. Ministério da Saúde. Secretaria de Atenção à Saúde. Departamento de Atenção Básica. Coordenação de Gestão da Atenção Básica. Brasília. Disponível em: <http://www.opas.org.br/observatorio/Arquivos/Destaque69.doc>. Acesso em: 10 set. 2008.

KIELING, G. O papel do fisioterapeuta na secretaria municipal de saúde de Curitiba: uma análise a partir da percepção do próprio profissional. 2008. 82 f. Monografia (Especialização em Saúde Pública) - Instituto Brasileiro de Pós-Graduação e Extensão, Curitiba, 2008.

KISNER, C.; COLBY, L. A. Exercícios Terapêuticos: Fundamentos e Técnicas. 4 ed. São Paulo: Manole, 2005.

LIMA, M. C. Monografia: a engenharia da produção acadêmica. São Paulo: Saraiva, 2004.

LINS, A. M. C. Atuação da Fisioterapia no Programa Saúde da Família (PSF), Fundamentada do projeto reabilitação baseada na comunidade (RBC). 2003. Monografia (Bacharelado em Fisioterapia) - Faculdade Integrada do Recife, Recife, 2003.

LUCAS, R. W. C. Fisioterapia: denominação inadequada para uma atuação profissional moderna. Conhecimento Interativo, São José dos Pinhais, v. 1, n. 1, p. 89-97, jul./dez. 2005.

MARIN, M. J. S. et al. Contribuciones de la comunidad para el trabajo del equipo de un PSF. Revista Latino-Americana de Enfermagem. Ribeirão Preto, n. 6, v.15, nov./dez. 2007.

MINGOTI, S. A. Análise de Dados através de Métodos de Estatística Multivariada: Uma Abordagem Aplicada. Belo Horizonte: Editora da UFMG, 2005.

NICIDA, D. P. Fisioterapia: uma ciência em construção. Fisioterapia UniFMU, São Paulo, ano 2, n. 3, p. 7-11, jan/jun. 2004.

OLIVEIRA, S. L. Tratado de metodologia cientifica: projetos de pesquisa, monografias, dissertação e teses. 2 ed. São Paulo: Pioneira, 2000. 
O`SULliVAN, S. B.; SCHMITZ, T. J. Fisioterapia: Avaliação e Tratamento. 2 ed. São Paulo: Manole, 2004.

PEREIRA, F. W. A. Avaliação do serviço de Fisioterapia de Média Complexidade Ambulatorial do SUS no Município de Sobral-CE. 2004. Monografia. (Aperfeiçoamento/Especialização em Especialização Caráter de Residência Saúde Família) Escola de Formação em Saúde da Família Visconde de Sabóia, cidade, 2004.

PEREIRA, F. W. A. et al. A inserção da Fisioterapia na Estratégia Saúde da Família em Sobral - CE. Revista Sanare: Revista de Políticas Públicas, Sobral, ano 5, n.1, p. 93-100, jan./mar. 2004.

RAGASSON, C. A. P. et al. Atribuições do Fisioterapeuta no Programa de Saúde da Família: reflexões a partir da prática profissional. Disponível em: <http://www.crefito5.com.br/web/downs/psf_ado_fisio.pdf>. Acesso em: 20 ago. 2006.

REBELATTO, J. R.; BOTOMÉ, S. P. Fisioterapia no Brasil: fundamentos para uma ação preventiva e perspectiva profissionais. 2 ed. São Paulo: Manole, 1999.

REZENDE, M. et al. A equipe multiprofissional da "Saúde da Família": uma reflexão sobre o papel do fisioterapeuta. Ciência e Saúde Coletiva, Rio de Janeiro, v. 14, p. 1-9, 2008. Disponível em: <http://www.abrasco.org.br/cienciaesaudecoletiva/artigos/artigo_int.php?id_artigo=1020>. Acesso em: 14 set. 2008.

RIBEIRÃO PRETO. Prefeitura Municipal de Ribeirão Preto. Secretária Municipal da Saúde. Plano de Saúde 2005-2008: Secretária Municipal de Saúde, 2005. Disponível em: <http://www.saude.ribeiraopreto.sp.gov.br/index.html>. Acesso em: 20 ago. 2006.

RIBEIRÃO PRETO. Prefeitura Municipal de Ribeirão Preto. Conheça Ribeirão. Ribeirão Preto: Secretária $\quad 2006 . \quad$ Disponível em: <http://www.saude.ribeiraopreto.sp.gov.br/Principaln.asp?pagina=/crp/I71institucional.HT>. Acesso em: 28 ago. 2006a.

RIBEIRÃO PRETO. Prefeitura Municipal de Ribeirão Preto. Secretária Municipal da Saúde. CSE "Joel Domingos Machado" - Sumarezinho. Ribeirão Preto: Secretária Municipal de Saúde, 2006. Disponível em: <http://www.saude.ribeiraopreto.sp.gov.br/SSAUDE/I16Principal.asp?pagina=/ssaude/rede/o este/I16Sumarezinho.htm>. Acesso em: 28 ago. 2006b.

RIBEIRÃO PRETO. Prefeitura Municipal de Ribeirão Preto. Relatório CAPSI. Equipe: Núcleo de Saúde da Família IV, mês de referência: setembro/2006. Ribeirão Preto: Prefeitura Municipal, 2006c. 
RIBEIRÃO PRETO. Prefeitura Municipal de Ribeirão Preto. Secretária da Saúde. Número de Profissionais por Unidade. Relação sintética de horas contratadas/CBO. Ribeirão Preto: Secretária Municipal de Saúde, $2008 . \quad$ Disponível em: $<$ http://www.saude.ribeiraopreto.sp.gov.br/ssaude/i16principal.asp?pagina=/ssaude/rede/i16in dprof.htm> . Acesso em: 5 mai. 2008a.

RIBEIRÃO PRETO. Secretaria de Assistência à Saúde/DAB - DATASUS. Secretária Municipal da Saúde. SIAB: Sistema de Informação de Atenção Básica. Consolidação das Famílias Cadastradas do ano 2008 do Modelo PSF, pág. 1, versão 4.2, data: 29/08/2008. Ribeirão Preto: Secretária Municipal de Saúde, 2008b.

RIBEIRÃO PRETO. Prefeitura Municipal de Ribeirão Preto. Secretária da Saúde. Programa de Atenção à Saúde da Pessoa com Deficiência - PASDEF. Pesquisa de Prevalência de Deficiências, Incapacidades e Desvantagens no município de Ribeirão Preto (1996-1998). Ribeirão Preto: Secretária Municipal de Saúde, 2008. Disponível em: <http://www.ribeiraopreto.sp.gov.br/ssaude/i16principal.asp?pagina=/SSAUDE/programas/I1 6indice.htm>. Acesso em: 30 out. 2008c.

RIBEIRO, K. S. Q. A atuação da Fisioterapia na atenção primária à saúde. Fisioterapia Brasil, Rio de Janeiro, v. 3, n. 5, p.311-8, set./out. 2002

RIBEIRO, K. S. Q. S. A contribuição da extensão comunitária para a formação acadêmica em Fisioterapia. Revista Fisioterapia e Pesquisa, São Paulo, v. 12, n. 3, p. 22-9. 2005.

ROBALO, L.; SILVA, M. G. A promoção e a proteção da saúde em Fisioterapia. EssFisiOnline, v. 1, n. 3, junho. 2005. Disponível em: $<$ http://www.ess.ips.pt/EssFisiOnline/vol1n3/pdfs/A\%20promocao\%20e\%20a\%20proteccao \%20da\%20saude\%20em\%20Fisioterapia.pdf>. Acesso em: 20 jul. 2008.

SANCHEZ, E. L. Histórico da Fisioterapia no Brasil e no mundo. Atualização Brasileira de Fisioterapia. São Paulo: Panamed, 1984, p. 29-36.

SAMPAIO, R. F. Promoção de saúde, prevenção de doenças e incapacidades: a experiência da Fisioterapia/UFMG em uma Unidade Básica de Saúde. Revista de Fisioterapia em Movimento, Curitiba, v. 15, n. 1, p. 19-23, abr./set. 2002.

SCHMIDT, L. A. T. Os Cursos de Fisioterapia no Paraná frente aos conceitos contemporâneos de saúde. 2002. 155 f. Dissertação (Mestrado do Centro de Ciências da Saúde) - Universidade Estadual de Londrina, Londrina, 2002.

SCHWINGEL, G. A Fisioterapia na Saúde Pública: um agir técnico, político e transformador. In: BARROS, F. B. M. (Org.). O fisioterapeuta na saúde da população: atuação transformadora. Rio de Janeiro: FisioBrasil, 2002, p. 227-238. 
SILVA, P. L. B. Serviços de Saúde: o dilema do SUS na nova década. São Paulo em Perspectiva. São Paulo, v.17, n.1., p. 69-85, 2003 . Disponível em: <http://www.scielo.br/pdf/spp/v17n1/v17n1a07.pdf >. Acesso em: 17 ago. 2008.

SILVA, D. E. et al. Integralidade na Atenção Básica: representações sociais dos profissionais da equipe do Programa de Saúde da Família sobre a atuação dos demais profissionais de saúde. 2006. 91 f. Monografia. (Especialização Multiprofissional em Saúde da Família) - Universidade Federal de Santa Catarina, Florianópolis, 2006.

SOUZA, H. M. O Programa de Saúde da Família no Contexto do Sistema Único de Saúde. In: I Seminário de Experiências Internacionais em Saúde da Família, 1999, Brasília. Relatório Final... Brasília: Coordenação de Atenção Básica, Ministério da Saúde; 1999, p. 23-26.

STARFIELD, B. Atenção Primária: equilíbrio entre necessidades de saúde, serviços e tecnologia. Brasília: UNESCO, Ministério da Saúde, 2002.

STOTZ, E. N. Necessidades de saúde: mediações de um conceito (contribuições das ciências sociais para a fundamentação teórico-metodológica de conceitos operacionais da área do Planejamento em Saúde). 1991. Dissertação (Doutorado pela Escola Nacional de Saúde Pública) - Escola Nacional de Saúde Pública, Rio de Janeiro, 1991.

TRELHA, C. S. et al. O fisioterapeuta no Programa de Saúde da Família em Londrina (PR). Revista Espaço para a Saúde, Londrina, v.8, n.2, p.20-25, jun. 2007.

UNIVERSIDADE DE SÃO PAULO (USP). Faculdade de Medicina de Ribeirão Preto.

Centro de Atenção Primária. Disponível em:
$<$ http://www.fmrp.usp.br/cap/index.php?option=com_wrapper\&Itemid=8 $>$. Acesso em: 20 mai. 2008.

VÉRAS, M. M. S. et al. O Fisioterapeuta na Estratégia Saúde da Família: primeiros passos na construção de um novo modelo de atenção. Revista Sanare: Revista de Políticas Públicas, Sobral-CE, Ano 5, n.1, p. 93-100, jan./mar. 2004.

VÉRAS, M. M. S. et al. A Fisioterapia no Programa Saúde da Família de Sobral - CE. Fisioterapia Brasil, Rio de Janeiro, v. 6, n. 5, p. 345-8, set./out. 2005.

VIANA, S. O. et al. Fisioterapia na Atenção Primária: uma Experiência de Integração entre Ensino, Serviço de Saúde e Assistência à Comunidade. Revista brasileira de Fisioterapia, São Carlos, v. 7, n. 2, p. 159-66, mai/agos. 2003. 


\section{ANEXO A}

“Relação de Famílias por Microáreas”, emitida pelo SIAB

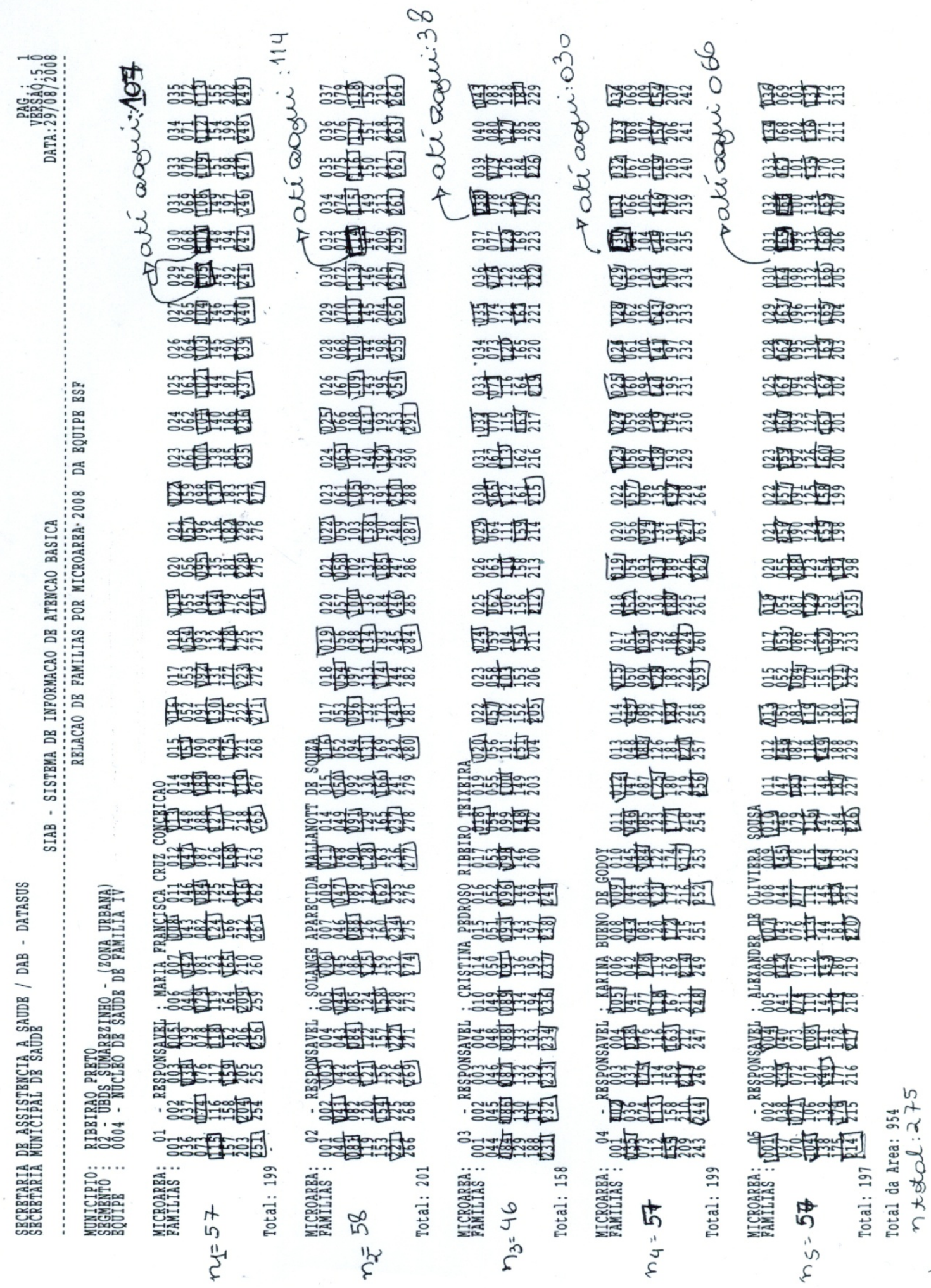


ANEXO B

\section{Autorização do Comitê de Ética em Pesquisa do CSE}

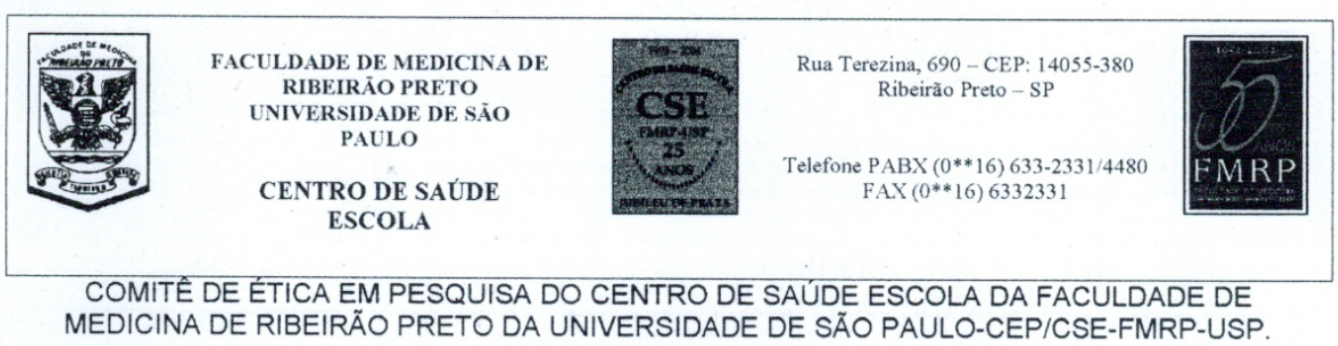

Ribeirão Preto, 13 de agosto de 2008.

Of. NN129/08/COORD.CEP/CSE-FMRP-USP.

-Senhora Professora,

Temos a grata satisfação de comunicar que o Coordenador do Comitê de Ética em Pesquisa do Centro de Saúde Escola da Faculdade de Medicina de Ribeirão Preto da Universidade de São Paulo, em reunião ordinária, realizada em 12 de agosto de 2008, analisou e apreciou o parecer, referente ao projeto de pesquisa intitulado: "Percepção das famílias cadastradas no Programa de Saúde da Família de Ribeirão Preto sobre fisioterapia e seu campo de atuação", protocolo $n^{\circ} .279 /$ CEP-CSE-FMRP-USP, que terá a orientação de V.S $S^{a}$ e da pesquisadora Sarah Tarcisia Rebelo Ferreira de Carvalho, foi aprovado ad - referendum.

Em atendimento à Resolução 196/96, deverá ser encaminhado a este CEP o relatório final da pesquisa e a publicação de seus resultados.

No ensejo, renovamos os votos de estima e consideração, despedimo-nos.

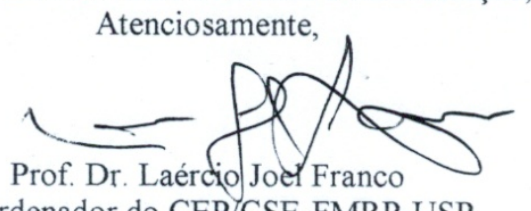

Coordenador do CEP/CSE-FMRP-USP

Ilma. Sra.

Prof ${ }^{a}$. Dr ${ }^{\mathrm{a}}$. Maria do Carmo G.G. Caccia-Bava

Departamento de Medicina Social da Faculdade de Medicina de Ribeirão Preto-USP. 


\title{
APÊNDICE A \\ TERMO DE CONSENTIMENTO LIVRE E ESCLARECIDO
}

\begin{abstract}
Prezado(a) Sr(a),
Estamos desenvolvendo a pesquisa intitulada: "Conhecimentos e percepções dos usuários da Estratégia Saúde da Família sobre a Fisioterapia”.

O referido estudo apresenta como objetivo geral: investigar os conhecimentos dos usuários de uma Unidade de Saúde da Família (USF) em relação à Fisioterapia, e as percepções dos mesmos quanto às suas principais necessidades para atuação do fisioterapeuta.

Assim, gostaríamos de contar com sua participação na realização de uma entrevista dirigida à população usuária de uma USF, através da aplicação de um questionário.

Sua colaboração será muito importante para a realização desse estudo. Todas as informações e opiniões emitidas pelo(a) senhor(a) não causarão dano, risco ou ônus à sua pessoa e serão tratadas anonimamente junto às dos demais participantes. Ainda, a qualquer momento da realização dessa pesquisa, caso não seja de seu interesse a continuidade na mesma, haverá possibilidade de retirar esse consentimento.

Agradecemos sua colaboração e ao mesmo tempo, nos colocamos à disposição para qualquer informação que o(a) senhor(a) julgar necessária.

Atenciosamente.
\end{abstract}

Dra. Maria do Carmo G. Caccia-Bava

Departamento de Medicina Social

FMRP-USP

Telefone para contato: 36023070
Sarah Tarcísia R. F. de Carvalho

Pesquisadora

Telefone para contato: (16) 91976265

sarahtrfc@hotmail.com

Eu, , aceito participar

da pesquisa “Conhecimentos e percepções dos usuários da Estratégia Saúde da Família sobre a Fisioterapia”. Fui informado(a) de que o presente estudo apresenta como objetivo geral: investigar os conhecimentos que os usuários de uma USF apresenta sobre a Fisioterapia, e as percepções destes quanto às suas principais necessidades para atuação do fisioterapeuta. Estou ciente de que a entrevista terá seu resultado tratado sigilosamente, e caso não queira participar da investigação, tenho total liberdade de retirar esse consentimento.

Ribeirão Preto, de de 2008. 


\section{APÊNDICE B}

\section{QUESTIONÁRIO}

Para uso do pesquisador.

As informações coletadas neste questionário são confidenciais.

Entrevistador:

Data da aplicação do questionário:
Microárea: ( ) 1
( ) 2
( ) 3
( ) 4
( ) 5

\section{CARACTERIZAÇÃO SÓCIO-FAMILIAR E DEMOGRÁFICA DO ENTREVISTADO}

1.1 Idade: anos

1.2 Sexo: ( ) Masculino

( ) Feminino

1.3 Cor/raça: ( ) Branca ( ) Preta ( ) Amarela ( ) Parda (mulata/mestiça) ( ) Indígena

1.4 Religião:

1.5 Situação conjugal:
( ) Solteiro(a)
( ) Separado(a)/Divorciado(a)
( ) Casado
( ) Viúvo(a)
( ) Amasiado

1.6 Ocupação:

1.7 Grau de Escolaridade:

( ) Analfabeto $/ 4^{\circ}$ ano do Ensino Fundamental

( ) $5^{\circ}$ a $8^{\circ}$ ano do Ensino Fundamental

( ) Ensino Fundamental completo/Ensino Médio incompleto

( ) Ensino Médio completo/Ensino Superior incompleto

( ) Ensino Superior completo

1.8 O Sr.(a) apresenta em sua casa qual (is) destes itens? Quantos?

\begin{tabular}{|l|l|l|l|l|l|}
\hline Itens & Não Tem & Tem Um & Tem Dois & Tem Três & $\begin{array}{l}\text { Tem Quatro } \\
\text { ou Mais }\end{array}$ \\
\hline Televisão em cores & & & & & \\
\hline Rádio & & & & & \\
\hline Banheiro & & & & & \\
\hline Automóvel & & & & & \\
\hline $\begin{array}{l}\text { Empregada } \\
\text { mensalista }\end{array}$ & & & & & \\
\hline Aspirador de pó & & & & & \\
\hline Máquina de lavar & & & & & \\
\hline $\begin{array}{l}\text { Videocassete e/ou } \\
\text { DVD }\end{array}$ & & & & & \\
\hline Geladeira & & & & & \\
\hline Freezer & & & & & \\
\hline
\end{tabular}


1.9 Grau de escolaridade do chefe da família:

( ) Analfabeto / Primário incompleto

( ) Primário completo / Ginasial incompleto

( ) Ginasial completo / Colegial incompleto

( ) Colegial completo / Superior incompleto

( ) Superior completo

1.10 Tempo em que mora na área adstrita ao NSF em anos:

1.11 Na sua família há pessoa (s) portadora (s) de deficiência (s) física (s) ou doença (s) grave (s)?

( ) Sim

( )Não

\section{CONHECIMENTOS SOBRE A FISIOTERAPIA}

2.1 O Sr (a) já ouviu falar em Fisioterapia? (Se a resposta for "não", encerrar a entrevista)
( ) Sim
( ) Não

2.2 Por qual(is) meio(s)? (Não ler as alternativas) Pode escolher mais de uma alternativa

( ) Profissional de saúde ( ) Meios de comunicação (TV, rádio, revista, jornal)

( ) Parente/amigo ( ) Outros

( ) Professor

2.3 Como o Senhor (a) avalia o seu conhecimento sobre a Fisioterapia?

O Senhor (a) acha que:
( ) Sabe o suficiente
( ) Não acha necessário saber sobre isso
( ) Gostaria de saber mais
( ) Não sabe responder
( ) Não tem conhecimento algum

2.4 Para o Senhor(a) o que é Fisioterapia?

2.5 Para o Senhor(a), qual é a importância dos serviços da Fisioterapia para a saúde da população?
( ) Sem importância
( ) Muito importante
( ) Pouco importante
( ) Não sabe responder

2.6 Para o Senhor(a), qual(is) recurso(s) o fisioterapeuta utiliza para realizar um atendimento? (Não ler as alternativas) Pode escolher mais de uma alternativa
( ) Aparelhos elétricos/térmicos
( ) Medicamentos
( ) Exercícios
( ) Pesos
( ) Massagens
( ) Gelo
( ) Bolas
( ) Outros:
( ) Não sabe responder 
2.7 Para o Senhor (a), para que serve a Fisioterapia? Pode mencionar mais de uma resposta

2.8 Para Senhor (a), o que apresentam ou quem são as pessoas que precisam dos serviços da Fisioterapia? (Não ler as alternativas) Pode escolher mais de uma alternativa ( ) Pessoas sadias ( ) Deficientes físicos

( ) Acamados

( ) Diabéticos/Hipertensos

( ) Doenças respiratórias

( ) Idosos/Doenças geriátricas

( ) Doenças cardíacas

( ) Crianças com déficit desenvolvimento

( ) Gestantes/complicações da gravidez

( ) Doenças neurológicas

( ) Pessoas com lesão/algias músculo-

( ) Acidentados do trabalho

( ) Outros esquelética

( ) Não sabe responder

2.9 Para o Senhor (a), em que lugares o fisioterapeuta trabalha? (Não ler as alternativas). Pode escolher mais de uma alternativa
( ) Clínicas
( ) Posto de Saúde
( ) Hospitais
( ) Atendimento em domicílio
( ) Academias
( ) Outros:
( ) Escolas
( ) Asilos
( ) Não sabe responder

2.10 Para o Senhor (a) quais dessas atividades o fisioterapeuta realiza? Pode escolher mais de uma alternativa
( ) Atividade domiciliar
( ) Atividade individual
( ) Ações de educação em saúde (palestras, orientações)
( ) Atividade de grupo
( ) Não sabe responder
( ) Outras

\section{PERCEPÇÕES DAS NECESSIDADE DE ATUAÇÃO DO FISIOTERAPEUTA}

3.1 O(A) Sr(a) acha necessário a inclusão do fisioterapeuta à equipe da USF em que está cadastrado?
( ) Sim
( ) Não
( ) Não sabe responder

3.2 Porque o Senhor(a) acha necessária/não necessária a inclusão do fisioterapeuta à equipe da USF em que está cadastrado?

3.3 O(A) Senhor(a) já foi atendido por um fisioterapeuta?(Se a resposta for negativa pular para 3.6)
( ) $\mathrm{Sim}$
( ) Não
( ) Não sabe responder 
3.4 Este atendimento foi realizado na rede pública de saúde?
( ) Sim
( ) Não

3.5 Por qual(is) motivo(s) o(a) Senhor(a) foi atendido por um fisioterapeuta? (Não ler as alternativas) Pode escolher mais de uma alternativa
( ) Acidentes de trabalho
( ) Doenças respiratórios
( ) Diabetes/Hipertensão
( ) Doenças cardíacos
( ) Doenças geriátricas
( ) Doenças neurológicas
( ) Deficiência física
( ) Lesão/algias músculo-esquelética
( ) Outros:
( ) Não sabe responder

3.6 Alguém da sua família já foi atendido (a) ou está sendo atendido (a) por um fisioterapeuta? (Se a resposta for negativa pular para 3.8)
( ) Sim
( ) Não
( ) Não sabe responder

3.7 Por qual (is) motivo (s)? (Não ler as alternativas) Pode escolher mais de uma alternativa
( ) Acidentes de trabalho
( ) Diabetes/Hipertensão
( ) Doenças geriátricas
( ) Deficiência física
( ) Lesão/algias músculo-esquelético

( ) Doenças respiratórios

( ) Doenças cardíacos

( ) Doenças neurológicas

( ) Outros:

( ) Não sabe responder

3.8 Como foi, ou está sendo, a sua experiência e/ou de seus familiares com a Fisioterapia?

3.9 Atualmente, o(a) Senhor(a) considera que precisa dos serviços de Fisioterapia?
( ) Sim
( ) Não

3.10 Por que precisa/por que não precisa? 